\title{
INDOOR-OUTDOOR AIR LEAKAGE OF APARTMENTS AND COMMERCIAL BUILDINGS
}

\author{
Price, P.N.; Shehabi, A.; Chan, R.W.; Gadgil, A.J.
}

\author{
Environmental Energy Technologies Division \\ Indoor Environment Department \\ Lawrence Berkeley National Laboratory \\ Berkeley, CA 94720
}

June 2006

This work was supported by the California Energy Commission through the U.S.

Department of Energy under Contract No. DE-AC02-05CH11231. 



\section{INDOOR-OUTDOOR AIR LEAKAGE OF APARTMENTS AND COMMERCIAL BUILDINGS}

Prepared For:

California Energy Commission

Public Interest Energy Research Program

Prepared By:

E. O. Lawrence Berkeley National

Laboratory

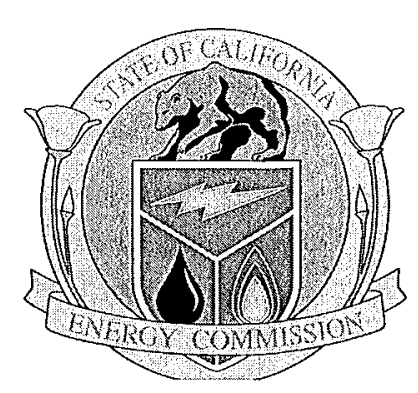

Arnold Schwarzenegger

Governor

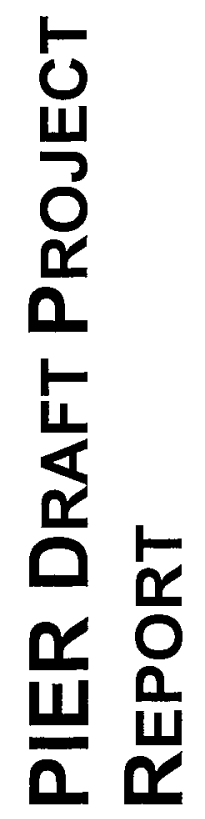

March 2006

CEC-500-2006-xxx 
Prepared By:

E. O. Lawrence Berkeley National Laboratory

Dr. Ashok Gadgil, Principal Investigator

Dr. Phillip N. Price, Scientist

Arman Shehabi, Graduate Research Assistant

Rengie Chan, Graduate Research Assistant

Berkeley, California

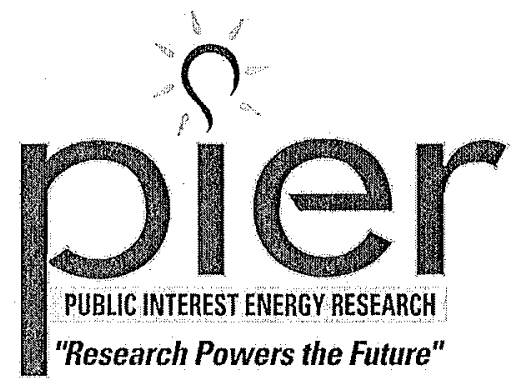

Contract No. 500-02-004

Work Authorization MR-035

Prepared For:

California Energy Commission

Public Interest Energy Research (PIER) Program

Gina Barkalow,

Project Manager

Kelly Birkinshaw,

Program Area Team Lead

Martha Krebs, Ph.D.

Deputy Director

ENERGY RESEARCH AND DEVELOPMENT

DIVISION

B. B. Blevins

Executive Director

\section{DISCLAIMER}

This report was prepared as the result of work sponsored by the California Energy Commission. It does not necessarily represent the views of the Energy Commission, its employees or the State of California. The Energy Commission, the State of California, its employees, contractors and subcontractors make no warrant, express or implied, and assume no legal liability for the information in this report; nor does any party represent that the uses of this information will not infringe upon privately owned rights. This report has not been approved or disapproved by the California Energy Commission nor has the California Energy Commission passed upon the accuracy or adequacy of the information in this report. 


\section{Acknowledgements}

Jeiwon Choi Deputy from LBNL performed the literature search to identify publications that contain data on apartment building leakiness, and tracked down copies of many of the publications.

Emily Wood from LBNL obtained additional publications, and performed most of the data entry for the apartment data.

Craig Wray, Darryl Dickerhoff, Douglas Black, Iain Walker, Rick Diamond, and Max Sherman from LBNL gave helpful advice, including discussion of practical issues that come up when measuring air leakage in large buildings, general impressions of data quality and availability, and guidance on prioritizing future work.

Steve Emmerich from NIST provided unpublished data that were obtained from the U.S. Army Corps of Engineers, and helped with interpreting the data.

Several anonymous reviewers, and Ed Vine, made helpful comments.

Please cite this report as follows:

Price, Phillip N, Shehabi A, and Chan R. 2006. Indoor-Outdoor Air Exchange Rates of California Apartments and Commercial Buildings. California Energy Commission, PIER. Publication number. 


\subsection{Abstract}

We compiled and analyzed available data concerning indoor-outdoor air leakage rates and building leakiness parameters for commercial buildings and apartments. We analyzed the data, and reviewed the related literature, to determine the current state of knowledge of the statistical distribution of air exchange rates and related parameters for California buildings, and to identify significant gaps in the current knowledge and data. Very few data were found from California buildings, so we compiled data from other states and some other countries. Even when data from other developed countries were included, data were sparse and few conclusive statements were possible. Little systematic variation in building leakage with construction type, building activity type, height, size, or location within the U.S. was observed. Commercial buildings and apartments seem to be about twice as leaky as single-family houses, per unit of building envelope area. Although further work collecting and analyzing leakage data might be useful, we suggest that a more important issue may be the transport of pollutants between units in apartments and mixed-use buildings, an under-studied phenomenon that may expose occupants to high levels of pollutants such as tobacco smoke or dry cleaning fumes. 


\subsection{Preface}

The Public Interest Energy Research (PIER) Program supports public interest energy research and development that will help improve the quality of life in California by bringing environmentally safe, affordable, and reliable energy services and products to the marketplace.

The PIER Program, managed by the California Energy Commission (Commission), annually awards up to $\$ 62$ million to conduct the most promising public interest energy. research by partnering with Research, Development, and Demonstration (RD\&D) organizations, including individuals, businesses, utilities, and public or private research institutions.

PIER funding efforts are focused on the following RD\&D program areas:

- Buildings End-Use Energy Efficiency

- Energy-Related Environmental Research

- Environmentally Preferred Advanced Generation

- Industrial/Agricultural/Water End-Use Energy Efficiency

- Renewable Energy Technologies

- Strategic Energy Research

What follows is the final report for PIER contract number 500-02-004, conducted by the Indoor Environment Department of Lawrence Berkeley National Laboratory. The report is entitled Indoor-Outdoor Air Leakage in Apartments and Commercial Buildings. The information from this project contributes to PIER's Energy-Related Environmental Research Program.

For more information on the PIER Program, please visit the Commission's Web site at: www.energy.ca.gov/research/index.html, or contact the Commission's Publications Unit at ( 916) 654-5200. 


\section{Table of Contents}

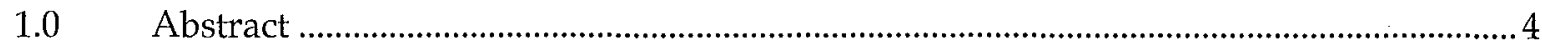

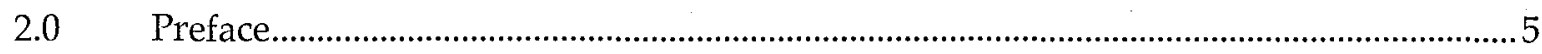

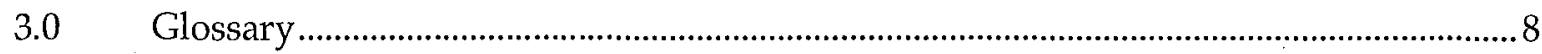

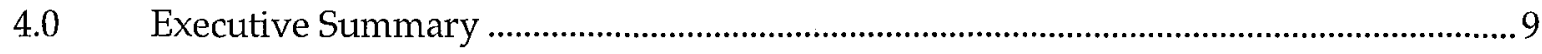

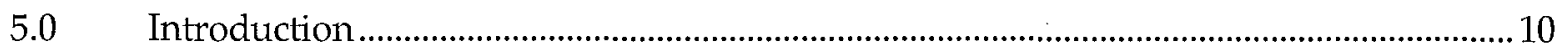

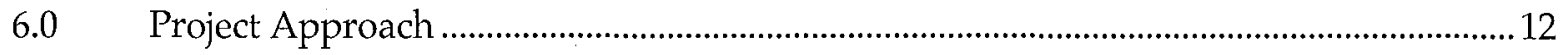

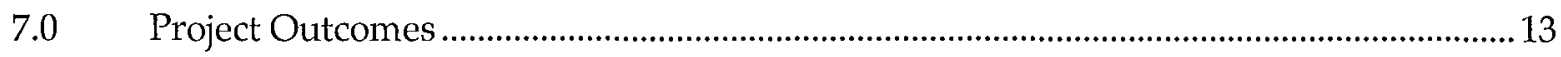

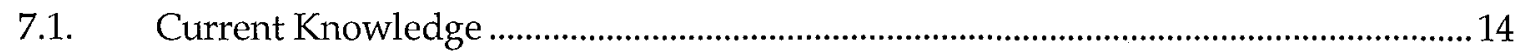

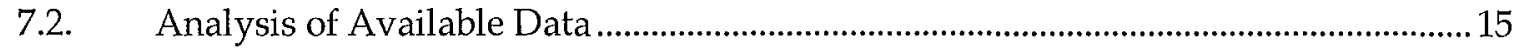

7.2.1. Commercial Buildings Data Analysis .................................................................... 16

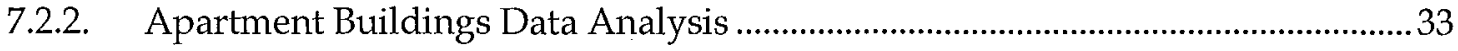

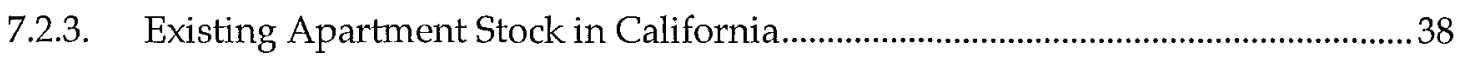

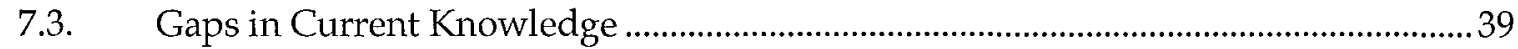

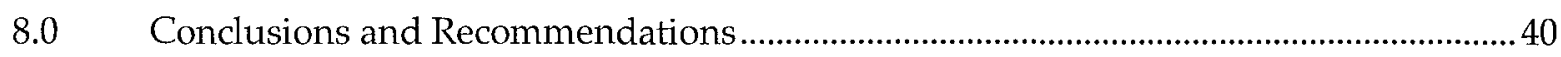

8.1. Possible Program to Characterize Apartment Building Leakiness............................. 42

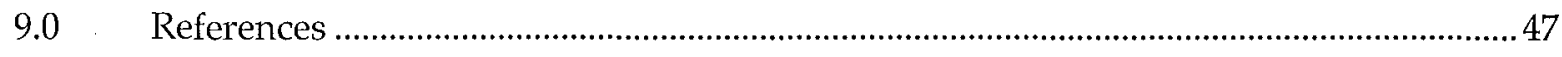

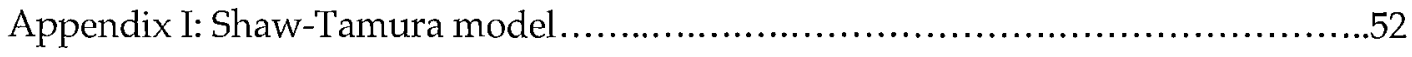

Appendix II: Statistical approach................................................. 59

Appendix III: Building data....................................................66

\section{List of Figures}

Figure 1 Histogram of air flow (liters per second per square meter of building shell) at $50 \mathrm{~Pa}$ indoor-outdoor pressure difference, for the 267 buildings in the commercial buildings database.

Figure 2: Air flow rate (liters per second, per square meter of building shell) at a 50 Pascal indoor-outdoor pressure difference, for each building in the database, grouped by building usage and construction type.

Figure 3: Same as Figure 2, for U.S. buildings only: Flow rate (liters per second, per square meter of building shell) at a $50 \mathrm{~Pa}$ indoor-outdoor pressure difference, for different types of buildings in the United States.

Figure 4: Observed geometric mean air flow rate (liters per second, per square meter of building shell) at a 50 Pascal indoor-outdoor pressure difference, with $68 \%$ confidence intervals, for U.S. building categories with at least 8 measurements, excluding strip malls...

Figure 5: Air flow rate (liters per second, per square meter of building shell) at a 50 Pascal indoor-outdoor pressure difference, for each building in the commercial buildings database, grouped by building usage and construction type, with indication of building height. 
Figure 6: Air flow rate (liters per second, per square meter of building shell) at a 50 Pascal indoor-outdoor pressure difference, for each building in the database, grouped by building usage and construction type, with indication of building footprint..

Figure 7: Air flow rate at $50 \mathrm{~Pa}$ indoor-outdoor pressure difference, in liters per second per square meter of building shell, versus number of floors in the building....................................2.27

Figure 8: Air flow rate at $50 \mathrm{~Pa}$ indoor-outdoor pressure difference, in liters per second per square meter of building shell, year in which the building was built.

Figure 9: Air flow rate at $50 \mathrm{~Pa}$ indoor-outdoor pressure difference, in liters per second per square meter of building shell, versus footprint area of the building. 28

Figure 10: Leakage of individual apartments within 16 different apartment buildings, in Air Changes per Hour $(\mathrm{ACH})$, measured under ambient wind and temperature conditions.

Figure 11: Air flow rate (liters per second, per square meter of building shell) at a 50 Pascal indoor-outdoor pressure difference, for apartment buildings....................................................38

\section{List of Tables}

Table 1: Number (and percentage) of buildings in the commercial buildings database, by building footprint area and building height (in stories).

Table 2: Number of buildings (and, in parenthesis, percentage of all buildings) in our commercial buildings database, by construction type and usage classification.

Table 3: Percentage of all commercial buildings in California, Oregon, and Washington that have a given combination of building usage and wall type

Table 4: Multi-unit or attached housing in California, by size of building 


\subsection{Glossary}

$\mathrm{ACH}$

Air Changes Per Hour

Airtightness

Building Shell

Building Envelope

Building Footprint

Exfiltration

Flow Coefficient

HVAC system

Infiltration

Leakage

Leakage Parameter

Leakiness

Pascal

\section{Air Changes per Hour}

Volume of building, divided by the flow rate (volume per hour) of air leaving the building.

Generic term for resistance to indoor-outdoor airflow that a building provides. See Leakiness.

Exterior walls and roof of a building. All parts of a building through which air can pass to the outdoors.

See Building Shell.

The total area enclosed by a building's foundation. Normally equal to the building's roof area.

Phenomenon of air leaving a building through pathways other than a ventilation system.

The term $C$ in the equation $Q=C \cdot A \cdot \Delta P^{n}$ (See Equation 6.1). This equation relates the Air Flow Rate $(Q)$ to the leakiness of the building (parameterized by C), the Area (A) of the building's shell, and the indoor-outdoor pressure difference $(\Delta P)$.

Heating, Ventilating, and Air Conditioning System. Mechanical systems that provide air, including air from the outdoors.

Phenomenon of air entering a building through pathways other than a ventilation system.

Air flow across the building shell. Same as infiltration.

Same as Flow Coefficient

Generic term for the lack of resistance to indoor-outdoor airflow that a building provides. See Airtightness.

Standard unit of pressure. 1 Newton per square meter. 


\subsection{Executive Summary}

Indoor-outdoor air-exchange rates affect energy costs because conditioned (heated or cooled) air that exits a building must be replaced by air from the outdoors. This air must then be brought to the indoor temperature through use of air conditioning or heating. Excess air exchange leads to unnecessary energy costs and a waste of resources.

Additionally, air exchange removes pollutants that were generated indoors and admits pollutants that were generated outdoors, so the air exchange rate is a key parameter in controlling indoor air quality. Most pollutant concentrations are much higher indoors than outdoors, so insufficient air exchange leads to inadequate indoor air quality and thus discomfort and detrimental health effects.

Indoor-outdoor air exchange takes place in two ways: through intentional ventilation and through undesired infiltration or "leakage." In this report we discuss what is known about leakage into apartment buildings and nonresidential buildings (which we will refer to as "commercial buildings," even though some of them are schools or other non-commercial uses). Much of our analysis concerns the leakage parameter, which quantifies amount of outdoor air that enters a building when there is a given pressure difference between indoors and outdoors. This is essentially a measure of the airtightness or leakiness of a building's shell. In contrast, a measurement of a building's air exchange rate, which is the rate at which air is entering the building at a particular time, depends not just on properties of the building but also on factors such as the wind speed and direction, operation of the mechanical ventilation system (if any), and the indoor-outdoor temperature difference. We consider both air exchange rate data and leakiness data in this report, but the emphasis is on the leakage parameter.

We reviewed the published literature to determine the current state of knowledge about air infiltration in commercial buildings and multifamily-residential buildings. Previous work in these areas has generally considered either small subsets of the available building data, or simple univariate summary statistics describing larger datasets. For apartment data these approaches are probably the best that can be done, due to the paucity of data, but for commercial buildings the available data, though sparse, allow more detailed analysis, which we have performed.

In contrast to the situation for single-family homes, where there is an available database of more than 70,000 measurements, the published database of leakage parameter measurements for apartments and commercial buildings is very small. We found data on fewer than 300 commercial buildings in the North America and Europe, and approximately 150 apartment buildings in North America, including unpublished data from 75 commercial buildings. Only a few buildings are from California, and it is unknown whether there is a large difference in leakiness between buildings in California and buildings elsewhere.

Due to (1) sparseness of data, and (2) the fact that buildings were not chosen to be statistically representative of typical buildings, the available data allow only very crude estimates of the statistical distribution of air exchange rates or building leakage area parameters, and of the relationship between leakage parameters and factors such as building size, construction materials, etc. They are, nevertheless, the best available source of information 
about these relationships and parameters. Given the limitations of the data, all results should be considered provisional.

Analysis of our commercial buildings database suggests that:

1. Within a given building activity (education, retail, etc.) there appears to be little systematic variation in leakage parameter as a function of construction type.

2. Within a given construction type (metal-frame, masonry, etc.) there is some evidence that schools and public assembly buildings tend to be somewhat tighter than average and that warehouses tend to be leakier than average.

3. For a given building activity and construction type, buildings with small "footprints" (i.e. small roof area), under $1000 \mathrm{~m}^{2}$, tend to be $25 \%$ to $50 \%$ leakier, per unit envelope area, than buildings with large footprints.

4. For a given building activity and construction type, taller buildings appear to be slightly tighter than shorter buildings (with single-story buildings being perhaps $10 \%$ to $25 \%$ leakier than taller buildings, per unit envelope area), but (a) the scarcity of tall buildings in the database gives us little statistical power to address this issue, and (b) almost all of the tall buildings are office buildings, so we cannot distinguish a height effect from an effect of building type (item 2).

5. For a given building activity, construction type, footprint size, and height, leakiness per unit envelope area is approximately lognormally distributed, with a geometric standard deviation (GSD) between about 1.7 and 2.2. (A "lognormal" distribution means that the logarithms of the data are distributed according to a Gaussian, or "normal," distribution).

6. On average, commercial buildings may be about twice as leaky as single-family houses, per unit of building envelope area.

Apartment building data are even more deficient than commercial building data, so no detailed analysis was possible. From the available data, indoor-outdoor air exchange rates and building leakage area per unit of building envelope area seem to be about twice as high (i.e. twice as leaky) for apartments as for single-family homes. This suggests that there may be a potential for substantial energy savings by reducing air infiltration rates for apartment buildings. However, reducing the infiltration rate of outdoor air without reducing the transport of pollutants such as cigarette smoke within the building may further increase the exposure of occupants to pollutants produced elsewhere in the building. The issue of internal transport of pollutants within apartment buildings and mixed-use buildings merits more attention than it has received.

\subsection{Introduction}

Indoor-outdoor air-exchange rates affect energy costs because conditioned (heated or cooled) air that leaves a building must be replaced by air from the outdoors. This air must then be brought to the indoor temperature through use of air conditioning or heating. Excess air exchange leads to unnecessary energy costs and a waste of resources. 
Additionally, air exchange removes pollutants that were generated indoors and admits pollutants that were generated outdoors, so the air exchange rate is a key parameter in controlling indoor air quality. Most pollutant concentrations are much higher indoors than outdoors, so insufficient air exchange leads inadequate indoor air quality and thus discomfort and detrimental health effects.

Excessive air exchange wastes energy, costs money, and generates pollution through unnecessary energy generation. Insufficient air exchange endangers public health and can lead to an uncomfortable and unhealthy indoor environment. Knowledge of the statistical distribution of air exchange rates can help determine whether government policy should mandate or encourage certain construction or ventilation practices, or whether additional research is needed before making such a determination.

Although concerns about energy and air pollution are the main motivations behind air infiltration research, knowledge of air infiltration rates is also necessary for assessing risks from intentional or unintentional chemical (or biological) exposures such as industrial accidents, "conventional" air pollution, or terrorist releases of toxic material. If people are told to "shelter in place" (close doors and windows, shut off ventilation) and remain indoors during an industrial accident, how much lower will indoor concentrations be than outdoors? The answer for a given house, apartment, or business depends on its air exchange rate, and the distribution of risk across the population depends on the statistical distribution of air exchange rates. This distribution is fairly well known for single-family homes, as a function of building age and other factors (Chan et al., 2005) but there is little information about apartments or commercial buildings.

In this report we will sometimes discuss the air exchange rate (which is a function of building-related parameters and also environmental condition such as wind speed) and sometimes the indoor-outdoor air flow rate for a given pressure drop across the building envelope (which is a property of the building alone). We refer to the air-infiltration-related properties of a building as the "airtightness" or "leakiness" of the building, a standard terminology (AIC 1981). The air flow rate at a specified pressure drop is a measure of building leakiness. Although leakier buildings generally experience higher air flow rates than "tighter" buildings, the air flow rate or air exchange rate depends not just on the building's leakiness but also on the magnitude of driving forces, principally wind and indoor-outdoor temperature differences, that drive air flow across the building shell.

This project had four objectives:

1. Literature review: locate publications and public data sources related to indoor-outdoor air leakage for commercial buildings and apartments, either in California or elsewhere. Compile a database of the available data.

2. Contact experts who have performed testing or measurement of air exchange rates. Ask about sources of private data, e.g. from companies that "commission" commercial heating, ventilation and air conditioning (HVAC) systems. If appropriate, contact those companies and request data. Through these discussions and the literature review discussed in item 1, determine the current state of knowledge about commercial building and apartment leakiness. 
3. Examine data from the U.S. Department of Energy's Residential Energy Consumption Survey, the American Housing Survey, and other sources, to characterize the existing multi-family building stock in California, in terms of age, building size, building type (multi-use or residential), and other factors.

4. Prepare a report that summarizes current knowledge of air exchange rates as a function of building type and age, and identifies gaps in the current knowledge.

The present document is the report that satisfies item 4.

\subsection{Project Approach}

We conducted a literature search to determine the current state of knowledge concerning commercial building and apartment airtightness. Although this report is oriented towards California buildings in particular, we quickly discovered that there are almost no data on California buildings, and thus little knowledge about these issues that is specific to the state. We broadened our search, for both data and reported data analyses, to the entire U.S., then the U.S. and Canada, and finally the U.S., Canada, and Europe.

We obtained all of the published data concerning leakage measurements in apartment buildings and commercial buildings (as we have defined them above), from approximately the last twenty years. We restricted our data search to publications that featured actual measurements in buildings, as opposed to measurements of individual leakage elements (such as duct or window leakage) or computer modeling or prediction of leakage. Some publications containing leakage measurements appear in a "gray literature" of conference proceedings or agency reports, rather than publications in refereed archival journals. We obtained these reports when we were aware of them but it is likely that, particularly for apartments, there are some gray-literature data that we did not find.

We feel more confident that we have a comprehensive set of measurements for commercial buildings than for apartments, because we spoke with Andrew Persily and Steven Emmerich of the National Institute of Standards and Technology, who have wide-ranging ongoing contacts with commercial building leakage researchers, and the database that we assembled contained almost all of their data, plus some that they did not have. They did have some new measurements from an Army Corps of Engineers database that we had not been aware of, which they provided to us and we have incorporated into our set of measurements (with identification of the specific buildings removed at the request of the Corps).

We also spoke with Richard Diamond, Craig Wray, and Darryl Dickerhoff, all of whom are colleagues in the Indoor Enviroment Department of Lawrence Berkeley National Laboratory and all of whom are experts in building leakage measurements. They were able to help us find additional apartment data. More apartment data seem to have escaped publication than is the case for commercial buildings, so it is possible that there are some apartment data that we were not able to obtain. However, Wray and Dickerhoff, who have extensive contacts in this area of research, do not believe that there are large amounts of such data beyond what we found.

There are at least two approaches to measuring or describing air exchange in buildings. One is to focus on the air exchange rate: how much air enters the building during a given time period. (This is equal to the amount of air that leaves the building in the same time period). The air exchange rate depends not just on the building itself, but also on the driving forces that the 
building is experiencing, that force air into the building. The dominant driving forces, other than operation of the ventilation system, are (1) wind and (2) the "stack effect": if the air in the building is warmer than the outdoor air, buoyancy forces push it upwards so that air tends to escape from the top of the building and to be replaced by incoming air entering the lower parts of the building, a situation that is reversed if the indoor-outdoor temperature difference is reversed. In this work we generally exclude consideration of the heating, ventilation, and air conditioning (HVAC) system (if any) because the air brought into the building through its operation is provided intentionally. In this report we focus on unintended air infiltration: how much air enters the building if the HVAC is turned off, or, as with many apartment buildings and a few commercial buildings, if the building has no HVAC system. We do provide a brief discussion of HVAC-induced air exchange in commercial buildings.

The other approach to quantifying or describing air exchange is to focus on parameters that describe the building itself, rather than the combined effect of the building and the driving forces. Experimentally, this is usually done by using a fan or "blower door" to pressurize the building to a specified level relative to the outdoors, and recording how much air must be provided to maintain that pressure. ASTM (formerly known as the American Society for Testing and Materials) has published standards (ASTM 1999) for performing such tests, Baylon et al. (1998) have proposed methods specifically for small multifamily buildings, and Brennan et al. (1992) have recommended methods specifically for school buildings. Most experiments applied a differential pressure of $50 \mathrm{~Pa}$, but some used 4 or $10 \mathrm{~Pa}$. In these cases, we adjusted the result, through application of Equation 6.1, to report the airflow (per unit area of building envelope) for a $50 \mathrm{~Pa}$ indoor-outdoor pressure difference.

After collecting the data we performed statistical analyses to look for systematic variation of building leakiness as a function of various factors, such as height, age, construction materials, building purpose, etc. We used a statistical technique known as "Bayesian hierarchical modeling" (see Gelman et al. 1995, chapter 8, for example) to address problems caused by small sample sizes. The disappointingly small amount of data, and the fact that the data are not statistically representative of California's building stock, preclude making definitive quantitative statements about building leakiness.

We also examined data from the the U.S. Department of Energy's (DOE) Commercial Building Energy Consumption Survey, or CBECS (EIA, 2003), to compare the types of buildings in our commercial building leakage database to the buildings in CBECS and thereby identify major data gaps.

We had originally contemplated summarizing data from residential surveys, to identify gaps in apartment building data as well, but we discovered that there are so few apartment building data that there is no point identifying "gaps": there is no category of apartment buildings for which data are adequate to make statements about leakiness with any degree of confidence. We discuss this in more detail in Section 7.1.

\subsection{Project Outcomes}

In the subsections below, we discuss the current state of knowledge about apartment and commercial building leakage, as determined through a literature search and through discussions with experts in the field. We then discuss the results of new data analyses to attempt to address some of the major questions of interest. 


\subsection{Current Knowledge}

Buildings are often divided into two categories: places where people live, which we call "residential" buildings, and places where people work, which we will call "commercial buildings" although this is not technically the correct term (since government buildings, schools and other non-commercial buildings are also workplaces).

Residential buildings can be divided into (1) single-family houses and (2) multi-family residences. Commercial buildings (as we have defined them above) can be divided into many sub-categories: office buildings, small or large retail buildings, schools, etc.

Of all of the many categories and sub-categories of buildings, the only category for which air exchange rates and leakage parameters are well known is single-family detached houses. Vast amounts of data are available for single-family homes, mostly as a result of "energy audit" programs that seek to quantify house leakiness or identify leaky homes in order to implement energy efficiency programs. The available data are subject to selection bias and other problems, but the overall picture is characterized well enough that most practical questions that rely on knowledge of the statistical distribution of house leakage parameters can be answered (Chan et al., 2005).

In contrast, the overall situation for commercial buildings and for apartment buildings is: data are sparse, and there are complications in both measuring and conceptualizing building leakage because some commercial buildings are compartmentalized into discrete stores, offices, etc. in such a way that air exchange between compartments can interact with air exchange between the building and the outdoors. One implication of the interaction between indoor flow and indoor-outdoor air exchange is that it is difficult to predict the air exchange rate as a function of wind, indoor-outdoor temperature, and building leakage parameters. In contrast, in single-family homes, which are small in absolute size and which have large surface-to-volume ratio, very simple formulae relate the environmental conditions and leakage parameter to the air change rate. This is not true for more complex buildings.

Persily (1999) has shown that, contrary to expectation of some experts, air infiltration is significant in commercial buildings. VanBronkhorst et al. (1995) estimate that infiltration accounts for $10 \%$ to $20 \%$ of the heating load in all office buildings nationwide, although they estimate it to have little effect on cooling loads, in part because of lower winds and lower indoor-outdoor absolute temperature difference in summer compared to winter.

Although air infiltration in commercial buildings is significant, the air exchange rate due to HVAC operation is almost always larger than the air infiltration rate. Therefore, removal of indoor pollutants, delivery of outdoor pollutants, and energy costs are largely determined by the details of HVAC design and operation. Moreover, since HVAC systems often mix air from different parts of the building, and deliver outdoor air approximately equally to different parts of the building, predicting indoor exposures to outdoor pollutants can be done fairly accurately using knowledge of HVAC operation alone. For these reasons it is somewhat understandable that little effort has gone into modeling air infiltration rates in commercial buildings, or into experiments to determine the relationship between building leakiness and air exchange for 
commercial buildings. Essentially, researchers and funders have collectively decided that since, for commercial buildings, HVAC operation is generally more important than infiltration, most effort spent in better understanding infiltration is not worth it. Still, some work on predicting commercial building infiltration from leakiness, temperature, and wind has been performed. The best, and best-validated work is from Shaw and Tamura (1977); that work is summarized in Appendix III, most of which is expected to appear in the dissertation of R. Chan (Chan, 2006).

Although the near neglect of the relationship between leakiness and infiltration in commercial buildings is understandable for reasons discussed above, the same cannot be said for the relationship between leakiness and infiltration in apartments. Many apartment buildings do not have central HVAC systems, so infiltration is a major contributor to overall air exchange rates. In buildings without HVAC systems, if people keep their windows closed and do not operate window air conditioners, infiltration is the only process of indoor-outdoor air exchange. So infiltration is a very important phenomenon in apartment buildings, and it is somewhat surprising, and disappointing, that more quantitative work on the relationship between leakiness and air exchange rates has not been performed. We speculate that small apartment buildings, and row houses, might reasonably be modeled similarly to single-family houses and that larger buildings might be modeled using the Shaw and Tamura model that was designed for commercial buildings, but there are no experimental data to support this assumption.

\subsection{Analysis of Available Data}

In an extensive review of the literature, we compiled all of the published articles that we could find that report measured air exchange rates or leakage parameters in commercial buildings or in apartments. This yielded:

1. Data on 267 commercial buildings in 5 developed countries. Of these, 164 buildings are from the US (but none of them are from California); the others are from Canada, UK, Sweden, and France. Tested buildings are mostly offices (18\%), industrial/ warehouses $(13 \%)$, and schools $(27 \%)$, followed by small retail $(7 \%)$ and strip malls $(6 \%)$, recreational buildings and auditoria (7\%), and with the remaining $21 \%$ being supermarkets, public buildings, restaurants, lodging (hotels and motels), health care facilities, malls, and others. Half of the buildings are classified as having masonry construction (including concrete block). Metal frame/metal panel and concrete panel/tilt-up are also common among the office and warehouse/industrial buildings tested. All of the raw data are presented in Appendix II.

2. Data from 162 apartments in 78 buildings in the U.S. and Canada. Only four of the apartments are in California, from two buildings in Oakland. In some of the apartment buildings, only the total leakage was measured (not the leakage from individual apartments); in others, measurements were made in individual apartments. In some cases researchers measured the leakage from one apartment to another within a building, in others they did not. In some cases air exchange rates were measured, while in other cases the air flow rate at a given pressure drop was measured. All of the raw data are presented in Appendix III. 
In addition to performing the literature search, we also communicated, by email or phone, with several researchers who perform building leakage measurements and/or analyze building leakage data: Andrew Persily and Steve Emmerich from the National Institute of Standards and Technology, and Max Sherman from Lawrence Berkeley National Laboratory. Emmerich was able to provide unpublished data collected by the U.S. Army Corps of Engineers. These data include leakiness measurements for 75 commercial buildings. Schools represent about half of these measurements, while the other half is comprised of community center and health care buildings. Most of these buildings are classified as masonry or metal frame construction.

\subsubsection{Commercial Buildings Data Analysis}

The commercial-building leakiness measurements used in this analysis are compiled from 15 different studies published in journal articles and conference proceedings. The studies represent measurements from several countries with the majority of measurement from the United States. Most leakiness measurements are obtained for energy efficiency programs and are focused on certain types of buildings in certain areas. The largest single set of measured leakage data is 69 buildings from the Florida Solar Energy Center (Cummings et al. 1996). These are buildings located in Florida and include many different building types, such as offices, schools, and retail. Two other studies measured different types of buildings (Litvak et al. 2001, Dumont 2000), but most focus on certain building types. Two studies measured leakage in schools (Shaw and Jones, Brennan et al. 1992), one measured supermarkets and malls (Shaw 1981), four measured offices (Shaw and Reardon 1974, Grot and Persily 1986, Potter and Jones 1992, Perera and Tull 1989), and five measured industrial warehouses (Lundin 1986, Potter and Jones 1995, Flury et al. 1998, Perera et al. 1997, Jones and Powell 1994). The limited data used in this analysis are not statistically representative of all commercial buildings: buildings were sampled opportunistically rather than as part of a systematic scheme.

The commercial building data include the rate of air exfiltration when the building is

pressurized to 4, 10,50, or 75 Pascals relative to outdoors. This is a measure of the "leakiness" of the building: Leakiness is related to the building's air exchange rate, but it is not the only or indeed the largest parameter controlling the air exchange rate for commercial buildings, which is normally dominated by the effects of the building's ventilation system. In a building without a ventilation system, or with a system that is not operating, the air exchange rate depends on both the leakiness of the building in addition to the magnitude of the forces that drive indooroutdoor air exchange: principally, wind forces and thermal buoyancy forces.

Most of the buildings in the leakiness database were built between 1960 and 2000, centering at around 1980. Sixty percent of the buildings have a footprint area $<1000 \mathrm{~m}^{2}$. About $75 \%$ of the buildings are single-story, but there are also 12 buildings that have 10 stories or more. Table 1 shows the distribution of each of these characteristics among the buildings sampled, both in absolute numbers and as a percentage of the total database. 
Table 1: Number (and percentage) of buildings in the commercial buildings database, by building footprint area and building height (in stories).

\begin{tabular}{|l|r|r|r|}
\hline & \multicolumn{2}{|c|}{ Footprint Area } & All Footprint Areas \\
\hline Building Height & $<1000 \mathrm{~m}^{2}$ & $\geq 1000 \mathrm{~m}^{2}$ & $208(78)$ \\
\hline 1 story & $129(48)$ & $79(30)$ & $33(12)$ \\
\hline 1.5 to 3 stories & $20(7)$ & $13(5)$ & $9(3)$ \\
\hline 3.5 to 5 stories & $2(1)$ & $7(3)$ & $17(6)$ \\
\hline$>5$ stories & $9(3)$ & $8(3)$ & $267(100)$ \\
\hline All heights & $160(60)$ & $107(40)$ & \\
\hline
\end{tabular}

We used reported leakage area measurements to determine the air flow rate (in liters per second) per square meter of building envelope, for an indoor-outdoor pressure difference of $\Delta P=50 \mathrm{~Pa}$, where the building envelope area, $A\left[\mathrm{~m}^{2}\right]$, includes both the vertical walls and the roof. In cases in which the experimental data were generated from a $\Delta P$ other than $50 \mathrm{~Pa}$, we adjusted them with the following relationship:

$$
Q=C \cdot A \cdot \Delta P^{n}
$$

Eqn 7.1

where $Q\left[\mathrm{~m}^{3} / \mathrm{s}\right]$ is the airflow rate needed to pressurize the building to a pressure difference of $\Delta P[\mathrm{~Pa}]$ with respect to the outdoors, $n$ is the flow exponent, and $\mathrm{C}$ is the flow coefficient (i.e. the leakage parameter.) Using pairs of $Q$ and $\Delta P$ measurements, $C$ and the flow exponent $n$ can be determined through a fitting procedure. According to the orifice flow equation (see Munson et al., 1998, for example), the theoretical limit of $n$ is between 0.5 and 1 . When a building is leaky, resistance from inertia is the largest effect restricting the airflow through the building envelope, and $n$ approaches 0.5 . On the other hand, when a building is tight, there is little airflow through the building envelope, and the flow resistance is dominated by drag through the building's cracks and $n$ approaches 1. We found the correlation coefficient between $C$ and $n$ is -0.44 with a $95 \%$ confidence interval of -0.55 to -0.32 . In AIVC Technical Note 44 "An Analysis and Data Summary of the AIVC's Numerical Database" (1994), $n$ is found to correlate with leakage with a correlation coefficient of -0.36 , which is similar to what we found here. The distribution of $n$ among buildings is also consistent with earlier studies: roughly normal, with a mean of 0.62 . For this analysis the Effective Leakage Area from each study was recalibrated to a pressure differential of $50 \mathrm{~Pa}$ and normalized to the surface area of the measured building. The power law flow exponent, $\mathrm{n}$, ranged for 0.3 to 0.9 , and was assumed to be 0.65 when not reported in the original publication.

For the 267 commercial buildings tested, the normalized building leakage (i.e. the building leakiness) is roughly lognormally distributed, with a geometric mean (GM) of about 4 
$\mathrm{L} / \mathrm{s} \mathrm{m}^{2}$ at $50 \mathrm{~Pa}$, and a geometric standard deviation (GSD) of about 2.3. Figure 1 shows a histogram of the distribution of the logarithms (base 10) of the data.

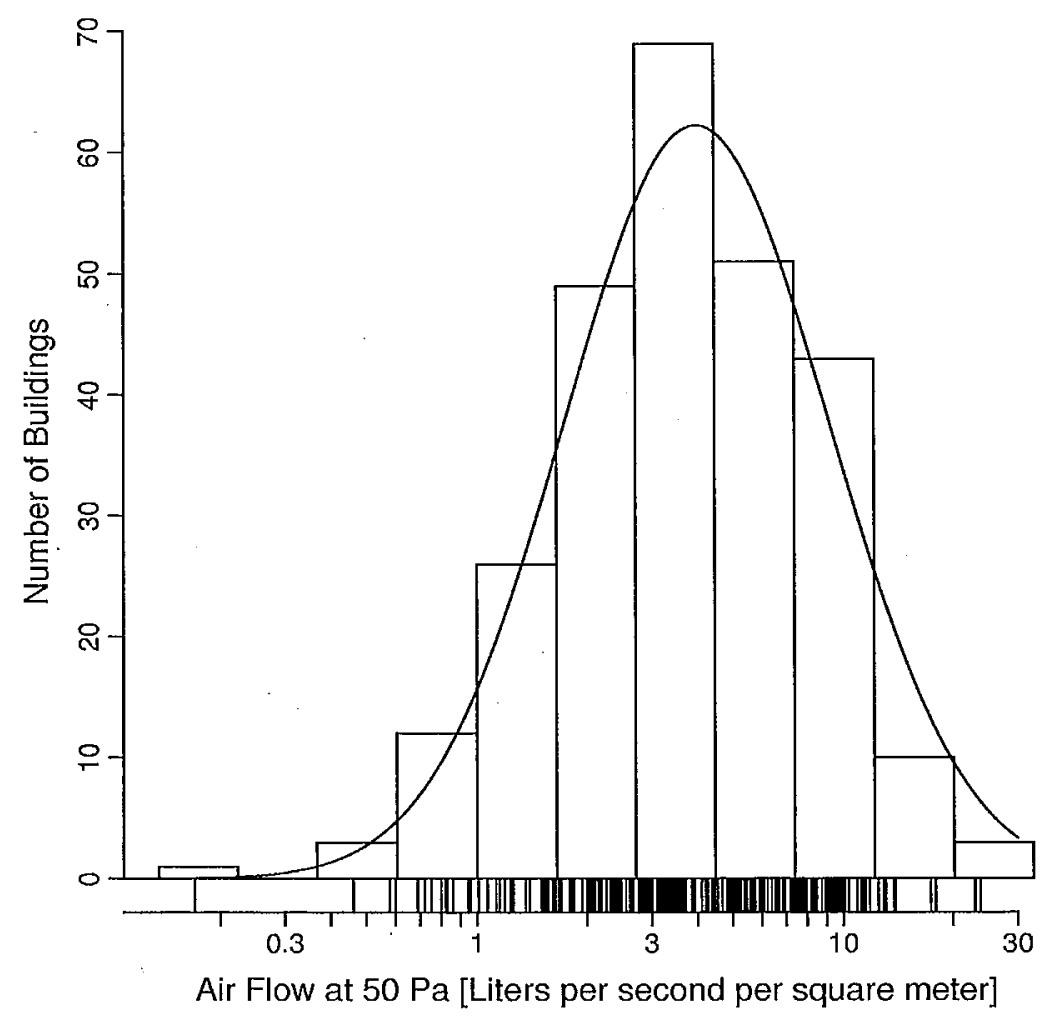

Figure 1 Histogram of air flow (liters per second per square meter of building shell) at $50 \mathrm{~Pa}$ indooroutdoor pressure difference, for the 267 buildings in the commercial buildings database. These data do not constitute a representative sample of all commercial buildings. The distribution is approximately lognormal, with a geometric mean (GM) of $4 \mathrm{~L} / \mathrm{s} \mathrm{m}^{2}$ and a geometric standard deviation (GSD) of 2.3 .

By contrast with the commercial building distribution, our recent analysis of the air leakage of US single-family houses (Chan et al. 2005) found that the leakage follows a lognormal distribution with a GM of $2.6 \mathrm{~L} /\left(\mathrm{s} \cdot \mathrm{m}^{2}\right)$, and a GSD of 1.6, at a $50 \mathrm{~Pa}$ indoor-outdoor pressure difference. Thus, based on this cursory summary of the data, commercial buildings seem to be somewhat leakier than single-family houses, and also to have leakiness that is more variable than single-family homes.

Based on the published information about the buildings that were measured, we classified each building according to usage (e.g. school, retail, etc.) and construction type (masonry, steel frame, etc.). "Manufactured building" refers to trailers or portable structures. Inevitably, there is some ambiguity in the classification of building usage and construction types. Our classifications are based on those used in the original studies, but we had to interpret some entries that did not perfectly match any of our categories. Table 2 summarizes the number of buildings in each classification and construction type, and the fraction of the total database 
that these numbers represent. In a later section we discuss the comparison of this distribution of buildings to the distribution in California as determined by a building survey.

Table 2: Number of buildings (and, in parenthesis, percentage of all buildings) in our commercial buildings database, by construction type and usage classification.

\begin{tabular}{|c|c|c|c|c|c|c|c|c|c|}
\hline & Masonry & $\begin{array}{c}\text { Frame/ } \\
\text { Masonry }\end{array}$ & $\begin{array}{c}\text { Concrete } \\
\text { Panel/ } \\
\text { Tilt-Up }\end{array}$ & $\begin{array}{c}\text { Metal } \\
\text { Frame/ } \\
\text { Metal } \\
\text { Panel }\end{array}$ & $\begin{array}{l}\text { Curtain- } \\
\text { wall }\end{array}$ & $\begin{array}{l}\text { Manu- } \\
\text { factured }\end{array}$ & $\begin{array}{l}\text { Wood } \\
\text { Frame/ } \\
\text { Frame }\end{array}$ & $\mathbf{n} / \mathbf{a}$ & Total \\
\hline Education & $\begin{array}{c}52 \\
(19)\end{array}$ & & & $\begin{array}{c}4 \\
(1)\end{array}$ & & $\begin{array}{c}1 \\
(0)\end{array}$ & $\begin{array}{c}1 \\
(0)\end{array}$ & $\begin{array}{l}14 \\
(5)\end{array}$ & $\begin{array}{c}72 \\
(27)\end{array}$ \\
\hline $\begin{array}{l}\text { Super- } \\
\text { market }\end{array}$ & $\begin{array}{c}7 \\
(3)\end{array}$ & & $\begin{array}{c}2 \\
(1)\end{array}$ & & & & & & $\begin{array}{c}9 \\
(3)\end{array}$ \\
\hline Mall & $\begin{array}{c}1 \\
(0)\end{array}$ & & & & & & & & $\begin{array}{c}1 \\
(0)\end{array}$ \\
\hline Office & $\begin{array}{l}20 \\
(7)\end{array}$ & & $\begin{array}{l}13 \\
(5)\end{array}$ & $\begin{array}{c}9 \\
(3)\end{array}$ & $\begin{array}{c}2 \\
(1)\end{array}$ & $\begin{array}{c}4 \\
(1)\end{array}$ & $\begin{array}{c}1 \\
(0)\end{array}$ & & $\begin{array}{c}49 \\
(18)\end{array}$ \\
\hline $\begin{array}{r}\text { Warehouse/ } \\
\text { Industrial }\end{array}$ & $\begin{array}{c}6 \\
(2)\end{array}$ & & $\begin{array}{c}6 \\
(2)\end{array}$ & $\begin{array}{l}20 \\
(7)\end{array}$ & & & & $\begin{array}{c}3 \\
(1)\end{array}$ & $\begin{array}{l}35 \\
(13)\end{array}$ \\
\hline $\begin{array}{l}\text { Small } \\
\text { Retail }\end{array}$ & $\begin{array}{l}10 \\
(4)\end{array}$ & $\begin{array}{c}1 \\
(0)\end{array}$ & & $\begin{array}{c}2 \\
(7)\end{array}$ & & & $\begin{array}{c}1 \\
(0)\end{array}$ & $\begin{array}{c}4 \\
(1)\end{array}$ & $\begin{array}{l}18 \\
(7)\end{array}$ \\
\hline Strip Mall & & $\begin{array}{l}12 \\
(4) \\
\end{array}$ & & & & & 4 & & $\begin{array}{l}16 \\
(6) \\
\end{array}$ \\
\hline Health Care & $\begin{array}{c}8 \\
(3)\end{array}$ & & & $\begin{array}{c}2 \\
(2)\end{array}$ & & & $\begin{array}{c}1 \\
(0)\end{array}$ & $\begin{array}{c}1 \\
(0)\end{array}$ & $\begin{array}{l}12 \\
(4)\end{array}$ \\
\hline $\begin{array}{r}\text { Public } \\
\text { Building }\end{array}$ & $\begin{array}{c}8 \\
(3)\end{array}$ & $\begin{array}{c}1 \\
(0)\end{array}$ & & $\begin{array}{c}5 \\
(2)\end{array}$ & , & & & $\begin{array}{c}5 \\
(2)\end{array}$ & $\begin{array}{l}19 \\
(7)\end{array}$ \\
\hline $\begin{array}{l}\text { Recreation/ } \\
\text { Auditorium }\end{array}$ & $\begin{array}{l}15 \\
(6)\end{array}$ & & & & & & $\begin{array}{c}1 \\
(0)\end{array}$ & $\begin{array}{c}2 \\
(1)\end{array}$ & $\begin{array}{l}18 \\
(7)\end{array}$ \\
\hline Restaurant & $\begin{array}{c}4 \\
(1)\end{array}$ & $\begin{array}{c}1 \\
(0) \\
\end{array}$ & & & & & $\begin{array}{c}2 \\
(1)\end{array}$ & & $\begin{array}{c}7 \\
(3) \\
\end{array}$ \\
\hline Lodging & $\begin{array}{c}5 \\
(2)\end{array}$ & & & & & & $\begin{array}{c}2 \\
(1)\end{array}$ & & $\begin{array}{c}7 \\
(3)\end{array}$ \\
\hline $\mathrm{n} / \mathrm{a}$ & & & & $\begin{array}{c}1 \\
(0)\end{array}$ & & & & $\begin{array}{c}3 \\
(1)\end{array}$ & $\begin{array}{c}4 \\
(1)\end{array}$ \\
\hline Total & $\begin{array}{l}136 \\
(51)\end{array}$ & $\begin{array}{l}15 \\
(6)\end{array}$ & $\begin{array}{l}21 \\
(8)\end{array}$ & $\begin{array}{c}43 \\
(16)\end{array}$ & $\begin{array}{c}2 \\
(1)\end{array}$ & $\begin{array}{c}5 \\
(2)\end{array}$ & $\begin{array}{l}13 \\
(5)\end{array}$ & $\begin{array}{c}32 \\
(12)\end{array}$ & $\begin{array}{l}267 \\
(100)\end{array}$ \\
\hline
\end{tabular}




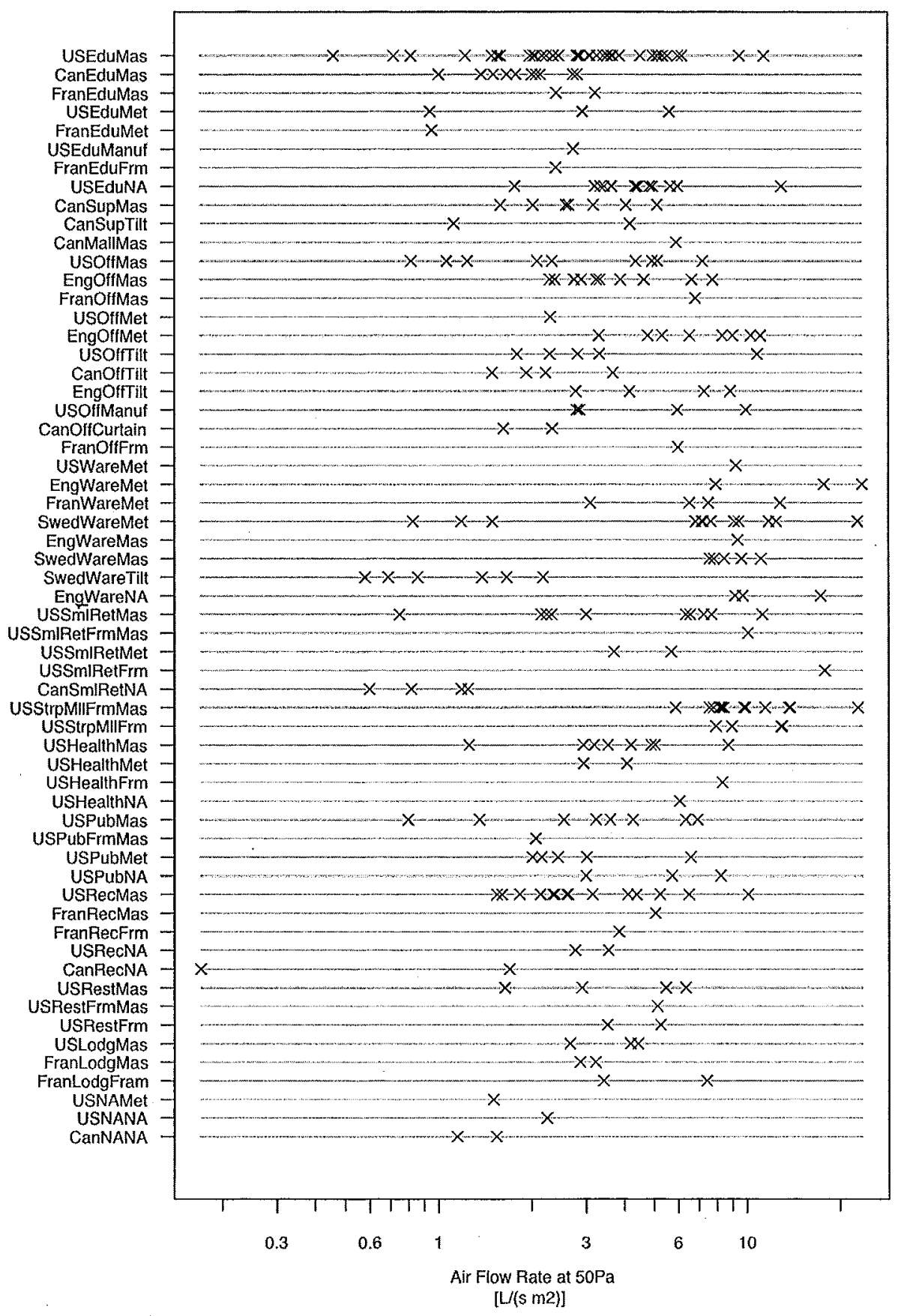

Figure 2: Air flow rate (liters per second, per square meter of building shell) at a 50 Pascal indoor-outdoor pressure difference, for each building in the database, grouped by building usage and construction type. $\mathrm{X}$-axis is a logarithmic scale. Countries are: U.S. = United States, Swe = Sweden, Fran = France, Can = Canada. Usage categories are: Edu $=$ Education, Off $=$ Office, Ware $=$ Warehouse, SmIRet $=$ Small Retail, Pub $=$ Public Assembly, Lodg = Lodging, StrpMII = Strip Mall, Health $=$ Health Care, Rest $=$ Restaurant. Construction categories are: Mas = Masonry, Tilt = "tilt-up", Met = Metal Panel, Mas = Masonry, Frm = Frame, NA = unknown). 


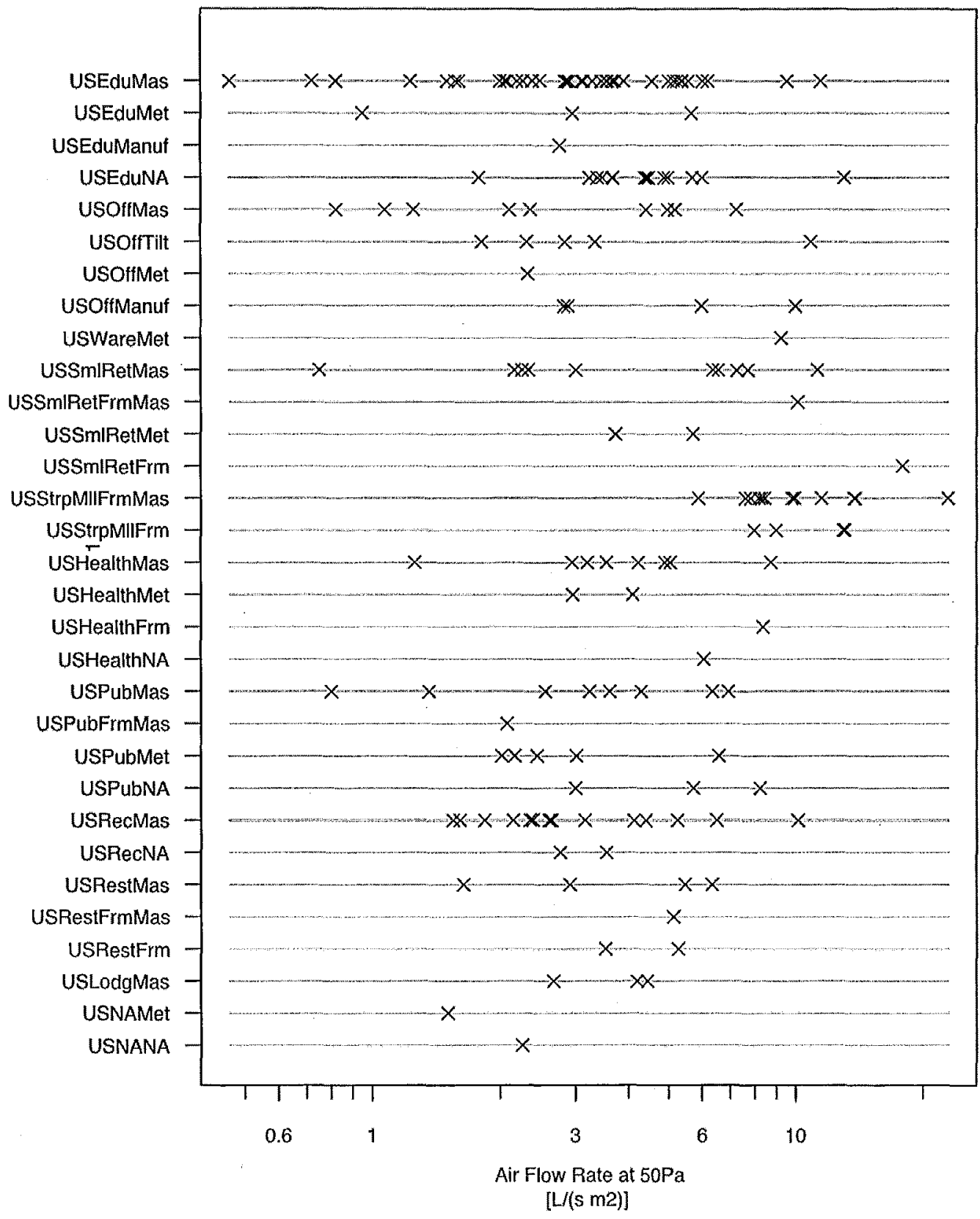

Figure 3: Same as Figure 2, for U.S. buildings only: Flow rate (liters per second, per square meter of building shell) at a $50 \mathrm{~Pa}$ indoor-outdoor pressure difference, for different types of buildings in the United States. X-axis uses a logarithmic scale. Usage categories are: Edu $=$ Education, Off $=$ Office, Ware $=$ Warehouse, SmIRet $=$ Small Retail, Pub $=$ Public Assembly, Lodg $=$ Lodging, StrpMII $=$ Strip Mall, Health $=$ Health Care, Rest $=$ Restaurant. Construction categories are: Mas = Masonry, Tilt = "tilt-up", Met = Metal Panel, Mas $=$ Masonry, Frm $=$ Frame, NA = unknown). 
Figure 2 shows the total flow rate at 50 Pascals, normalized to the building surface area, for each subtype of building for which we have data. For instance, each $\mathrm{x}$ on the uppermost line (USEduMas) indicates the logarithm of the flow rate at $50 \mathrm{~Pa}$ for U.S. "educational" buildings with masonry construction. The $x^{\prime} s$ are spread rather widely along the $x$-axis, indicating that some of these buildings are much less leaky than others (farther right indicates higher leakiness). Figure 3 shows just the U.S. data.

As can be seen in Figures 2 and 3, there is some evidence that a few building types are leakier than others. The real standout is U.S. frame-masonry strip malls (middle of Figure 3), for which reported leakiness is very high (a geometric mean of $9 \mathrm{~L} /\left(\mathrm{s} \cdot \mathrm{m}^{2}\right)$ at $50 \mathrm{~Pa}$ ). However, the experimental method used to generate these measurements included leakage to other units within the building, not just to the outdoors, so the leakiness to the outdoors is probably much less than reported. For this reason we exclude strip malls from many of the following discussions.

Ignoring strip malls, and considering only the U.S. buildings, there is, perhaps surprisingly, little evidence of systematic variation of leakiness with building type or construction type. However, our statistical power to address this issue is quite poor: in the U.S., excluding strip malls there are only four combinations of building type and construction method for which 10 or more measurements are available. We'll refer to the combination of building type and construction method as the "building category." Figure 4 shows the observed geometric mean for the U.S. building categories with 8 or more observations, excluding strip malls. Confidence bounds (one multiplicative standard error), based purely on small-sample error and not accounting for potential sample bias, are shown with error bars. Only the U.S. Educational buildings with unknown (NA) building type have a geometric mean that is "statistically significantly" different (at the $\mathrm{p}<0.05$ level) from the overall geometric mean for the data.

However, by restricting ourselves to the well-sampled building categories we are excluding more than $60 \%$ of the data. What's more, we are failing to take advantage of the fact that we expect at least the potential for some relationship between various building categories; for instance we might expect masonry buildings to group together somewhat in leakiness and that metal-frame buildings might do the same, and so on. We also expect some similarity between U.S. masonry office buildings and similar buildings in other countries. To explore these possibilities and quantify the results we used a standard but somewhat complicated statistical method, known as Bayesian Hierarchical Modeling (or Multi-level Modeling), results of which are discussed below and are presented in detail in Appendix IV.

We modeled some of the variability in commercial building leakiness by correlating building characteristics with the air leakage coefficient measured. There are two types of explanatory variables in the dataset: continuous and categorical. Continuous explanatory variables include the year-built, floor area, and height of the building. Categorical explanatory variables include the functional and construction type of the building. We only examined the 
variables listed here, but there are other factors that might affect the air leakage of a building, for which we have no data. For example, differences in building codes and practices between countries, due to climatic concerns or other issues, can affect the airtightness of buildings. How carefully the building was constructed and maintained can also affect the air leakage.

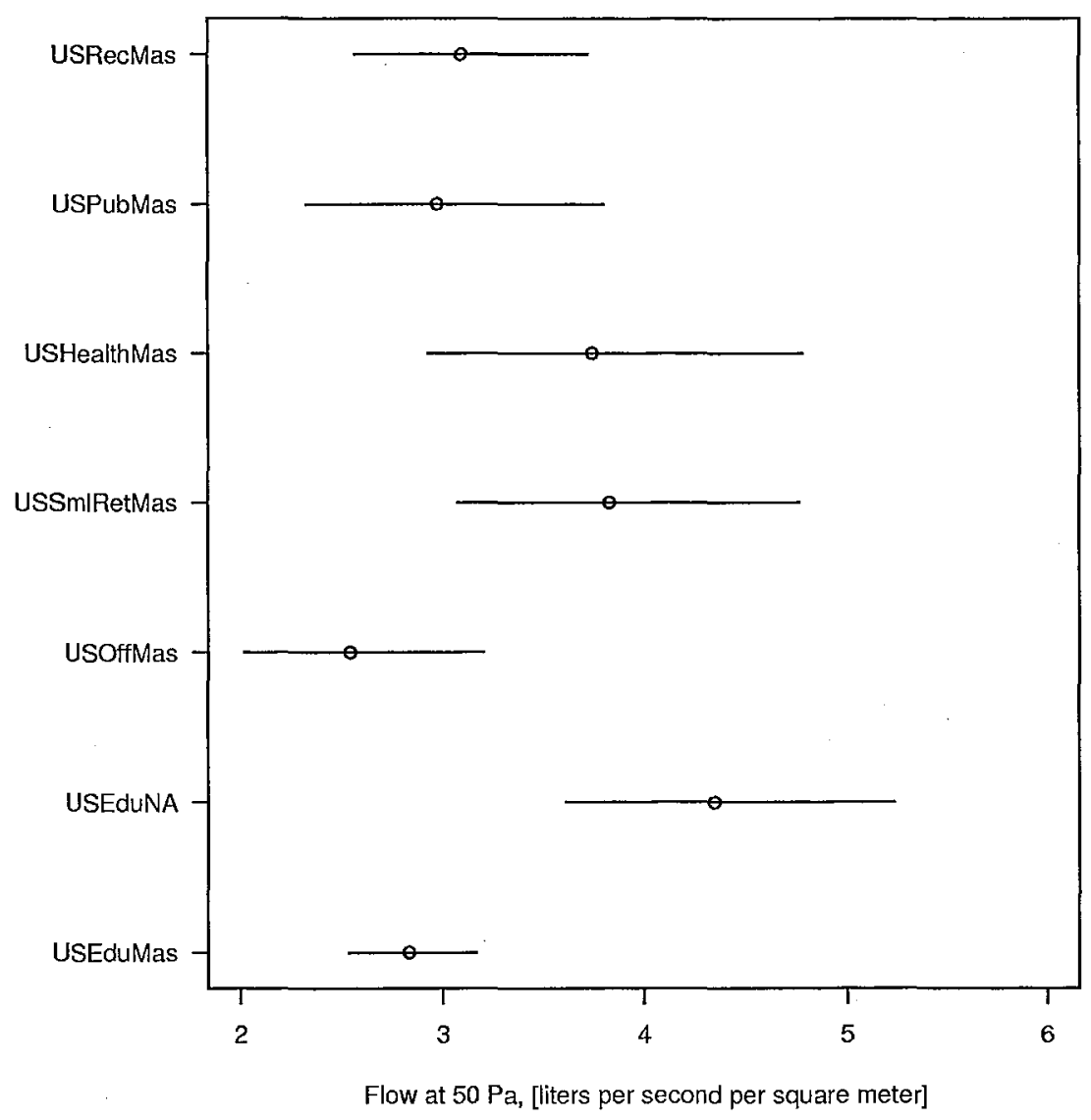

Figure 4: Observed geometric mean air flow rate (liters per second, per square meter of building shell) at a 50 Pascal indoor-outdoor pressure difference, with $68 \%$ confidence intervals, for U.S. building categories with at least 8 measurements, excluding strip malls. Usage categories are: Edu $=$ Education, Off $=$ Office, SmIRet $=$ Small Retail, Pub $=$ Public Assembly, Health $=$ Health Care .

Construction categories are: Mas = Masonry, NA = unknown). 
Before discussing the analysis, we present the raw data in more detail. Figures 5 and 6 display the building leakiness data, by function and construction type (similarly to Figure 2 and Figure 3), but now using plotting symbols that distinguish the buildings by height and by footprint area. From visual inspection, there is little evidence of a substantial relationship between height and leakage, footprint and leakage, or building age (or year built) and leakage (see Figure 8). Nevertheless, in addition to building categories we included footprint and height categories in the statistical analyses.

Our main results, discussed below, concern multivariate analyses that consider all of the available explanatory variables together, but we also performed some univariate comparisons:

1. For buildings with footprint area greater than or equal to 1000 square meters $(\mathrm{n}=107)$, the geometric mean flow rate at $50 \mathrm{~Pa}$ was $4.5 \mathrm{~L}$ per second per square meter of building shell. For buildings with footprint area less than 1000 square meters $(n=160)$ the geometric mean flow rate at 50 Pa was $2.6 \mathrm{~L}$ per second per square meter of building shell.

2. For buildings with 5 or more floors $(n=26)$, the geometric mean flow rate at $50 \mathrm{~Pa}$ was $3.3 \mathrm{~L}$ per second per square meter of building shell. For buildings with fewer than 5 floors $(n=241)$, the geometric mean flow rate at $50 \mathrm{~Pa}$ was approximately the same, $3.7 \mathrm{~L}$ per second per square meter of building shell.

3. For buildings built in 1986 or later $(n=131)$, the geometric mean flow rate at $50 \mathrm{~Pa}$ was $3.8 \mathrm{~L}$ per second per square meter of building shell. For buildings built before $1986(n=136)$, the geometric mean flow rate at $50 \mathrm{~Pa}$ was approximately the same, $3.5 \mathrm{~L}$ per second per square meter of building shell.

Multivariate analyses (i.e. including more than one explanatory variable at a time) suggest that there may be effects associated with building footprint and height, but in no case did the parameters associated with building age indicate the presence of a substantial building age effect, so we excluded age from our main analysis. The lack of evidence for an effect related to building age may be surprising, given that new single-family homes have become much more air-tight over the past twenty years (Chan et al. 2005). However, there is little reason to believe that airtightness in commercial buildings must increase just because single-family residential airtightness increases: first, construction techniques for most commercial buildings are very different from those for houses, and second, cost-conscious homebuyers have more incentive to save than do cost-conscious business owners since less than $1 \%$ of a typical company's payroll is spent on heating and cooling. Persily (1999) has previously noted that although many researchers and laypeople assume that commercial buildings have become more airtight in recent years, there is no evidence that this is true. Our analysis suggests that, as Persily suggests, commercial buildings from the 1990s are about the same, in terms of leakiness, as those from earlier decades. Effects related to building age could also be difficult to interpret to a variety of effects such as changes in leakiness (or mechanical ventilation rates) due to renovations; shell or duct leakage that change with time due to degradation of caulking or duct tape (an effect that might depend on both building design and construction details), and so on. 


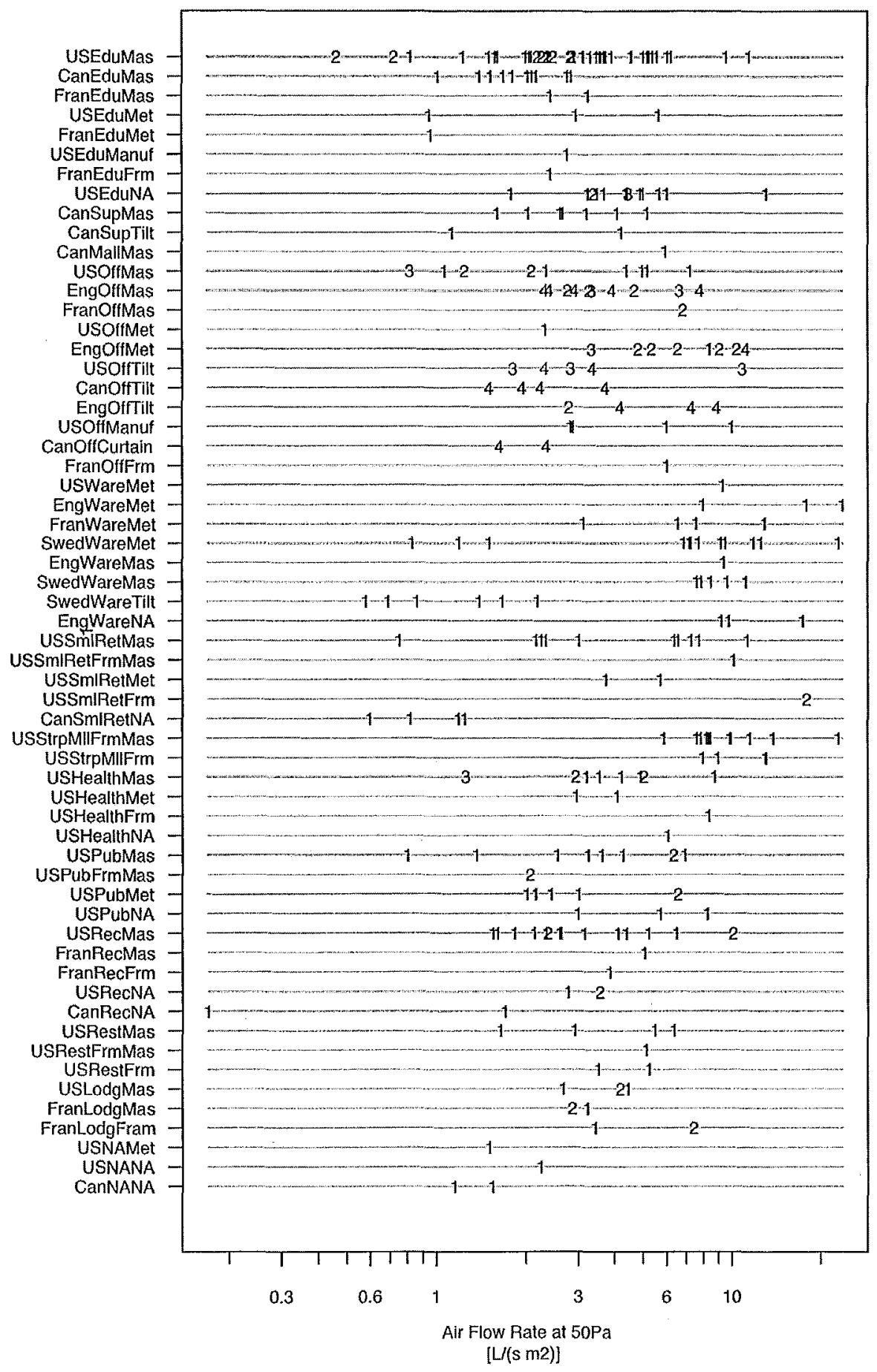

Figure 5: Air flow rate (liters per second, per square meter of building shell) at a 50 Pascal indoor-outdoor pressure difference, for each building in the commercial buildings database, grouped by building usage and construction type, with indication of building height. Building height classes are: $1=$ single story, $2=2-$ 3 stories, $3=4-5$ stories, $4=6$ or more stories. See Figure 7 as well. 


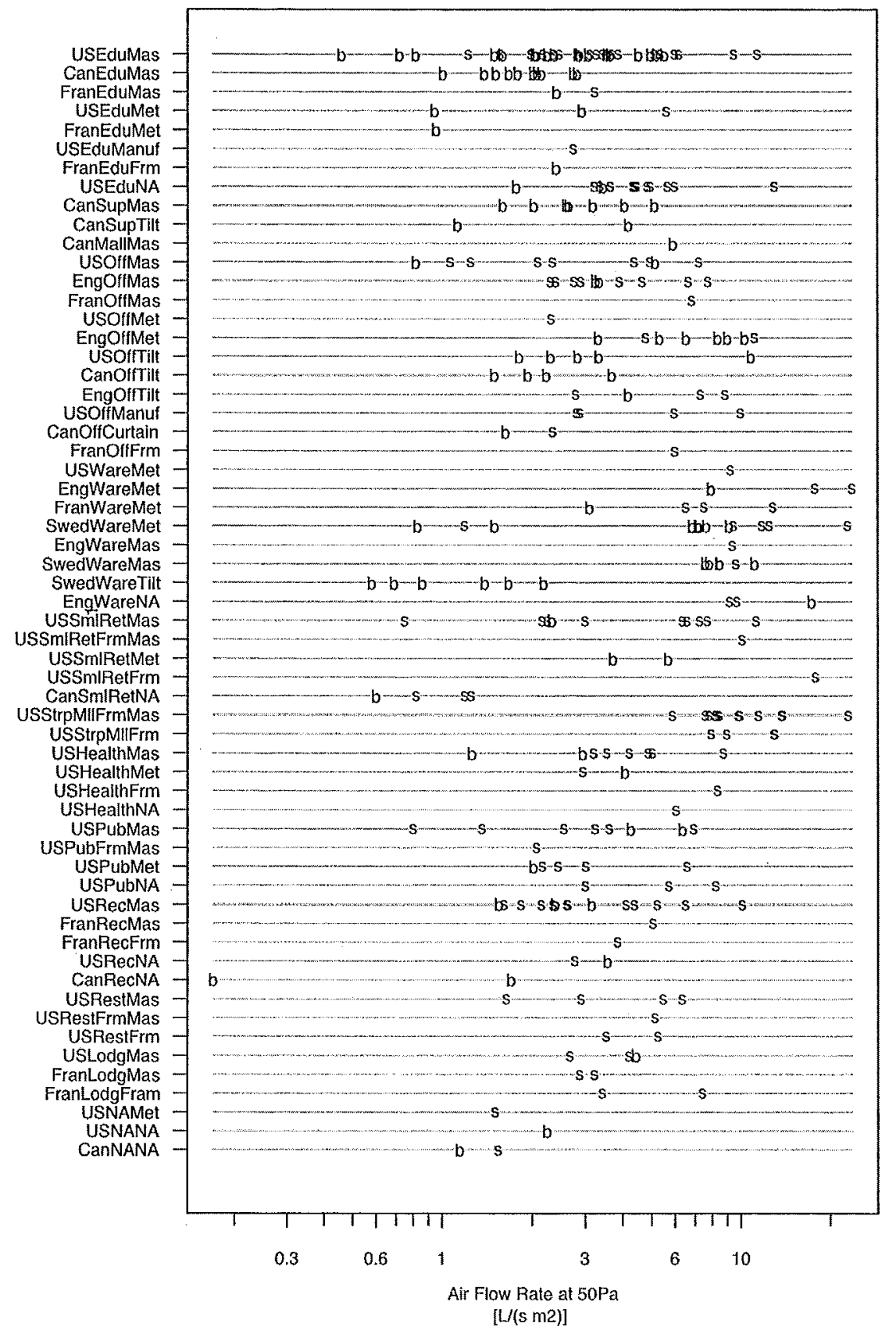

Figure 6: Air flow rate (liters per second, per square meter of building shell) at a 50 Pascal indoor-outdoor pressure difference, for each building in the database, grouped by building usage and construction type, with indication of building footprint. "b" represents "big" footprint (1000 square meters or larger), "s" represents "small" footprint (under 1000 square meters). Symbols for US Educational Masonry buildings (top row) are obscured by over-printing, but contain a mix of "b" and " $\mathrm{s}$ " throughout the central part of the data, 


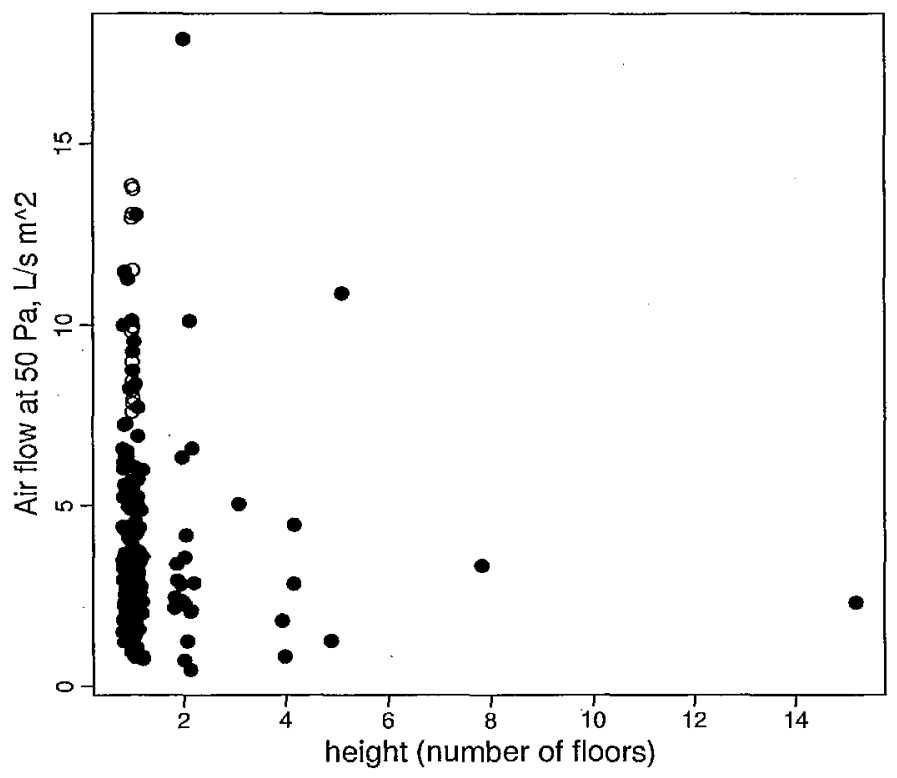

Figure 7: Air flow rate at $50 \mathrm{~Pa}$ indoor-outdoor pressure difference, in liters per second per square meter of building shell, versus number of floors in the building. Some horizontal "noise" has been added to separate the points. Measurements in strip malls are shown with open circles, all other data are solid circles.

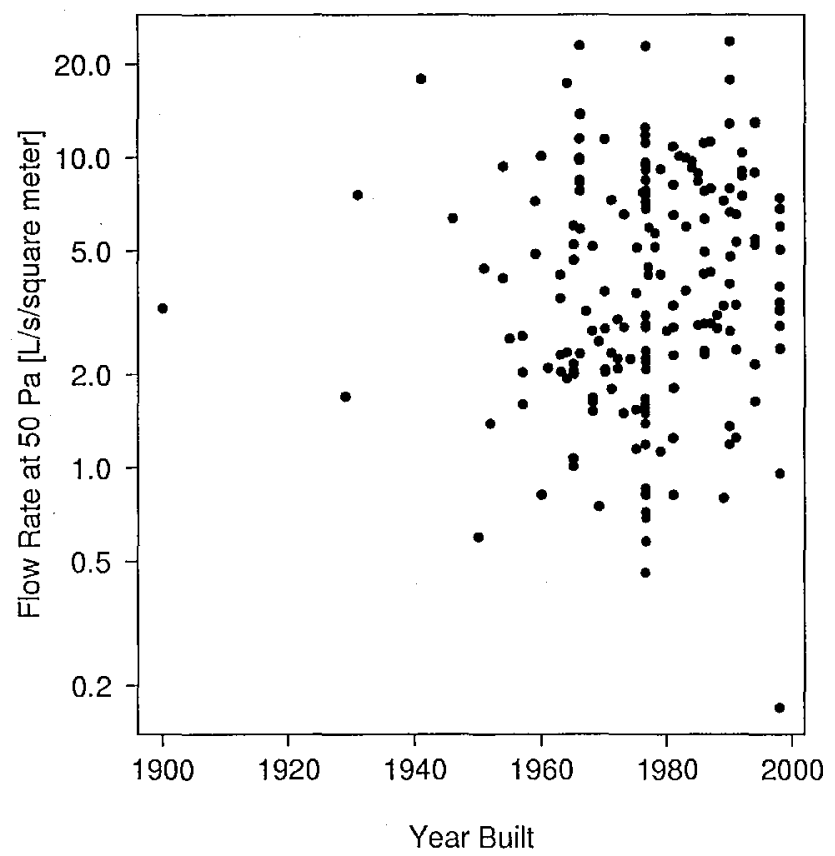

Figure 8: Air flow rate at $50 \mathrm{~Pa}$ indoor-outdoor pressure difference, in liters per second per square meter of building shell, versus year in which the building was built. $Y$ axis is a logarithmic scale. 


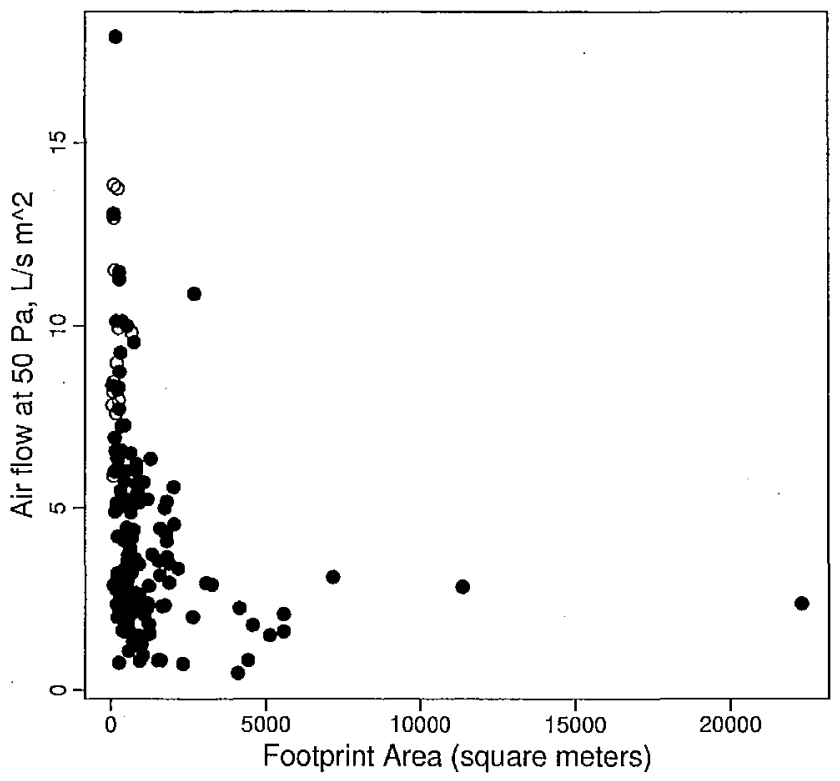

Figure 9: Air flow rate at $50 \mathrm{~Pa}$ indoor-outdoor pressure difference, in liters per second per square meter of building shell, versus footprint area of the building. Open circles are used for strip malls, solid circles for all other data.

We analyzed the data to look for systematic variation between construction materials, building types, building heights, and the country in which the building is located. For each building, we know its height, volume, envelope construction material or construction type (metal frame, masonry, etc.), and the category of activity that takes place in the building (education, retail, etc.). In some cases we also know what year the building was built.

Details of the analysis methods, and the resulting parameter estimates, are presented in Appendix IV. As discussed above, our data set is not statistically representative and sample sizes are small, so we choose not to emphasize the exact numerical parameter estimates. Instead, we summarize the general results that we think are likely to be true of the general building stock.

The analyses suggest that (ignoring strip malls for reasons discussed above):

1. Within a given building activity (education, retail, etc.) there appears to be little systematic variation with construction type. At a $50 \mathrm{~Pa}$ indoor-outdoor pressure difference, a typical building of a "leaky" construction type may experience flow about $5 \%$ to $15 \%$ higher per unit area of building envelope than a typical building; there is some evidence that frame and frame-masonry construction are slightly leakier than others. This amount of variation between construction types is much less than the amount of variability within a construction type.

2. Within a given construction type (metal-frame, masonry, etc.) there is some evidence that schools and public assembly buildings tend to be tighter than average and that 
warehouses tend to be leakier than average. At a $50 \mathrm{~Pa}$ indoor-outdoor pressure difference, a typical building of a "leaky" building category might experience air flow about 20 to $40 \%$ higher per unit area of building envelope than a building in a "tight" building category.

3. For a given building category, buildings with small "footprints" (i.e. small roof area), under $1000 \mathrm{~m}^{2}$, tend to be $25 \%$ to $50 \%$ leakier, per unit envelope area, than buildings with large footprints. Large-footprint areas tend to have a higher fraction of their total envelope area in the form of their roof, so if roofs are tighter than walls then we would expect the leakiness per unit of envelope area to decrease with footprint size. It is also possible that a substantial leakage path is the joint between walls and roof, which increases only linearly with building footprint whereas envelope area increases quadratically; this, too, is a possible explanation for the decrease of leakiness per unit envelope area as the footprint increases.

4. For a given building category, taller buildings appear to be slightly tighter than shorter buildings (with single-story buildings being perhaps $10 \%$ to $25 \%$ leakier than taller buildings, per unit envelope area), but (a) the scarcity of tall buildings in the database gives us little statistical power to address this issue, and (b) almost all of the tall buildings are office buildings, so we cannot distinguish a height effect from an effect of building type (item 2). Visual inspection of Figure 7 may suggest that taller buildings are much tighter, but this is largely illusory: there are so many more data points from the single-story category that (in terms of absolute numbers) most of the leaky buildings have a single story.

5. For buildings of a given construction type and activity category, leakiness per unit envelope area is approximately lognormally distributed, with a GSD between about 1.7 and 2.2.

To the extent that the category of activity in the building is related to building leakiness, this is presumably because the building activity category is a proxy for unknown or unspecified construction methods and design features, rather than due to a causal relationship between activities and leakiness. For instance, the design and construction details of metal-frame strip malls tend to differ from metal-frame office buildings in systematic ways, so it makes sense that metal-frame strip malls tend to have different leakage characteristics than metal-frame office buildings. However, if a strip mall were converted into offices, we would expect its leakage to be similar to that of strip malls, not office buildings. As a result, we are not able to predict what might occur for combinations of construction methods and building usage categories that are not in our data. It is not clear that, say, a curtain-wall public assembly building would in fact be particularly tight, even though other curtain-wall buildings appear to be tight, and public buildings tend to be tight, since a curtain-wall public assembly building would probably differ greatly in design from all of the other public assembly buildings and curtain wall buildings in our database.

The Commercial Buildings Energy Consumption Survey (CBECS), a Department of Energy data collection effort, characterizes the commercial building stock of the United States in a variety of ways (EIA, 2003). As with our definition of "commercial" for purposes of this report, CBECS includes many buildings that are not places of business: its sampling frame 
includes "all buildings in which at least half of the floorspace is used for a purpose that is not residential, industrial, or agricultural, so they include building types that might not traditionally be considered 'commercial,' such as schools, correctional institutions, and buildings used for religious worship." The CBECS data are summarized in Table 3, which is in a later section. In the Pacific region, which consists of California, Oregon, and Washington, the CBECS reports that $17 \%$ of commercial buildings (other than malls) are "educational", as opposed to the $27 \%$ in our database. We assume in this report that the mix of buildings in California is similar to that for the Pacific Region as a whole. CBECS was not designed to provide state-by-state estimates of the prevalence commercial building types; although it may be possible to re-analyze the raw CBECS data to obtain statistically valid California-specific data, we have not attempted to do so.

Small retail buildings and strip malls are also over-represented in our data, representing $13 \%$ of our data but only $7 \%$ of the buildings in the region. Conversely, service types buildings (e.g. vehicle service, dry cleaner, gas station, etc.) are under-represented in our database; indeed, it's not clear that any of them are included (although some may be reported as "small retail," so it's hard to be sure). Other types of buildings, including food sales, lodging, warehouses, and health care buildings are represented in our data in approximately the same proportions that they occur in the region.

Considering the lack of a sampling plan or indeed any coordination whatsoever between research groups the overall sample of construction types and building categories is remarkably close to what we find in our region. Recall, however, that our database contains data from several different countries, not just the region that includes California.

Table 3 shows the fraction of buildings in a variety of categories of building usage and wall type. To some extent the percentages in this table can be compared to those in Table 2, although there are some differences: for instance, the CBECS data do not include malls (of which there is one in our database). More importantly, in our data we separate "small retail" from "strip mall", but these are combined in the CBECS data. Finally, some of the wall information in the CBECS does not exactly match the information in our database. Our database groups concrete blocks, brick, and stone into a "masonry" category, but the CBECS data counts brick and stone as one category and concrete in another category that includes both concrete panels and concrete block.

In California, roughly half of the commercial buildings have exterior walls that are built of brick or stone, and a substantial portion of the rest are concrete block. Most of the rest have siding (typically masonry or wood) or shingles that are made with various type of materials as the exterior walls, or are built with metal panels. The classification system we used is slightly different from the one used in the 1995 CBECS report because we are limited by the information published in the original studies. In general, the representations of the various wall types in our data are roughly comparable to the CBECS dataset: masonry exterior walls are the most common, followed by wood and metal panels, and finally concrete panels and curtain wall. 
Table 3: Percentage of all commercial buildings in California, Oregon, and Washington that have a given combination of building usage and wall type. From CBECS (EIA, 2003), Pacific Region data.

\begin{tabular}{|c|c|c|c|c|c|c|c|c|c|}
\hline $\begin{array}{l}\text { Percent of } \\
\text { non-mall } \\
\text { commercial } \\
\text { buildings }\end{array}$ & Masonry & $\begin{array}{l}\text { Concrete } \\
\text { Panel/ } \\
\text { Tilt-up }\end{array}$ & $\begin{array}{l}\text { Concrete } \\
\text { (block or } \\
\text { poured) }\end{array}$ & & $\begin{array}{l}\text { Siding or } \\
\text { shingles }\end{array}$ & Metal panel & $\begin{array}{l}\text { Glass/glass } \\
\text { curtain }\end{array}$ & other & Total \\
\hline Education & 10 & 1 & & 1 & 5 & 0 & 0 & 0 & 17 \\
\hline Food sales & 2 & $\overline{0}$ & & $\overline{0}$ & 1 & 0 & 0 & 0 & 4 \\
\hline Office & 11 & 1 & & 2 & 5 & 2 & 0 & 0 & 22 \\
\hline $\begin{array}{l}\text { Warehouse/ } \\
\text { industrial }\end{array}$ & 2 & 2 & & 1 & 1 & 6 & 0 & 0 & 12 \\
\hline $\begin{array}{l}\text { Retail (other } \\
\text { than mall) }\end{array}$ & 4 & 0 & & 1 & 1 & 1 & 0 & 0 & 7 \\
\hline Health care & 2 & 0 & & $\overline{0}$ & $\overline{0}$ & 1 & 0 & 0 & 3 \\
\hline $\begin{array}{l}\text { Public } \\
\text { assembly/ } \\
\text { worship }\end{array}$ & 7 & 1 & & 2 & 2 & 1 & 0 & $\overline{0}$ & $\overline{14}$ \\
\hline Food service & 4 & $\overline{0}$ & & $\overline{1}$ & $\overline{1}$ & $\overline{0}$ & $\overline{0}$ & & 6 \\
\hline Lodging & 1 & $\overline{0}$ & & $\overline{0}$ & 1 & $\overline{0}$ & 0 & 0 & 2 \\
\hline Service & 4 & 0 & & 1 & 0 & 5 & 0 & 0 & 11 \\
\hline Total & 48 & 6 & & 1 & 17 & 14 & 1 & 1 & 100 \\
\hline
\end{tabular}

Application of the Shaw and Tamura model (Shaw and Tamura, 1977) can predict air infiltration rates - leakage rates - if certain parameters are specified: the leakage parameter, the building's height, the indoor-outdoor temperature difference, the wind speed, and the wind angle relative to the building's walls. Chan (2006) has used this approach, assuming leakage parameters are in the range discussed above, using building heights from the CBECS, and using annual meteorological data from across the U.S. Results suggest that air infiltration is in the range 0.1 to $1 \mathrm{ACH}$ for most commercial buildings in the U.S.

\subsubsection{Air Exchange due to operation of the Heating, Ventilating, and Air Conditioning System}

Although air exchange due to the HVAC system is not in the scope of this report, we include a brief discussion to provide context for the leakiness results.

The ASHRAE 62 (1999) ventilation standard recommends that outdoor air be delivered at a rate of at least 20 cubic feet per minute per person, or 0.0094 cubic meters per second person, in most indoor environments. Grot and Persily (1986) found that most of the eight office buildings that they measured operated very close to or below the recommended ventilation rate. Measured monthly average ventilation rates ranged from 0.3 to 1.0 air changes per hour $(\mathrm{ACH})$ during the winter months, and were typically well over $1 \mathrm{ACH}$ in most buildings in spring and fall. Air change rates tend to be highest in mild weather because many commercial buildings switch automatically (or in some cases manually) into an "economizer mode" in which recirculation of building air is decreased and outdoor air is used to cool the buildings. 
Lagus and Grot (1995) measured the total air-exchange rates (including both HVAC operation and leakage) of 22 office buildings and 13 retail buildings in California and found the median to be 1.1 and 1.8 ACH respectively. Assuming a conversion factor of 20 cubic feet per minute per person $=0.8 \mathrm{ACH}$, the authors concluded that the measured ventilation rates are higher than the ASHRAE ventilation rate recommendations, which would be $0.8 \mathrm{ACH}$ for office buildings, and 1.2 ACH for retail buildings. This study also found that schools tend to have higher air-exchange rates on average (median $=2.2 \mathrm{ACH}$ ), but still not high enough to satisfy the ventilation standard recommended for schools. Among the full set of 49 buildings tested by Lagus and Grot (1995), the typical air-exchange rates under normal operating conditions were in the range of 1 to $3 \mathrm{ACH}$, with a minimum at roughly $0.5 \mathrm{ACH}$.

Ludwig et al. (2002) reported the ventilation rates of 100 office buildings determined as part of the US EPA Building Assessment Survey and Evaluation (BASE) Study. These buildings were randomly selected in 37 cities located in 25 states. The ventilation rates were determined using occupant-generated carbon dioxide as a tracer gas. Ideally, the steady-state carbon dioxide level would be obtained and used to compute the air-exchange rate based on mass balance. In practice, however, factors like building occupancy level and the fresh-air intake rate of the ventilation system all vary with time. Thus, the indoor $\mathrm{CO} 2$ concentrations measured are also time varying. To overcome these problems, the authors chose the 90 th percentile carbon dioxide concentration measurement to estimate the air-exchange rates. Justification of this choice is detailed in their paper. They found that $80 \%$ of the ventilation rates estimated are in the range between 20 and 65 cubic feet per minute per person. Assuming that the same conversion factor of 20 cubic feet per minute per person $=0.8 \mathrm{ACH}$ (Lagus and Grot, 1995) also applies here, then the air-exchange rate of the 100 BASE buildings ranges from 0.8 to $2.6 \mathrm{ACH}$.

As would be expected, this evidence indicates that air infiltration rates, which are estimated to range between 0.1 and $1 \mathrm{ACH}$ as discussed in the previous section, are usually much lower than the air-exchange rate induced by mechanical ventilation system. In two of the studies in which both the air infiltration rate and the air-exchange rate the HVAC operating were measured in buildings (Cummings et al., 1996; Lagus and Grot, 1995), the observed ratios of these two rates were mostly in the range of 0.1 to 0.8 . Similar expectations for this ratio are implied by the difference between the range of air infiltration rates estimated by Chan (2006) using the Shaw and Tamura model (1977) which is 0.1 to $1 \mathrm{ACH}$, and the range of air-exchange rates measured in buildings, which is 1 to $3 \mathrm{ACH}$. The variability in this ratio means that the reduction in the amount of outdoor air brought into the building by turning off the mechanical ventilation systems can be very significant in some buildings, but only modest in others. The amount of fresh outdoor air intake that the mechanical ventilation systems supply at also tends to vary seasonally, as discussed previously.

Air infiltration rate predictions yield higher values in the winter because of stronger driving forces. As a result, in winter the amount of outdoor air bought into the building by uncontrolled air infiltration can approach that provided by mechanical ventilation. On the other hand, when the climate is mild and many buildings have their ventilation systems operating at high rate of outdoor air intake, HVAC dominates uncontrolled leakage as a contributor to overall air exchange. 


\subsubsection{Apartment Buildings Data Analysis}

Compiling, summarizing, and analyzing the available data on apartment leakiness was one of the primary goals of this study, at the same level of importance as analyzing the commercial buildings data. However, the extreme scarcity of apartment data and the complexities of the existing data make it impossible to go beyond the most basic data summaries and analyses. Therefore, the discussion of apartment data is substantially shorter and less detailed than the discussion of the commercial building data.

Data were collected from 13 different studies on apartment buildings in the U.S. and Canada (Wray 2000, Palmiter et al. 1995, Dietz et al. 1985, Lagus and King 1986, Love 1990, Hill 2001, Gulay et al 1993, DePani and Fazio 2001, Shaw et al 1990, Reardon et al. 1987, Kelly et al. 1992, Feustel and Diamond 1996, Diamond 1993, Flanders 1995). Most of the researchers attempted to

Apartment buildings are, of course, composed of many individual apartments or "suites" that are at least somewhat isolated from each other in terms of air exchange. For this reason, there are several separate issues related to ventilation in apartment buildings.

1. There is leakage from individual apartments to (or from) the outdoors. This is important from the standpoint of energy efficiency, since undesired infiltration (or exfiltration) increases heating or cooling costs. It is also important for occupant comfort, since it affects drafts, the presence of moisture problems (which can lead to mold or mildew), indoor temperatures, and the exposure of occupants to outdoor air pollution. This is the primary focus of the portion of the present work that deals with apartments.

2. There is leakage from one apartment to another. This is important from the standpoint of occupant satisfaction, since cooking and smoking odors from one apartment can bother occupants of an adjacent apartment. It is also important from the standpoint of occupant health and safety, as occupants are exposed to environmental tobacco smoke and other pollutants from other apartments. This issue falls outside the scope of the present report, which focuses on indoor-outdoor leakage; however, it is clear to us from our literature review that this is a rather neglected area of research. Leakage between apartments (and from commercial establishments to apartments, in mixed-use buildings) may lead to large unintentional exposure of apartment dwellers to potentially hazardous or irritating substances such as tobacco smoke; dry cleaning chemicals or photographic chemicals; cooking gases, particles, or odors; and other pollutants.

3. There is an interaction between the whole-building leakage and apartment-toapartment leakage (i.e. interaction between 1 and 2 above). If buildings are well compartmentalized (item 1) individual suites or floors can be separately ventilated, but if not, one suite can affect another (e.g. opening a window can change air flows into or out of every apartment on the floor or even throughout the building). This issue is outside the scope of the present report.

Ten years ago, Diamond et al. (1996) conducted a literature review and analysis of all of the apartment leakage data that were then available. They noted that "the literature on air flow and air leakage measurements in high-rise multifamily buildings is quite limited." They also said that "what emerges from a review of [the available] studies is the paucity of information characterizing air leakage in multifamily buildings and the typically poor level of control in the 
provision of ventilation for the building occupants." The paucity of data hampered their ability to make quantitative statements concerning the numbers of apartments or apartment buildings for which infiltration is undesirably high. We had hoped that additional data from the past decade would be sufficient to change this situation, but this was not the case: compared to the data available to Diamond et al., we found data on only about thirty additional apartments in about twenty additional buildings in all of North America. The same general statements about the lack of data, made by Diamond et al. ten years ago, apply to the situation today.

For apartment buildings, many of the available data concern air change rates rather than leakiness parameters. There are advantages and disadvantages to this. The advantage is that the leakiness parameter is a characteristic of the building alone, independent of the wind, buoyant forces, and other driving forces. That advantage is also a disadvantage, since it means that in order to determine the air exchange rate a model must be applied, that takes into account how the wind speed, indoor-outdoor temperature difference, and building leakage parameters affect the air exchange rate. Since no two buildings act exactly the same, the predicted air exchange rate for any particular building and environmental conditions will often be in error by $30 \%$ or more. The alternative approach of directly determining the air exchange rate - usually by measuring how quickly a tracer gas leaks out of the apartment - has the advantage that it accurately measures the air exchange rate, but it does so only for the specific set of driving forces that are acting at the time of the experiment. If the wind speed and indoor and outdoor temperatures are measured at the time of the experiment, then the air change rate for other environmental conditions can be estimated, by using the same sort of error-prone model that must be used in conjunction with leakage measurements. (But at least the model will give the right answer for the conditions that apply during the experiment). Most, but not all, of reports of air exchange rates also included wind and temperature information.

Figure 10 shows data on the air exchange rates of individual apartments within seventeen different apartment buildings. In eleven of the buildings, only a single apartment was measured. The only two apartment buildings from California (both are from Oakland) are identified as L1 and L2 in the y-axis labels. No other data are from buildings in climates that could be considered similar to the Mediterranean climate of Oakland, California.

Data are quantified in terms of air changes per hour $(\mathrm{ACH})$, which is the volume of the apartment divided by the volume of air that crosses the exterior wall(s) of the apartment in one hour. These measurements were made under ambient wind speed and temperature conditions, and thus are not directly comparable to measurements based on a fixed indoor-outdoor pressure difference. This is a measure of the connection to the outdoors, not the total amount of air that enters the apartment from all sources, including other apartments and hallways. Researchers used a variety of methods to attempt to characterize the building with all windows closed, including closing all of the windows (in a University-owned dormitory), asking residents to close windows during testing, and pressurizing adjacent apartments to attain neutral pressure with apartments where testing occurred. We did not investigate each researchers' approach, but accepted their results as a measurement of $\mathrm{ACH}$ with windows closed. 


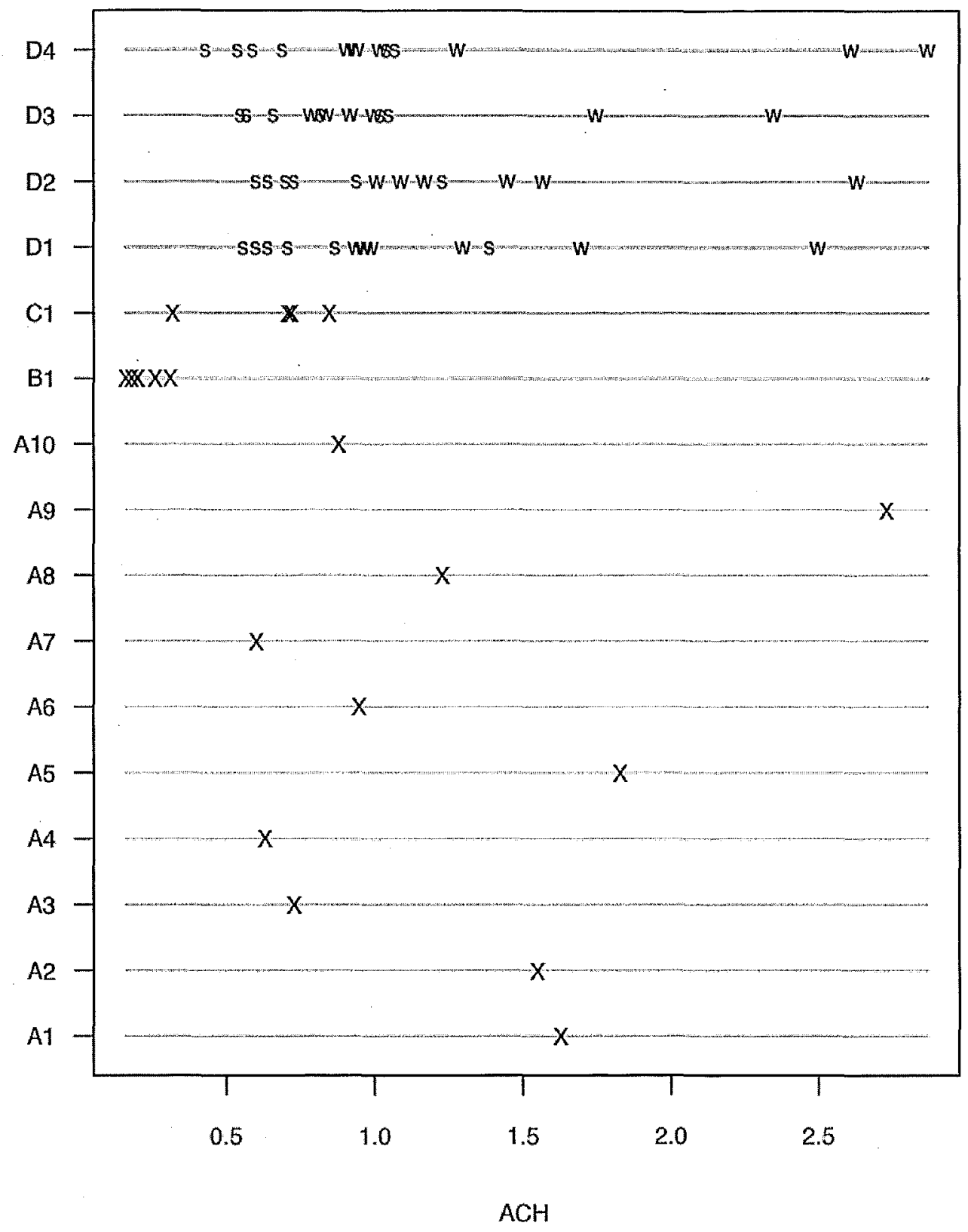

Figure 10: Leakage of individual apartments within 16 different apartment buildings, in Air Changes per Hour $(\mathrm{ACH})$, measured under ambient wind and temperature conditions. " $\mathrm{s}$ " and " $w$ " represent summer and winter measurements, respectively, for a study in which the same apartments were measured in both seasons. For the row names, letters A-D indicate different studies; numbers indicate different buildings within each study; and each plotted symbol represents a different apartment within the building. 
In winter, warm air in a building tends to rise and escape the building through the upper levels, and to be replaced by air entering from below. (The situation is reversed in summer, if the building is air-conditioned). Consequently, researchers have previously noted (Diamond et al., 1996) that heating costs on upper floors of apartments are expected to be less than on lower floors, and that this has been observed in the (sparse) data on the subject. Thus, although apartment-to-apartment air movement is not a particularly important factor for the building as a whole - for which the whole-building air exchange rate is the relevant factor - it does have implications for the comfort and health of individual apartment-dwellers. If apartments are billed separately for heating or cooling, apartment-to-apartment air exchange also has cost implications, and may be a cause of non-uniform heating or cooling costs among apartments.

Apartment-to-apartment air exchange also has health and comfort implications, since it means that occupants of one apartment are exposed to pollutants produced in other apartments (Levin 1988). The very small amount of data concerning apartment-to-apartment air exchange suggest that $10-40 \%$ of the air in an apartment comes from another apartment, not from outside (Levin 1988, Palmiter et al 1995). Even higher values are possible: Dietz et al. (1986) report on a single-family house in which, in certain weather conditions, all (100\%) of the air on the topmost level enters from the floor below. Certainly the same phenomenon can occur in multi-unit buildings as well. This issue is outside the scope of this report, which is focused on indooroutdoor air exchange, but we believe it is an area of research that needs far more attention than it has received and we will revisit it briefly in the "Conclusions and Recommendations" section below.

As discussed earlier, air exchange rates (as quantified here in $\mathrm{ACH}$ ) are controlled not just by characteristics of the building itself but also by the driving forces of wind, and buoyancy due to indoor-outdoor temperature differences. For multi-story, multi-unit buildings such as apartments, there is no simple relationship between the air change rate $(\mathrm{ACH})$ and building leakage parameters (such as the flow rate at $50 \mathrm{~Pa}$ ): the relationship depends on details such as the wind direction, the amount of open area that connects different levels of the building, and other such parameters that are not available in the published data.

The reported air change rates in our database include data from a variety of indooroutdoor temperature differences, from near $0 \mathrm{C}$ to over $25 \mathrm{C}$, with most of the data taken when the indoor-outdoor temperature difference was less than $20 \mathrm{C}$. Wind speeds were generally low or moderate, below $1 \mathrm{~m} / \mathrm{s}$ for most of the data and below $2.5 \mathrm{~m} / \mathrm{s}$ for all of the data.

The observed air change rates, mostly from 0.5 to $2 \mathrm{ACH}$, are higher than data from single-family houses in weather conditions such as these: typical air exchange rates in houses in these conditions would be of the order of 0.2 to $1 \mathrm{ACH}$ (Pandian et al. 1998, Wilson et al. 1996), or about half what we see in the apartment data.

Based on the small amount of available data there is no evidence of large variations in air exchange rate among apartment buildings, with one exception: Building 12 in our database, (identified as "B1" in the y-axis of Figure 10) built in Portland, Oregon in 1992 under a special energy efficiency program ("Super Good Cents"), and reports lower leakage than do other 
buildings. The individual apartments within this building have air change rates between 0.2 and 0.4 air changes per hour under moderate wind and temperature conditions, in line with tight single-family homes. Unless windows are opened or additional ventilation is provided in some other way (such as the use of bathroom or kitchen exhaust fans), these apartments, if they were in California, might fail to meet California Energy Code (CEC) requirements: Sherman and McWilliams (2005) report that the CEC requirements correspond to approximately 0.25 air changes per hour.

So far we have discussed data on air infiltration rates under ambient conditions. We now discuss data on leakiness, measured in terms of the flow rate per unit of exterior building envelope, at a $50 \mathrm{~Pa}$ indoor-outdoor pressure difference. The data are shown in Figure 10. The median flow rate is $4 \mathrm{~L} /\left(\mathrm{s} \cdot \mathrm{m}^{2}\right)$, the GM is $4.8 \mathrm{~L} /\left(\mathrm{s} \cdot \mathrm{m}^{2}\right)$, and the GSD is 1.7. Given the sparse, non-representative data it is hard to draw any firm conclusions, but these numbers are in line with the observed data from commercial buildings and seem somewhat leakier than typical single-family homes, which have a flow rate distribution at $50 \mathrm{~Pa}$ that has a GM $=2.6 \mathrm{~L} /\left(\mathrm{s} \cdot \mathrm{m}^{2}\right)$ and a GSD of 1.6. However, the apartment GM is uncertain by about $10 \%$ simply from smallsample variability (see a statistics text such as Spiegel 1992, for example, for the relationship between sample size and statistical uncertainty). The potential for selection bias is far larger than the small-sample uncertainty, so the air infiltration results are only suggestive.

As previously discussed, for apartment buildings there is no straightforward, validated method of predicting air exchange rates from leakiness measurements. Furthermore, the apartments in which air exchange rates were measured are not the same apartments, or even the same buildings, as the ones in which flow at $50 \mathrm{~Pa}$ was measured.

The observed apartment indoor-outdoor air exchange rates of 0.5 to $2 \mathrm{ACH}$ are 1.5 to 2 times those of single-family houses, and the observed apartment leakiness values in the range of 3 to $8 \mathrm{~L} /\left(\mathrm{s} \cdot \mathrm{m}^{2}\right)$ are approximately 1.5 to 2 times the values observed in single-family houses. So, apartments seem to be about 1.5 to 2 times as leaky per unit surface area and to have 1.5 to 2 times the infiltration rate as single-family houses, which seems like a consistent story. However, the situation is considerably more complicated than this suggests: the ratio of exterior wall area per unit of interior volume is generally lower for apartments than for single-family houses, the volumes are different, most apartments don't have a ceiling (roof) that provides a direct pathway to the outdoors, and there are considerable differences between houses and apartment buildings in terms of the connectivity of interior spaces (e.g. different floors). Therefore it is by no means obvious that the fact that apartment buildings have double the leakiness per unit envelope area should imply that they have double the air exchange rate. Given these caveats, and the fact that the data are so sparse, we consider the observation that apartment buildings "twice as leaky as houses, and have twice as much air exchange" to be preliminary. 


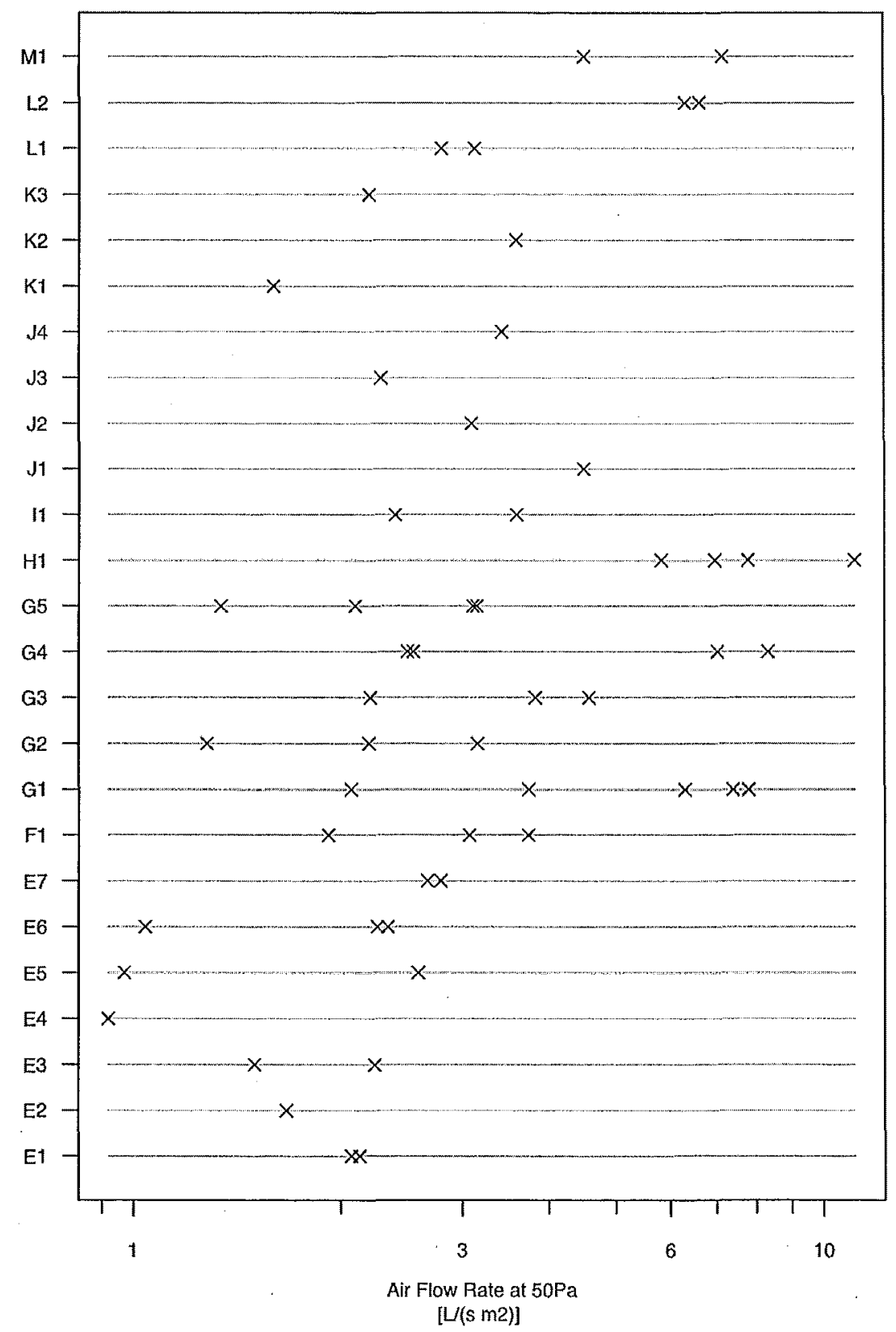

Figure 11: Air flow rate (liters per second, per square meter of building shell) at a 50 Pascal indooroutdoor pressure difference, for apartment buildings. In the $Y$-axis labels, letters E-M indicate different studies, and numbers indicate different buildings within each study. Each $X$ represents a different apartment within the building.

\subsubsection{Existing Apartment Stock in California}

The American Community Survey (ACS, see Bennefield and Bonnette, 2000, for discussion; 2004 data, discussed in this section, were obtained from U.S. Census website) collects housing data from 244 counties and most large metropolitan areas in the U.S. The ACS does not currently 
sample every county in California, although the Census Bureau intends to modify the survey to do so in the future. The survey is designed to permit estimates of statewide statistical distributions even though not all counties are included. The 2004 results estimate that there are 12 million occupied housing units in California, and another 800,000 unoccupied units (about $80 \%$ of them apartments). Most California housing units (58\%) are single family detached houses, and about $4.5 \%$ are mobile homes. The remaining $37.5 \%$ of housing units are in multiunit structures, including duplexes, townhouses or row houses, and apartment buildings.

Table 4: Multi-unit or attached housing in California, by size of building.

\begin{tabular}{|l|r|r|l|}
\hline Type of building & $\begin{array}{l}\text { Number of } \\
\text { units } \\
\text { (thousands) }\end{array}$ & $\begin{array}{l}\text { Percent of all } \\
\text { housing units }\end{array}$ & $\begin{array}{l}\text { Percent of non- } \\
\text { single-unit- } \\
\text { detached housing } \\
\text { units }\end{array}$ \\
\hline 1-unit attached & 940 & 7 & 17 \\
\hline 2 units & 320 & 3 & 6 \\
\hline 3 or 4 units & 720 & 6 & 13 \\
\hline 5 to 9 units & 820 & 5 & 12 \\
\hline 10 to 19 units & 660 & 11 & 25 \\
\hline 20 or more units & 1402 & 6 & 15 \\
\hline
\end{tabular}

Table 4 shows the numbers of housing units that occur in buildings of different sizes. Excluding single-family detached houses, about half of the remaining housing units are in buildings that contain at least five apartments, and about a quarter are in buildings that contain 20 or more apartments.

There is considerable variation in the housing stock between heavily urbanized areas and less urban areas. For example, in San Francisco County (which contains San Francisco, California, one of the densest cities in the country) $24 \%$ of all housing units are in buildings of 20 units or more, and $45 \%$ are in buildings of 5 units or more. In contrast, in Tulare County, a rural county south of Fresno, only $2 \%$ of all housing units are in buildings of 20 units or more, and only $6 \%$ are in buildings of 5 units or more.

\subsection{Gaps in Current Knowledge}

The general lack of knowledge about building leakiness has been noted by previous researchers, for both commercial buildings and apartments (Diamond et al. 1996, Persily 1999). Based on available data, we cannot definitively answer even some basic questions, such as:

1. How many buildings of different types are leaky or extremely leaky? 
2. What is the total statewide energy loss attributable to undesired air infiltration?

3. What is the reduction in exposure to airborne pollutants when people shelter indoors from an outdoor airborne hazard, especially in buildings that lack HVAC systems or that are not operating such systems?

There are two ways to look at the coverage of our commercial buildings database. On the one hand, comparing the data in the commercial buildings database with data on the overall mix of commercial buildings in the Pacific Region (Table 3), it does not appear that most categories of building are proportionally under-sampled or over-sampled, with three exceptions: (1) Service buildings (such as gas stations, car washes, dry cleaners, etc) are somewhat undersampled, (2) educational buildings are somewhat over-sampled, and (3) small retail buildings are somewhat under-sampled. On the other hand, in terms of absolute numbers, there are very few categories of buildings that are sampled well enough to characterize the distribution of air leakage accurately. Only five building categories in the U.S. have as many as 8 measurements, for example. Additional sampling needs are not so much a matter of filling specific gaps, as simply collecting more of everything.

As for apartment data, we were (unpleasantly) surprised at the paucity of information in this area. There is no prospect of comparing, say, new apartment buildings to old ones, or mechanically ventilated ones to naturally ventilated ones, or tall ones to short ones. The available database is extremely deficient.

Another important knowledge gap is outside the scope of this report, but in researching this report we were struck by it: what is the statistical distribution of air flow between apartments within an apartment building, or between businesses and apartments in a mixeduse building? Although it was not a focus of our work, we did encounter publications that discussed this issue, and some of them (Levin 1988, Palmiter et al. 1995) reported that more than $50 \%$ of the air entering some apartments came from elsewhere in the building rather than from outdoors. This suggests that apartment dwellers may be exposed to significant amounts of pollution, such as cigarette smoke, dry cleaning or photo developing chemicals, cooking gases and odors, etc., that originates in other units in their building. Lawrence Berkeley National Laboratory researchers Craig Wray and Darryl Dickerhoff identified this issue (in private communication) as one of the largest data gaps related to residential ventilation and air quality.

\subsection{Conclusions and Recommendations}

Researchers have previously noted that the existing data on leakiness of commercial buildings and apartments are sparse, are collected using a variety of protocols, and are based on a non-representative sample of buildings. Based on our review of the literature and our discussions with researchers in the field, those data shortcomings still exist.

The available commercial buildings database that we compiled includes 164 buildings from the United States, and 267 buildings in all. Some categories of buildings, such as masonry schools, are fairly well represented, but data on most building categories are extremely sparse or, in some cases, completely missing. Also, the data are not statistically representative, but instead generally represent whatever buildings the researchers were able to access, and were able to find funding to measure. What's more, almost all of the buildings in the database are 
from outside California. As a result, we can draw no definitive conclusions about the situation in California. However, the data suggest the following with regard to commercial buildings overall:

1. Within a given building activity (education, retail, etc.) there appears to be little systematic variation in leakiness as a function of construction type.

2. Within a given construction type (metal-frame, masonry, etc.) there is some evidence that schools and public assembly buildings tend to be somewhat tighter than average and that warehouses tend to be leakier than average.

3. Buildings with small "footprints" (i.e. small roof area), under $1000 \mathrm{~m}^{2}$, tend to be $25 \%$ to $50 \%$ leakier, per unit envelope area, than buildings with large footprints.

4. Taller buildings appear to be slightly tighter than shorter buildings (with single-story buildings being perhaps $10 \%$ to $25 \%$ leakier than taller buildings, per unit envelope area), but (a) the scarcity of tall buildings in the database gives us little statistical power to address this issue, and (b) almost all of the tall buildings are office buildings, so we cannot distinguish a height effect from an effect of building type (item 2).

5. For buildings of a given construction type and activity, footprint size, and height, leakiness per unit envelope area is approximately lognormally distributed, with a geometric standard deviation between about 1.7 and 2.2.

6. On average, commercial buildings may be about twice as leaky as single-family houses, per unit of building envelope area.

The deficiencies in the available commercial building data could be addressed through an experimental program to measure air exchange rates or leakage parameters in a representative sample of buildings. If such a program is to be undertaken, it should not rely on the usual past practice of using a "convenience sample" of buildings that happen to be available to the researchers or in which the building owner or operator is especially motivated to participate in an experimental program. The use of convenience samples has been very important in the past - indeed, if not for this practice we would have no commercial building measurements at all! However, any future research program needs to be large enough to make measurements in at least 10 buildings in each category on which it focuses, and those buildings should be selected to be statistically representative of their categories. Ideally, a stratified random sample of the buildings in California would be conducted, with stratification used to ensure that some buildings are sampled even for unusual building categories. Such a program could provide useful, accurate, quantitative data concerning building leakiness. A much less ambitious program would focus only on specific issues. Rather than simply sampling fewer buildings of each type than would be sampled in an ideal program, a less ambitious program could reduce the scope (in terms of the types of buildings sampled) but still sample at least ten of each type. For instance, an obvious question of practical interest is whether buildings are getting tighter (and thus, generally, more energy efficient) with age; this could be addressed by sampling, say, 15 new medium-sized office buildings and 15 old medium-sized office buildings, 
using representative samples of each. Whether such a program would be worthwhile, and on what issues it would focus, is a matter for policy-makers.

With regard to apartments, available data suggest that apartment buildings tend to be about twice as leaky as single-family houses, as quantified by air flow per unit area of building shell when a given indoor-outdoor pressure difference is applied. Data from the U.S. and Canada are consistent with apartment leakage parameters being approximately lognormally distributed, with a geometric standard deviation between 1.5 and 2.5. Almost none of the available data are from California, so we have no ability to say whether California buildings are typical of others in the database. We might speculate that they should be somewhat leakier, since there is less need or incentive to insulate them (because of the generally mild climate in the most populous portions of the state), but we have no direct evidence that this is the case.

Obtaining useful amounts of information about California apartment leakiness would require a substantial experimental program, which we outline below.

\subsection{Possible Program to Characterize Apartment Building Leakiness}

Apartment building data are even more deficient than commercial building data, so no detailed analysis was possible. From the available data, indoor-outdoor air exchange rates and building leakiness per unit of building envelope area seem to be about twice as high (i.e. twice as leaky) for apartments as for single-family homes. This finding suggests that there may be a potential for substantial energy savings by reducing air infiltration rates for apartment buildings. It also suggests that "sheltering" indoors from an outdoor pollution (a chemical spill, a terrorist attack, or simply a high-pollution period) may be substantially less effective in apartment buildings than in houses. However, given the data limitations it is very hard to be sure that this is the case.

There are some obvious targets for a substantial research program. One question of importance is the level of protection offered by apartments against outdoor air pollution episodes or toxic releases. A program that targets apartment buildings in specific locations where these issues are most likely to be important, such as near refineries and chemical plants, could provide important and perhaps even critical information about risks. Another obvious question, as with commercial buildings, is whether construction or design practices are improving with time, for which the same sort of program as that discussed above for commercial buildings could be performed.

Experiments to measure apartment leakage are usually harder to perform than those for commercial buildings, for several reasons: (1) apartment buildings often do not have central air handling units and thus pressurization or depressurization must rely on equipment provided by the experimenters; (2) the design of apartment buildings, as individual partially-isolated units, can introduce complications; and (3) conducting experiments in apartment buildings generally requires cooperation from many individuals who must provide access to their apartment, compared to experiments in commercial buildings which often involve only a small number of tenants (or only one). These complications are probably some of the reasons that so few experiments have been done, concerning air leakage in apartments. 
To precisely characterize the leakiness of apartment buildings of different types and ages would require measuring leakage parameters in hundreds of apartments, in dozens or hundreds of buildings. Such a program would require many person-years of effort, and would cost millions of dollars. It is possible in principle that such a program could be justified or could even be necessary - if, for instance, some tenants are receiving such inadequate ventilation that their health is at grave risk - but there is no evidence that this is so. On the other hand, so little is known about apartment air leakage that the possibility cannot be ruled out, either. This is particularly true for new buildings: although existing data do not indicate that newer buildings are particularly airtight, Lawrence Berkeley National Laboratory's Richard Diamond (private communcation) reports speaking with an apartment builder who have believed that his building would be "too airtight," so he took steps to ensure that its windows cannot be fully closed. It is possible that new construction techniques, or designs and techniques used by some builders, create apartments that provide inadequate outdoor air unless windows are opened or other actions are taken. We note that some of the apartment buildings discussed above (building B1 in Figure 9, and E4 and E5 in Figure 10) seem to have apartments that are very airtight.

One possibility to address the dearth of apartment building data is to perform a small experimental program that collects data on of the order of 30 to 50 apartment buildings of various sizes, ages, and construction techniques. Such a program would have three goals:

1. Improve upon protocols for measuring apartment leakiness in different types of apartment buildings;

2. Provide a rough estimate of the statistical distribution of leakiness of apartments in California; and

3. Detect large differences in leakiness among common building types or building ages, if such differences exist.

We now briefly discuss each of these goals.

\section{Develop standard protocols for measuring apartment building leakiness}

McWilliams (2002) reviews dozens of published techniques for quantifying air leakage, or leakage parameters, in large buildings. Classes of techniques include single- or multi-gas tracer gas methods (for measuring air exchange rates) and single- or multi-zone pressurization or depressurization methods (for measuring leakage parameters). Each class of techniques includes many variants, some of them developed by researchers trying to cope with features encountered in certain buildings or types of buildings. For example, to measure leakage parameters of the exterior building shell, a common approach is to pressurize (relative to outdoors) a given apartment within a building, and also to pressurize apartments adjacent to the given apartment so that there is no inter-apartment airflow and all flow must escape to the outdoors. Although this works in some buildings, it fails in others because gaps between walls or between floors can provide another pathway for air to escape.

As is clear from the apartment building data discussed in the previous section of this report, researchers who have measured leakage parameters in apartments have done so in only a small number of buildings. Probably no experimenter or experimental team in the world has 
experience with making measurements in a wide variety of building types. Conducting experiments on 30 to 50 buildings would allow an experimental team to gain experience and proficiency, and to develop methods for dealing with problems that arise in various building types.

\section{Estimate the statistical distribution of California apartment building leakiness}

The apartment building data discussed in the previous section are inadequate to characterize the distribution of apartment leakiness in the country. What's more, they include only a few measurements from buildings in California, and conditions in California might well differ from the rest of the country because California buildings tend to differ in style and construction from those elsewhere in the country, in part because of climate differences.

An experimental investigation that measures leakage parameters in 30 to 50 California apartment buildings, with measurements in 2 to 6 apartments per building, could probably quantify the overall leakiness distribution well enough to address most questions of interest to the California Air Resources Board, the California Energy Commission, and other concerned agencies. For instance, if the air flow rate at 50 Pascals is lognormally distributed with a geometric standard deviation (GSD) near 2, then 30 measurements will allow both the geometric mean (GM) and the GSD to be estimated with a standard error of about $15 \%$ in

principle. In practice, for a realistic sampling strategy, the standard error might be closer to $20 \%$ for reasons discussed later.

\section{Detect large differences in leakiness among common building types}

Apartment buildings are extremely variable in both design and construction. Some of these differences include:

1. Frame materials can be wood, steel, concrete, etc.;

2. Facades can be brick, concrete, wood, etc.;

3. Windows can be single- or multi-pane;

4. Heating or cooling systems can be central or apartment-by-apartment, or nonexistent;

5. Building sizes range from a few units to dozens of units;

6. Buildings may or may not have connected ceiling plenums or wall spaces;

7. The building may be insulated, uninsulated, or partially insulated;

8. The building may be new, old, or in between.

Some of these apartment building features are correlated with each other; for instance, larger apartment buildings are more likely to have connected ceiling plenums or wall spaces.

An experimental program that includes several building types and ages could determine whether some types of buildings tend to be much leakier than others. A program that includes 
only 30 to 50 buildings clearly cannot hope to address this issue for every building type in the state. However, a carefully designed program could answer questions such as: do large buildings tend to be leakier or more airtight than small buildings, and do new buildings tend to be leakier or more airtight than old buildings?

\section{Sampling strategy for an experimental program}

Theoretically, the best way to estimate the relevant statistical distribution of apartment building leakage parameters would be to perform measurements in a simple random sample of apartment buildings in California, weighted by occupancy (so that an apartment building that has more residents would be more likely to be sampled). Such a sampling strategy would be impractical, however, since it would require researchers to traverse much of the state in order to perform the experiments. The resulting travel costs, travel time, and housing costs would be enormous drains on the budget.

A more realistic approach than a simple random sampling scheme would be to use a stratified sampling scheme. This might be rather complicated, but is nevertheless routine, and many groups or consultants, such as the University of California's Survey Research Center, can define a complicated sampling scheme and determine the appropriate statistical weight to assign to each member in the sample.

One possibility would be to select three or four small areas on which to focus. For instance, one county could be selected from urban coastal Northern California counties, one from urban coastal Southern California counties, one from the Central Valley, and one from the remaining counties in the State. A stratified random sampling system could be used to choose the counties, although in practice simply selecting them for convenience would probably yield adequate results. Within each county, researchers would attempt to make measurements in approximately 12 buildings, including at least 3 large new buildings, at least 3 large older buildings, at least 3 small new buildings, and at least 3 small older buildings.

Once the counties are selected, further spatial subdivsion is possible if desired, such as selecting (preferably at random) a portion of the county, such as a single town or city, from which a sample of apartment buildings is to be selected. City rental property records can then be consulted to create a list of rental buildings and the number of units in each. Buildings can be selected from this list, and their owners and occupants can be approached to determine willingness to participate, which in this case means (mostly) willingness to provide access. Logistical issues can be rather challenging, as a set of tenants must all be willing to provide access (for blower door installation, for example) at the same time on the same day.

The effect of a stratified rather than simple sampling scheme is always to reduce the "efficiency" of the data: the statistical uncertainty in summary statistics (such as geometric mean and geometric standard deviation) is always larger with a stratified sampling scheme. The loss of efficiency cannot be quantified without detailed information about the sampling scheme, but for a scheme such as that discussed above, the efficiency might be about half that of a simple random scheme. That is, a simple random sample of 20 buildings might yield the same statistical uncertainties as a 40-building sample collected according to the stratified scheme 
discussed above. However, measurements on a simple random sample of 20 buildings would likely cost far more than twice as much as the 40-building stratified scheme.

The experimental program outlined here would require a substantial investment of both experimenter time and money. Although the actual measurements in a building can probably be performed in a few days, this must follow a substantial planning period for each building, during which the placement of blower doors, flow meters, and pressure sensors must be selected. Some preliminary experiments might have to be performed and analyzed in order to determine whether air leakage into wall, ceiling, or floor cavities is a substantial effect, and the experimental setup might need to be altered to address such issues if they arise. Obtaining permission from building owners and tenants will also be time-consuming, and may not be possible in all cases, in which case additional effort will be required to identify alternative buildings. Overall, the program should assume that preparation, setup, and performance of the experiments will take a total of at least two weeks per building. Adding administrative time, data analysis, and report-writing suggests this to more than a 2-year project, requiring two fulltime researchers plus some additional help to perform experiments in large buildings (when it is necessary to have extra people to help control blower doors and perform various set-up tasks). Including equipment costs, travel, salaries, and overhead, a program such as this might cost in the range of $\$ 1.5$ million to $\$ 2.5$ million.

\section{Additional data that could be collected}

The discussion above deals with indoor-outdoor air exchange and air leakage, which is the subject of this report. In researching this report, though, we discovered another issue that we think is even more important than this, perhaps by a large margin: the transport of pollutants within an apartment building. A few researchers have studied this issue, and although we were not specifically looking for these data, researchers who have measured transport within a building also inevitably quantify the leakage out of the building, so there is a great deal of overlap in the literature between indoor-outdoor air exchange and apartment-to-apartment air exchange. As such, although it was not a focus of this report, we feel confident in saying that transport within a building may lead to very large occupant exposures to pollutants - such as cigarette smoke; cooking fumes, particles, and odors; and spores, bacteria, or viruses - and that data concerning these issues are entirely inadequate. In mixed-use buildings, building occupants may be exposed to dry cleaning chemicals, photo developing chemicals, and so on. The issue of internal transport of pollutants within apartment buildings and mixed-use buildings merits more attention than it has received. We feel that it should be a relatively highpriority area of research.

Research in this area can be performed using passive perfluorocarbon tracer gas techniques (Dietz et al., 1985) that are relatively inexpensive and non-intrusive. If the experimental program described above is performed, it would also make sense to perform within-building experiments in the same buildings at the same time. This would probably increase the program cost by less than $20 \%$ and would provide a great deal of valuable data. 


\subsection{References}

AIC, 1981."AIRGLOSS: Air Infiltration Glossary", English edition. Air Infiltration Centre, Berkshire, Great Britain.

AIVC, 1994. "Numerical Data for Air Infiltration and Natural Ventilation Calculations", Technical Note 44, Air Infiltration and Ventilation Centre (formerly Air Infiltration Centre), Berkshire, Great Britain.

ASTM, 1999. ASTM Standard E779: "Standard test method for determining air leakage by fan pressurization." American Society of Testing and Materials, Philadelphia, PA.

Bay Area Economics (Consultatn), "San Francisco Housing Data Book", Commissioned by San Francisco Board of Supervisors, 2002.

Baylon, D. and J. Heller,. "Methodology and Results of Blower Door Testing in Small Multifamily Buildings, " Proceedings of the ACEEE Summer Study on Energy Efficiency in Buildings, vol. 2 pp. 11-23, Washington DC: ACEEE, 1998.

Brennan, T., W. Turner, G. Fisher, B. Thompson, and B. Ligman. "Fan pressurization of school buildings." Proceedings of Thermal Performance of the Exterior Envelopes of Buildings V, American Society of Heating, Refrigerating and Air-Conditioning Engineers, Inc., pp. 643-45, 1992.

Chan, W.R., W.W. Nazaroff, P.N. Price, M.D. Sohn and A.J. Gadgil, "Analyzing a database of residential air leakage in the United States," Atmospheric Environment,39:3445-3455, 2005.

Chan, W.R., "Assessing the Effectiveness of Shelter-in-Place as an Emergency Response to Large-Scale Outdoor Chemical Releases," Ph.D. dissertation, Department of Civil and Environmental Engineering, University of California, Berkeley, 2006.

Cummings, J.B., C.R. Withers, N. Moyer, P. Fairey, and B. McKendry. Uncontrolled Airflow in Non-residential Buildings. Florida Solar Energy Center, FSEC-CR-878-96, 1996.

DePani, S. and P. Fazio, "Airtightness Testing and Air Flow Modeling of a Three-Unit Multifamily. Building," Conference Proceedings from The Canadian Conference on Building Energy Simulation, 2001.

Diamond, R.C., "Chicago Affordable Housing Multifamily Building Rehab Study: Multizone Air Leakage Study", Lawrence Berkeley Laboratory, Berkeley, CA, 1993.

Dietz, R.N., T.W. D'Ottavio, and R.W. Goodrich, "Multizone Infiltration Measurements in Homes and Buildings Using a Passive Perfluorocarbon Tracer Method," ASHRAE Transactions, Vol. 91 (2), pp. 1761-1776, 1985.

Dietz, R.N., R.W. Goodrich, E.A. Cote, and R.F. Wieser, "Detailed description and performance of a passive perfluorocarbon tracer system for building ventilation and air exchange measurements," in Measured Air Leakage of Buildings, ASTM STP 904, H.R. Treschel and P.L. Lagus, eds. American Society for Testing and Materials, Philadelphia, 1986.

Dumont, R.S., Saskatchewan Research Council, Personal Communication, 2000 (Data reported by G Proskiw, 2001 for Canadian Mortgage and Housing Corporation) 
EIA, 2003. "Commercial Buildings Energy Consumption Survey - Overview of Commercial Buildings Characteristics." Energy Information Administration.

Feustel, H.E. and R.C. Diamond, "Diagnostics and Measurements of Infiltration and Ventilation Systems in High-Rise Apartment Buildings," Proceedings of the 1996 Summer Study on Energy Efficiency in Buildings, American Council for an Energy Efficient Economy, Washington DC, 1996.

Flanders, S.N., "Implementing the Results of Ventilation Research," $16^{\text {th }}$ AIVC Conference, Palm Springs, Conference Proceedings, 1995.

Fleury, E., J.R. Millet, J.G. Villenave, O. Veyrat, C. Morisseau, "Theoretical and field study of air change in industrial buildings," 19th AIVC Conference, Oslo, Norway, 28-30 September, 1998.

Gelman, A., J.B. Carlin, H.S. Stern, and D.B. Rubin. "Bayesian Data Analysis," Chapman and Hall, New York, 1995.

Grosso, M.. Wind pressure distribution around buildings: a parametrical model. Energy and Buildings 18, 101-131, 1992.

Grot, R.A. and A.K. Persily, "Pressurization testing of federal buildings," Measured Air Leakage of Buildings, ASTM STP 904, p. 151-183, 1986.

Gulay, B.W., Stewart, C.D., and G.J. Foley, "Field Investigation Survey of Airtightness, Air Movement, and Indoor Air Quality in High Rise Apartment Buildings," Canada Mortgage and Housing Corporation, Summary Report, 1993.

Hill, D.,"Valuing Air Barriers," Home Energy, 2001; see www.homeenergy.org

Jones, P.J. and G. Powell, "Reducing air infiltration losses in naturally ventilated industrial buildings", The Role of Ventilation, 15th AIVC Conference, Buxton, Great Britian, 27-30 September, 1994.

Kelly, M., J. McQuail, and R. O'Brien,"Case Study of Ventilation Improvements in a Multifamily Building," Proceedings of the 1992 Summer Study on Energy Efficiency in Buildings, American Council for an Energy Efficient Economy, Washington DC, 1996.

Lagus, P.L. and R.A. Grot, "Consultant report: air change rates in non-residential buildings in California." Lagus Applied Technology, Inc., P400-91-034BCN, California Energy Commission, Sacramento, CA. 1995.

Lagus P.L. and J.C. King, "Air Leakage and Fan Pressurization Measurements in Selected Naval Housing," Measured Air Leakage of Buildings, ASTM STP 904, H. R. Trechsel and P. L. Lagus, Eds., American Society for Testing and Materials, Philadelphia, pp. 5-16, 1986.

Levin P, Air Leakage Between Apartments, Proceedings of the 9th AIVC Conference, Belgium, 1988.

Litvak, A., D. Boze, and M. Kilberger, "Airtightness of 12 non residential large buildings results from field measurement studies," 22nd AIVC conference, Bath, UK, Sept 2001. 
Love, J.A., "Airtightness Survey of Row Houses in Calgary, Alberta," Air Change Rate and Airtightness in Buildings, ASTM STP 1067, M. H. Serman, Ed., American Society for Testing and Materials, Philadelphia, pp. 194-210, 1990.

Ludwig, J.F., B.J. Baker, J.F. McCarthy, Analysis of ventilation rates for the base study: assessment of measurement uncertainty and comparison with ASHRAE 62-1999. Proceedings: 9th International Conference on Indoor Air Quality and Climate, June 30-July 5, Monterey, California, 2002.

Lundin, L.I., "Air leakage in industrial bulidings - description of equipment," Measured Air Leakage of Buildings, ASTM STP 904, HR Trechsel and PL Lagus, Eds., ASTM, Philadelphia, p. 101-105, 1986.

McWilliams J., "Review of Airflow Measurement Techniques," Lawrence Berkeley National Laboratory publication LBNL-49747, Berkeley, California, 2002.

Modera. M., Brunsell, J., and R. Diamond, "Improving Diagnostics and Energy Analysis for Multifamily Buildings: A Case Study" in Proceedings, of the Thermal Performance of the Exterior Envelopes of Buildings, Clearwater, Florida, 1985.

Munson, B. R., D. F. Young, and T. H. Okiishi. 1998. Fundamentals of Fluid Mechanics. John Wiley and Sons, Inc. 3rd edition.

Pandian M.D., J.V. Behar, W.R. Ott, L.A. Wallace, L.A. Wilson, S.D. Colme, and M. Koontz, Correcting errors in the nationwide data base of residential air exchange rates, Journal of Exposure Analysis and Environmental Epidemiology 8:577-586, 1998.

Palmiter, L., J. Heller, and M. Sherman,"Measured Airflows in a Multifamily Building," Airflow Performance of Building Envelopes, Components, and Systems, ASTM STP 1255, 1995

Perera, M.D.A.E.S., J. Henderson, and B.C. Webb, "Predicting Envelope Air Leakage in Large Commercial Buildings Before Construction," 18th AIVC Conference, Athens, Greece, 23-26 September, 1997

Perera, M.D.A.E.S. and R.G. Tull,"Envelope leakiness of large, naturally ventilated buildings,", \10th AIVC Conference, Dipoli, Finland, 25-28 September, 1989.

Persily, A.K., "Myths About Building Envelopes," ASHRAE Journal, Vol. 41(3) pp. 39-47, 1999.

Persily A.K. and E.M. Ivy, Input data for multizone airflow and IAQ analysis. NISTIR 6585. National Institute of Standards and Technology, Gaithersburg, MD, 2001.

Persily, A.K. and D. Leber, "Suite of homes representing the U.S. housing stock," Proceedings of 24th Air Infiltration and Ventilation Centre (AIVC) Conference and Building Environment and Thermal Envelope Council (BETEC) Conference, Washington, DC, pp. 15-20, 2003.

Potter, I.N., T.J. Jones, and W.B. Booth, "Air leakage of office buildings," Technical Note TN 8/95, Building Services Research and Information Association, 1995.

Potter, I.N. and T.J. Jones, "Ventilation heat loss in factories and warehouses,",Technical Note TN 7/92, Building Services Research and Information Association, 1992. 
Reardon, J.T., A.K. Kim, and C.Y.Shaw, "Balanced Fan Depressurization Method for Measuring Component and Overall Air Leakage in Single and Multifamily Dwellings," ASHRAE Transactions, Vol. 93 (2), pp. 137-152, 1987.

Shaw, C.Y., and G.T. Tamura, The calculation of air infiltration rates caused by wind and stack action for tall buildings. ASHRAE Transactions 83 (2), 145-158, 1977.

Shaw, C.Y. and L. Jones, "Air tightness and air infiltration of school buildings," ASHRAE Transactions, Vol 85, Part I, p.85-95, year.

Shaw, C.Y., "Air tightness: supermarkets and shopping malls,",ASHRAE Journal, March 1981, p. $44-46$

Shaw, C.Y. and J.T. Reardon, "Changes in Airtightness Levels of Six Office Buildings," Airflow Performance of Building Envelopes, Components, and Systems, ASTM STP 1255, 1974.

Shaw, C., S. Gasparetto, and J.T. Reardon,. "Methods for Measuring Air Leakage in High-Rise Apartments," Air Change Rate and Airtightness in Buildings, ASTM STP 1067, M. H. Serman, Ed., American Society for Testing and Materials, Philadelphia, pp. 222-230, 1990.

Sherman M.H. and J.A. McWilliams, "Report on Applicability of Residential Ventilation Standards in California," Lawrence Berkeley National Laboratory publication LBNL-58713, Berkeley, California, 2005.

Spiegel, M.R., "Schaum's Outline of Theory and Problems of Statistics", 2nd edition, McGraw Hill, Inc., New York, 1992.

Tamura, G.T., and C.Y. Shaw, Studies on exterior wall air tightness and air infiltration of tall buildings. ASHRAE Transactions 82 (1), 122-134, 1976.

Bennefield R and R. Bonnette, Structural and Occupancy Characteristics of Housing: 2000, U.S. Census Bureau, November 3003.

VanBronkhorst, D. A., AK Persily, and SJ Emmerich, "Energy Impacts of Air Leakage in U.S. Office Buildings," 16th AIVC Conference: Implementing the Results of Ventilation Research Proceedings, September 19-22, 1995, Palm Springs, CA, pp. 379-391, 1995.

Wilson, A.L., S.D. Colome, Y. Tian, E.W. Beck, P.E. Baker, D.W. Behrnes, I.H. Billick, and C.A. Garrison, "California residential air exchange rates and residence volumes," Journal of Exposure Analysis and Environmental Epidemiology 6:311-326, 1996.

Wray, C.P., "Suite Ventilation Characteristics of Current Canadian Mid- and High- Rise Residential Buildings," ASHRAE Transactions, Volume 110 (Part 2), 2002. 


\section{APPENDIX I: AIR INFILTRATION MODEL FOR LARGE BUILDINGS}

The body of this report contains data and discussion of the leakage parameter in commercial buildings. The leakage parameter quantifies the air flow through the building shell for a given indoor-outdoor pressure difference. A natural question is how these leakage parameters are related to the amount of air flow across the building shell in normal operation, when the pressure drop across the building shell varies due to wind and due to temperature differences between indoors and outdoors. This Appendix describes the best currently available model for predicting the air flow from the leakage parameter, wind speed and direction, and indooroutdoor temperature difference.

\section{Driving Forces for Air Infiltration}

With mechanical ventilation systems off, the driving forces for air infiltration through the building envelope are wind, which exerts pressure on walls, and indoor-outdoor temperature difference, which induces "stack flow" in the building. The windward side(s) of the buildings will be over-pressurized and other side(s) will be under-pressurized. Further, the vertical distribution of pressure differences can be significant for tall buildings. The interaction between stack and wind driven flow can also be potentially different. All these factors make estimation of air infiltration rates more complex.

Multizone models are commonly used to predict airflow in large indoor spaces. In such models, a building is represented as a collection of well-mixed spaces linked by flow paths (Lorenzetti, 2002). These models can calculate the zone-to-zone flows, as well as estimate infiltration and exfiltration rates across the building envelope. However, multizone models are very data intensive to apply (Persily and Ivy, 2001; Price et al., 2004). Not only are the air leakage characteristics of the building envelope needed, but the air leakage characteristics of each internal flow path also need to be known. This requires more detailed knowledge than the floor plan and ventilation duct configuration of the building. Furthermore, the wind-pressure coefficients on all building façades as a function of the wind direction must also be specified. Because of the demanding data requirements, it is impractical to use a multizone model to predict the air infiltration rates on an ensemble of buildings.

\section{Shaw-Tamura Infiltration Model}

An alternative approach to multizone modeling is to focus on the building envelope across which infiltration occurs, and to conceptualize the internal partitioning and connectivity of a building as adjustment factors. Tamura and Shaw (1976) and Shaw and Tamura (1977) developed a method for calculating infiltration rates of tall buildings caused by wind and stack effect separately, based on the physics of fluid flow. Then, data from wind tunnel experiments were used to combine the two effects to give the overall air infiltration rates. Their model is outlined here. 


\section{Stack Effect}

When the outdoor air is cooler than the indoor air, the denser outdoor air causes the vertical rate of change in pressure to be faster than the indoor. Near the roof of the building, the relatively lower outdoor pressure drives air to escape through the building envelope. Air infiltrates through the lower parts of the building to replace the exfiltrating air. The stack effect can be reversed in the summer time when the indoor temperature, $T_{i}$, is lower than the outdoor temperature, $T_{0}$. The pressure difference caused by the stack effect $\left(\Delta P_{s}\right)$ is:

$$
\Delta P_{s}=\rho_{o} \cdot g \cdot\left(\frac{T_{i}-T_{o}}{T_{i}}\right) \cdot\left(H^{\prime \prime}-h\right)
$$

where $\rho_{o}\left(\mathrm{~kg} / \mathrm{m}^{3}\right)$ is the outdoor air density, and $\mathrm{g}=9.8 \mathrm{~m} / \mathrm{s}^{2} . H^{\prime \prime}(\mathrm{m})$ is the height where the indoor and outdoor pressure equals, which is often referred to as the neutral pressure height. When the indoor temperature is higher than the outdoor, infiltration occurs from ground level $(h[\mathrm{~m}]=0)$ up to $\mathrm{H}^{\prime \prime}$. When the stack effect is reversed, infiltration occurs from the top of the building $H(\mathrm{~m})$ down to $\mathrm{H}^{\prime \prime}$. In large buildings, many factors can affect the location of the neutral pressure level. These include internal partitions, stairwells, elevator shafts, utility ducts, chimneys, vents, operable windows, and mechanical supply and exhaust system. An opening with a large area relative to the total building leakage can cause the neutral pressure level to be pulled towards the positioning of the leakage element.

Large buildings also tend to have many internal partitions that can cause significant internal airflow resistance. In a building with airtight separations at each floor, each story will act independently such that the stack effect is discontinuous from floor to floor. In this case, stack effect induced infiltration for the building can be much less than that which would result from the theoretical stack effect. Further, the location of the neutral pressure height can also be affected. To quantify this effect, thermal draft coefficient, $\gamma(-)$, is defined as the sum of the pressure differences across the exterior wall at the bottom and at the top of the building, divided by the total theoretical draft for the building. For a building without internal partitions, the total theoretical draft is achieved, and thus $\gamma=1$. Conversely, when the air leakage of the internal partitions is much tighter than the exterior envelope, $\gamma$ approaches 0 .

The Shaw-Tamura Infiltration Model estimates the air infiltration rates driven by the stack effect, $Q_{s}\left(\mathrm{~m}^{3} / \mathrm{s}\right)$, by considering the amount of airflow on an incremental surface area $d A$ $\left(\mathrm{m}^{2}\right)$ on the vertical walls of the building envelope. By assuming that the building has a uniform building perimeter with height, the incremental surface area can be expressed as the product of the building perimeter $S(\mathrm{~m})$ and the incremental height of the building $d h(\mathrm{~m})$. Starting with the power-law relationship between air-leakage coefficient and air infiltration rate, the total air infiltration rate driven by stack effect is the integral of $d Q_{s}$ over the portion of the building envelope where infiltration occurs. 


$$
\begin{aligned}
d Q_{s} & =C \cdot d A \cdot\left(\Delta P_{s}\right)^{n} \\
& =C \cdot S \cdot d h \cdot \gamma \cdot\left(\rho_{o} \cdot g \cdot\left(\frac{T_{i}-T_{o}}{T_{i}}\right) \cdot\left(H^{\prime \prime}-h\right)\right)^{n} \\
Q_{s} & =C \cdot S \cdot \gamma \cdot\left(\rho_{o} \cdot g \cdot\left(\frac{T_{i}-T_{o}}{T_{i}}\right)\right)^{n} \cdot \int_{0}^{H^{n}} h^{n} \cdot d h \\
& =C \cdot S \cdot \gamma \cdot\left(\rho_{o} \cdot g \cdot\left(\frac{T_{i}-T_{o}}{T_{i}}\right)\right)^{n} \cdot \frac{(\beta \cdot H)^{n+1}}{n+1}
\end{aligned}
$$

where $b[-]=H^{\prime \prime} / H$. For example, $b=0.5$ means that the neutral pressure level is at the midheight of the building. The derivation assumes that air leakage is evenly distributed on the building envelope with respect to height. In other words, the air leakage coefficient $C$ is assumed constant, and not a function of $h$.

\section{Wind Effect}

The pressure difference caused by the kinetic energy of wind impinging on the building envelope at $U(\mathrm{~m} / \mathrm{s})$ is described by:

$$
\Delta P_{w}=C_{p} \cdot \frac{1}{2} \cdot \rho_{o} \cdot U^{2}
$$

where $C_{p}(-)$ is known as the wind-pressure coefficient. As wind blows around a building, it generates areas of positive and negative pressure on the building envelope. Typically, the windward wall(s) will be pressurized with respect to the indoor, and the adjacent wall(s) may be depressurized. To reflect this, the value of $C_{p}$ is different at each façade of the building. $C_{p}$ can be measured using pressure taps on a model building in wind tunnel experiments or on real buildings in full-scale tests. Detailed airflow models would require $C_{p}$ as a function of position on the different building façades to permit reliable predictions. For simplicity, the ShawTamura Infiltration Model reduces these to one mean wind-pressure coefficient per façade, $C_{p}$, which is determined as the weighted mean of the pressure differences measured in wind tunnel experiments (Shaw and Tamura, 1977).

The wind-pressure coefficient, $C_{p}^{\prime}$, is a function of wind angle, shielding from surrounding structures, and terrain effects. The maximum pressure difference is observed on a building wall when the wind is approaching normal to it. The remaining three walls are typically depressurized when this happens. For a $45^{\circ}$ wind-wall angle, two windward walls are likely to be pressurized at the same time, but the $C_{p}{ }^{\prime}$ is lower in value. To account for this effect, a wind-angle correction factor, $a$, is defined as follows. 


$$
\alpha=\left(\frac{C_{p}{ }^{0} \theta, 1}{C_{p}{ }^{0} 0,1}\right)^{n}+\frac{W}{L} \cdot\left(\frac{C_{p}{ }^{0} \theta, 2}{C_{p}{ }^{\prime} 0,1}\right)^{n}
$$

The subscript $q$ is the wind angle impinging at the longer wall of the building, with $q=$ $0^{\circ}$ being normal to the wall. The next subscript is the wall number. Wall 1 is the longer wall by default. This equation assumes a rectangular-shaped building, so only wall 1 and wall 2 are considered explicitly. When the wind angle is $0^{\circ}$, the maximum wind-pressure coefficient $C_{p 0,1}^{\prime}$ occurs on the longer wall. In wind tunnel experiments, the ratios of mean wind-pressure coefficients are measured by the ratios of mean pressure difference on the envelope of the model building. $L(\mathrm{~m})$ and $W(\mathrm{~m})$ are the length and width of the building footprint. The ratio of these two lengths is needed to account for the wall area where infiltration occurs on the shorter wall (wall 2). The total air infiltration rate driven by wind effect on the building envelope is therefore:

$$
\begin{aligned}
Q_{w} & =C \cdot A \cdot\left(\Delta P_{w}\right)^{n} \\
& =C \cdot(L \cdot H) \cdot \alpha \cdot\left(C_{p}{ }^{0,1} \cdot \frac{1}{2} \cdot \rho \cdot U^{2}\right)^{n}
\end{aligned}
$$

In the Shaw-Tamura Infiltration Model, shielding is accounted for by direct adjustment to the mean wind-pressure coefficient. Conceptually, two factors are important in determining the appropriate mean wind-pressure coefficient to use. One is the plan area density (Grosso, 1992), a ratio of built area to total area within a certain radius from the considered building. The other is the relative building height, which is the ratio of the height of the considered building to the height of the surrounding buildings. Wind-pressure coefficients decrease with increasing plan area density, as more buildings can shield wind from impinging on the considered building. For a similar reason, wind-pressure coefficients decrease as the height of the surrounding building exceeds that of the considered building. Grosso (1992) presented a literature review on available wind tunnel data from which these observations are made.

Terrain roughness affects the vertical wind profile and the level of incident turbulence intensity on building walls. The power-law exponent of the wind profile, which describes how wind velocity changes as a function of vertical distance from a reference height, increases with increasing roughness of the surface. Wind-pressure coefficients are inversely related to the power-law coefficient as shown from wind tunnel experiments (Grosso, 1992). In a downtown urban area with enhanced surface roughness, the overall mean wind-pressure coefficients of buildings are expected to be lower than for buildings that are located in suburban areas. 


\section{Combined Stack and Wind Effects}

The relative importance of the wind and stack driven air infiltration in buildings depends on a number of factors besides the strength of the respective driving forces, including building height, internal resistance to vertical airflow, location and flow resistance characteristics of envelope openings, local terrain, and the immediate shielding of the building. Tall, narrow buildings with little internal resistance to airflow are likely to have a strong stack effect. Unshielded buildings on a relatively smooth terrain are more susceptible to wind effects. For any building, there will be ranges of wind speed and temperature difference for which the amount of air infiltration is dominated by the wind effect, stack effect, or neither.

Shaw and Tamura carried out a few experimental studies to determine how the stack and wind effects combine to give the total air infiltration rate. Methods developed by Shaw and Tamura (1977) and by Shaw (1979) are the empirical formulations resulting from wind tunnel experiments using a tall building model. Shaw (1979) included the shielding effect from lower structures of uniform height that surround the tall building being studied; this study also investigated the influence of wind angle on the adjustment factor. Overall, the results obtained are within $20 \%$ of the predictions by method Shaw and Tamura (1977), which did not include shielding from surrounding structures, nor the wind angle effect.

(i) $Q_{\text {total }}=Q_{\text {large }} \cdot\left(1+0.24 \cdot\left(\frac{Q_{\text {small }}}{Q_{\text {large }}}\right)^{3.3}\right)$

(ii) $Q_{\text {total }}= \begin{cases}Q_{\text {large }} \cdot\left(1+(-0.0074 \cdot \theta+0.39) \cdot\left(\frac{Q_{\text {small }}}{Q_{\text {large }}}\right)^{3.6}\right) & \text { for } 0^{\circ} \leq \theta \leq 45^{\circ} \\ Q_{\text {large }} \cdot\left(1+(0.01 \cdot \theta-0.48) \cdot\left(\frac{Q_{\text {small }}}{Q_{\text {large }}}\right)^{2.5}\right) & \text { for } 45^{\circ} \leq \theta \leq 90^{\circ}\end{cases}$

where : $Q_{\text {sinall }}=\min \left(Q_{s}, Q_{w}\right) Q_{\text {large }}=\max \left(Q_{s}, Q_{w}\right)$

and $\theta$ is in unit of degree $\left({ }^{\circ}\right)$

These relationships suggest that the total air infiltration rate is largely driven by either the stack or wind effect, whichever is higher. Only in the cases when both effects are similar in magnitude do the lesser terms also contribute significantly to the total air infiltration rate.

Shaw (1980) measured air infiltration rates at two school buildings in Canada, where the pressure differences were measured across the exterior walls at 7 locations continuously for 8 months. The stack and wind induced pressure difference were also computed using the ShawTamura Infiltration Model, as described earlier. The computed sums of the wind and stack 
driven pressure differences were found to be good approximations of the overall pressure difference measured. According to this study, the relationship to obtain $Q_{\text {total }}$ from $Q_{s}$ and $Q_{w}$ is:

$$
\begin{aligned}
Q_{\text {total }} & =C \cdot\left(\Delta P_{s}+\Delta P_{w}\right)^{n} \\
& =C \cdot\left(\left(\frac{Q_{s}}{C}\right)^{1 / n}+\left(\frac{Q_{w}}{C}\right)^{1 / n}\right)^{n} \\
& =\left(Q_{s}^{1 / n}+Q_{w}^{1 / n}\right)^{n}
\end{aligned}
$$

Other studies have observed relationships other than those presented here. For example, Fletcher and Johnson (1992) found that simple linear combination of wind speed and the square root of indoor-outdoor temperature difference is sufficient to explain the air infiltration rates variability observed in a small factory unit. This would imply adding $Q_{s}$ and $Q_{w}$ linearly to obtain $Q_{\text {total }}$. Experiments by Tanaka and Lee (1986) on a high-rise building found that the linear sum of pressure differentials owing to stack, wind, and forced ventilation is not the same as the overall pressure differentials measured. In practice, it is likely that no single empirical relationship would fit all buildings. Fortunately, differences in formulations are significant only when the stack and wind driven air infiltration rates nearly equal to one another. When either $Q_{s}$ or $Q_{w}$ is one half of the other or less, the different formulations give a total air infiltration rate that agrees within $20 \%$ of each other.

\section{Air Infiltration Model Parameters and Uncertainties}

Performance of air infiltration models often depends on whether site-specific information of the building being modeled is available. The Shaw-Tamura Infiltration Model has a number of adjustable parameters, namely the neutral pressure level $(b)$, the thermal draft coefficient $(g)$, the wind angle factor $(a)$, and the wind-pressure coefficient $\left(C_{p}^{\prime}\right)$. A range of values is expected for each of these parameters in a group of buildings, which will contribute to the overall variability of the air infiltration rate predictions. If their distributions are known, their influences on the air infiltration rate predictions can be modeled. However, data on these input parameters are limited. Input parameters can also be time variant depending on the building operating conditions and the local meteorology. Discussed below are studies where these parameters have been measured. Even though the available data are insufficient to derive a representative distribution for each of the parameter, they do provide some indication of the range of values expected in real buildings. 


\section{Neutral Pressure Level and Thermal Draft Coefficient}

All experiments were carried out when the mechanical systems were off. When pressure differential measurements were taken under various outdoor temperatures, it is found that $b$ is unaffected by it. Sealing of air intake and exhaust dampers have shown to lower the neutral pressure level. The range of $b$ observed is from 0.3 to 0.76 , with mean $=0.48$. Despite that the limited data do not suggest any particular distribution for the parameter, it is nonetheless reasonable to consider a possible range of $b$ from 0.2 to 0.8 , with the mean centering at 0.5 . The two 1-storey schools measured by Shaw (1980) both has $b=0.7$. It appears that there is no significant difference in terms of the vertical pressure differences distribution between high-rise and low-rise buildings.

The resistance to flow in the vertical direction is not high even in tall buildings. The thermal draft coefficient is in the range of 0.63 to 0.82 . Both studies found that $g$ is lower when the ventilation system is on, indicating higher flow resistance from floor to floor. Based on these very few data points, it appears the range of $g$ is narrower than $b$. A reasonable range to consider is perhaps from 0.6 to 0.9 , with the mean centering at 0.8 .

\section{Wind Angle Correction Factor and Wind-Pressure Coefficient}

Pressure differential data from wind tunnel experiments and full-scale tests on buildings are more abundant. A review by Grosso (1992) summarizes the existing literature, models that compute wind-pressure coefficient distributions, and regression analysis of the wind-pressure coefficients measurements. The mean wind-pressure coefficients for adjacent sides of a building are out of phase by $90^{\circ}$ with respect to wind angle (Shaw and Tamura, 1977; Shaw, 1979; Akins et al., 1979; Shaw, 1980). That is, wall 2 (shorter wall) has a mean wind-pressure coefficient at $90^{\circ}$ wind angle that is roughly the same as wall 1 (longer wall) at $0^{\circ}$. At $45^{\circ}$, the two adjacent walls have roughly equaled mean wind-pressure coefficients that sum to the same total as when wind is approaching normal to a wall.

Mathematical models of the dependence of wind-pressure coefficients on wind angle are available (Grosso, 1992). However, to apply this dependence for a population of buildings will require detailed local wind data as well as information on the location and orientation of each building. The uncertainties associated with such inputs would be large. Favoring a simple model that can provide reasonable results without excessive needs for input data, the analysis to follow assumes that the wind always approaches normal to the long wall. In other words, $a$ is assumed to be 1 . This assumption tends to cause a slight overprediction of air infiltration rate when the building footprint has a very large aspect ratio. When the building footprint is close to square, the orientation of the building with respect to wind direction is less unimportant. This is true, however, only if air leakage is uniformly distributed on all walls of a building. The modeling approach here also assumes that all buildings have simple rectangular geometry.

Mean wind-pressure coefficients are also subject to local shielding and terrain. A review by Orme et al. (1994) summaries the dependence of wind-pressure coefficient on the height of surrounding structures relative to the building being modeled. The mean wind-pressure coefficient under heavy shielding, which occurs when the building is surrounded on all sides by obstructions of similar height, can be one-third the value when there is little obstruction 
surrounding the building. Wind-pressure coefficients are also subject to the overall building density in the vicinity of the modeled building: surrounding buildings can only affect the mean wind-pressure coefficients of the modeled building when they are in close proximity. Increasing the plan area density to 10 (i.e. the footprint area of the building is 10 times the effective area to its closest adjacent buildings. as measured by the product of the closest two distances between the modeled building and the adjacent building) from the no-shielding case can reduce the wind-pressure coefficients to half their unshielded value (Grosso, 1992).

Judging from existing wind tunnel and full-scale experiments (Akins et al., 1979; Grosso, 1992; Orme et al., 1994; Persily and Ivy, 2001), mean wind-pressure coefficients for the windward wall is typically in the range of 0.3 to 0.9 .

\section{References for Appendix I.}

Akins, R.E., J.A. Peterka, and J.E. Cermak, Averaged pressure coefficients for rectangular buildings. Proceedings: 5th International Conference on Wind Engineering, July 8-14, Fort Collins, CO, 1979.

Grosso, M.,. Wind pressure distribution around buildings: a parametrical model. Energy and Buildings 18, 101-131, 1992.

Lorenzetti, D.M., 2002. Assessing multizone airflow simulation software. Proceedings: 9th International Conference on Indoor Air Quality and Climate, June 30-July 5, Monterey, CA.

Orme, M., M. Liddament, and A.Wilson, An analysis and data summary of the AIVC's numerical database. Technical Note 44, Air Infiltration and Ventilation Centre, Coventry, UK, 1994.

Persily, A.K., and E.M. Ivy, Input data for multizone airflow and IAQ analysis. NISTIR 6585. National Institute of Standards and Technology, Gaithersburg, MD, 2001.

Price, P.N., S.C. Chang, and M.D. Sohn, Characterizing buildings for airflow models: what should we measure? LBNL-55321, Lawrence Berkeley National Laboratory, Berkeley, CA, 2004.

Shaw, C.Y., 1979. A method for predicting air infiltration rates for a tall building surrounded by lower structures of uniform height. ASHRAE Transactions 85 (1),72-84.

Shaw, C.Y., Wind and temperature induced pressure differentials and an equivalent pressure difference model for predicting air infiltration in schools. ASHRAE Transactions 86 (1), 268-279, 1980.

Shaw, C.Y., and G.T. Tamura, The calculation of air infiltration rates caused by wind and stack action for tall buildings. ASHRAE Transactions 83 (2), 145-158, 1977.

Tamura, G.T., and C.Y. Shaw, Studies on exterior wall air tightness and air infiltration of tall buildings. ASHRAE Transactions 82 (1), 122-134, 1976.

Tanaka, H., and Y. Lee, 1986. Scale model verification of pressure differentials and infiltration induced across the walls of a high-rise building. Journal of Wind Engineering and Industrial Aerodynamics 25, 1-14. 


\section{APPENDIX II: ANALYSIS OF COMMERCIAL BUILDING DATA}

While the 267 building measurements used in this paper comprise the largest nonresidential air leakage collection to date, the data set is still too small to produce any meaningful conclusion using traditions analysis methods. Analysis is further complicated by the broad range of building types and locations within this data set. The measured buildings are located in five different countries, and include 12 different building usage types (schools, offices, etc.), and 7 different construction types (masonry, tilt-up, etc.).

The potential combinations from these three parameters (420) outnumbers the total numbers of building measurements (267) so some combinations are only represented by one or two measurements and other combinations to have no measurements at all. All combinations of building use, construction and location with relatively good representation show approximately lognormal distributions of building leakage, but the minimal data prevents performing a separate analysis on each combination in the data.

The entire data set, taken as a whole, also follows an approximately lognormal distribution (i.e. the logarithms of the data are distributed according to a Gaussian or "normal" distribution).

Simple approaches to data analysis would either (1) "pool" all of the data or large parts of it, by decreasing the number of building categories so that sample sizes in each category are increased, or (2) analyze each building category completely independently. The first approach would lump together data that should be kept separate, while the latter would fail to take into account any similarities between building types and would lead to severe problems with small sample sizes for many of the building categories.

"Bayesian Hierarchical Modeling" (also known as Bayesian Multilevel Modeling) provides a middle road, allowing partial sharing of information across categories. We will not attempt to explain Bayesian Hierarchical Modeling here, as it is a large subject and excellent reference materials are available (we recommend Gelman et al. 1995). Instead we explain the basic concept of pooling of information.

Suppose we had a lot of data from, say, masonry schools, masonry office buildings, masonry masonry retail stores, and masonry warehouses, so that we could estimate the statistical distribution of leakage for each of these building categories with very high accuracy. Further suppose that the median leakage in each of these categories was very similar. In that case, even without seeing any data from masonry health care buildings, we would expect that the median educational building should be fairly close to that from the other categories. Now suppose we have just two data points concerning masonry health care buildings, and that the data points both show rather high leakiness. Although it's possible that masonry health care buildings tend to be leaky compared to all of the other types of masonry buildings, it's also possible that masonry health care buildings are about the same as the others and that we happened to sample two rather leaky buildings. If we know the amount of variability in leakage within a building category, and we know the amount of variation between building categories, then statistical methods can quantify how much information we get from two data points in a category and how much we get from the data concerning other building categories.

To implement this approach, we create a statistical model that describes what we think is happening with the data, and then use routine methods (implemented in a program called 
BUGS, for Bayes Using Gibbs Sampling) to fit the model to data. For our statistical model, we assume that buildings of a given construction type have some similarity to each other (with the degree of similarity to be determined by fitting the model), and that buildings of a given usage category have some similarity to each other (ditto), so that the log leakage of a building can be predicted from the sum of a "building usage coefficient" plus a "construction type coefficient" plus some other terms.

The model generates an estimate of a building's normalized air leakage from the sum of category coefficients as shown below

$$
\log (\text { leakage })=\beta_{\text {total }}=\beta_{\text {country }_{i}}+\beta_{\text {building }_{j}}+\beta_{\text {construction }_{k}}+\beta_{\text {height }_{m}}+\beta_{\text {footpr int }_{n}}+\beta_{\text {combo }_{p}}
$$

The category variables determined from this analysis are presented in the tables below.

\section{Beta Values}

Each building characteristic (Country, Building-Type, Construction-Type, etc.) contains a group of coefficients, represented here as beta values. For example, there are five different beta values for the five possible countries where a building in the data may be located. Each "betaCountry" estimate represents the contribution of the country location on building leakage. The mean of the beta values is applied here as the best estimate of this contribution. The standard error in the table represents the uncertainty of this estimate. The median and the $2.5,25,75$, and 97.5 percentiles are also presented to further quantify the uncertainty in the coefficient, since the uncertainty may not be normally distributed.

\section{Sigma Values}

Each building characteristic also contains a single sigma value that represents the variability of beta values within a building characteristic. For example, the "sigmaCountry" value represents the variability between the all possible betaCountry values, thus defining the normal distribution from which all the betaCountry values are assumed to be drawn. The sigma values are not of direct interest, but are an intermediate modeling parameter.

\section{Example}

Leakage for a building with a set of building characteristics is estimated as the sum of the appropriate beta values. For example, the leakage for a large, single story, masonry built school located in the U.S. would be calculated from the following beta values. From the country effect table, the beta value for the U.S. (betaCtry[1]) would be chosen. The beta value for education (betaBldg[1]) would be chosen from the building effect table. The beta values for masonry (betaConst[1]), single story (betaFN[1]), and for a large footprint (betaFP[2]) would also be chosen. A final beta value for the combination of country, building-type, and construction-type would then be chosen (betaCombo[1]). This final beta value acts as an error parameter by accounting for leakage differences in different combinations of building characteristics that may not have been predicted by the previous beta values. The sum of the chosen beta values represents the estimated log of leakage for a building with this particular set of characteristics. 


$$
\begin{array}{lll}
\text { United States } & =\beta_{\text {country }_{1}} & =0.445 \\
\text { Education } & =\beta_{\text {building }_{1}} & =-0.080 \\
\text { Masonry } & =\beta_{\text {consiruction }_{1}} & =-0.008 \\
\text { Single Story } & =\beta_{\text {height }_{1}} & =0.019 \\
\text { LargeFootprint } & =\beta_{F P_{2}} & =0.046 \\
+ \text { US - Edu - Masory } & =\beta_{\text {combo }_{1}} & =-0.047 \\
\hline \log (\text { leakage) } & =\beta_{\text {total }_{1}}= & 0.375
\end{array}
$$

The leakage estimate for this particular building is then $10^{0.375}$, or $2.37 \mathrm{~L} / \mathrm{sec}-\mathrm{m}^{2}$. Note that positive beta values indicate an increase in building leakage while negative beta values indicate a tighter building. Relative differences between beta values translate to differences in building leakage. A 0.01 difference between two beta values, for example, indicates at difference of a factor of 1.02 difference in building leakage $\left(10^{0.01}\right)$.

\section{Computer code}

We implemented the statistical model using the package BUGS, which stands for Bayes Using Gibbs Sampling. Specifically, we used WinBUGS version 1.4. The computer code to fit the model is given below.

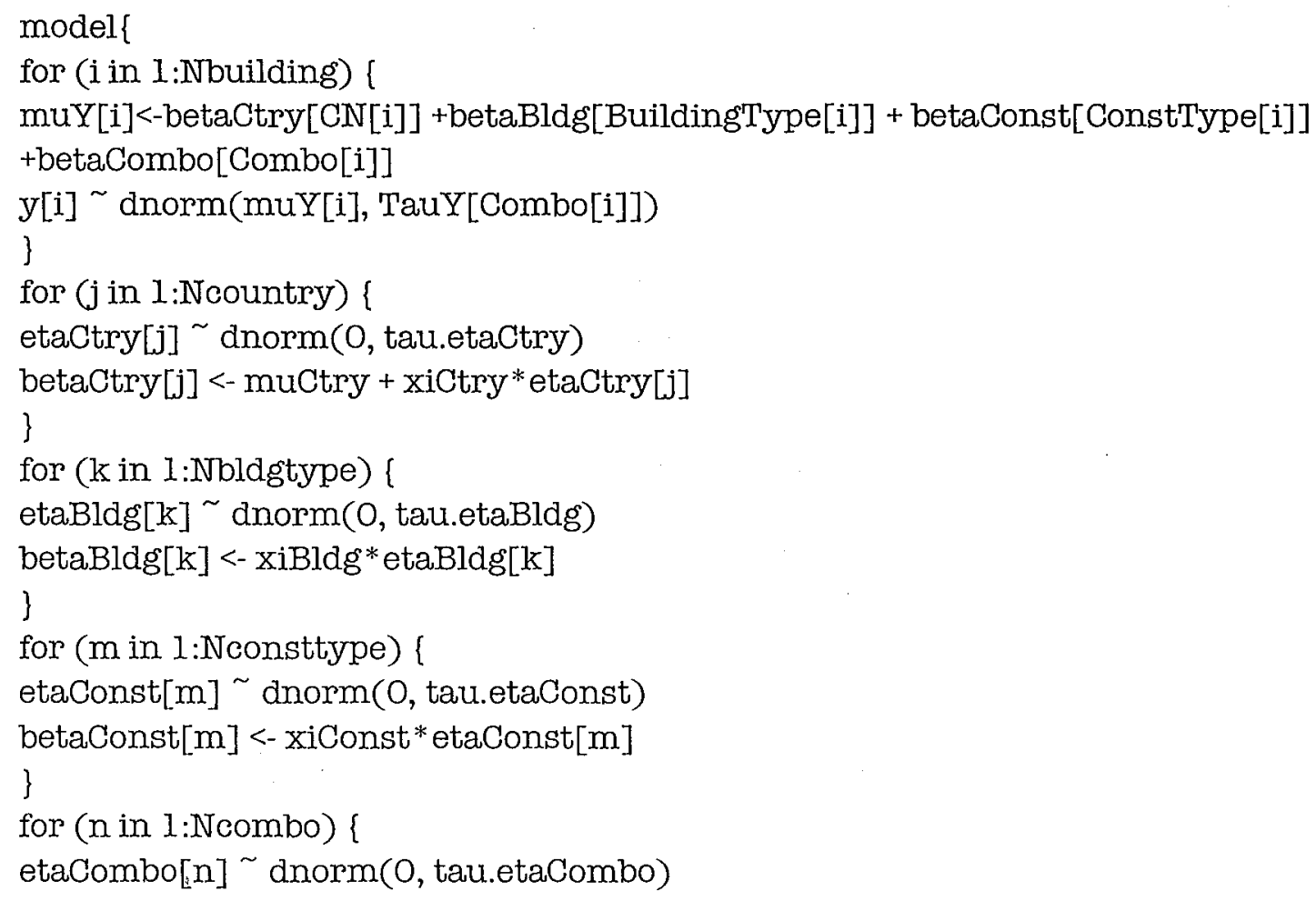




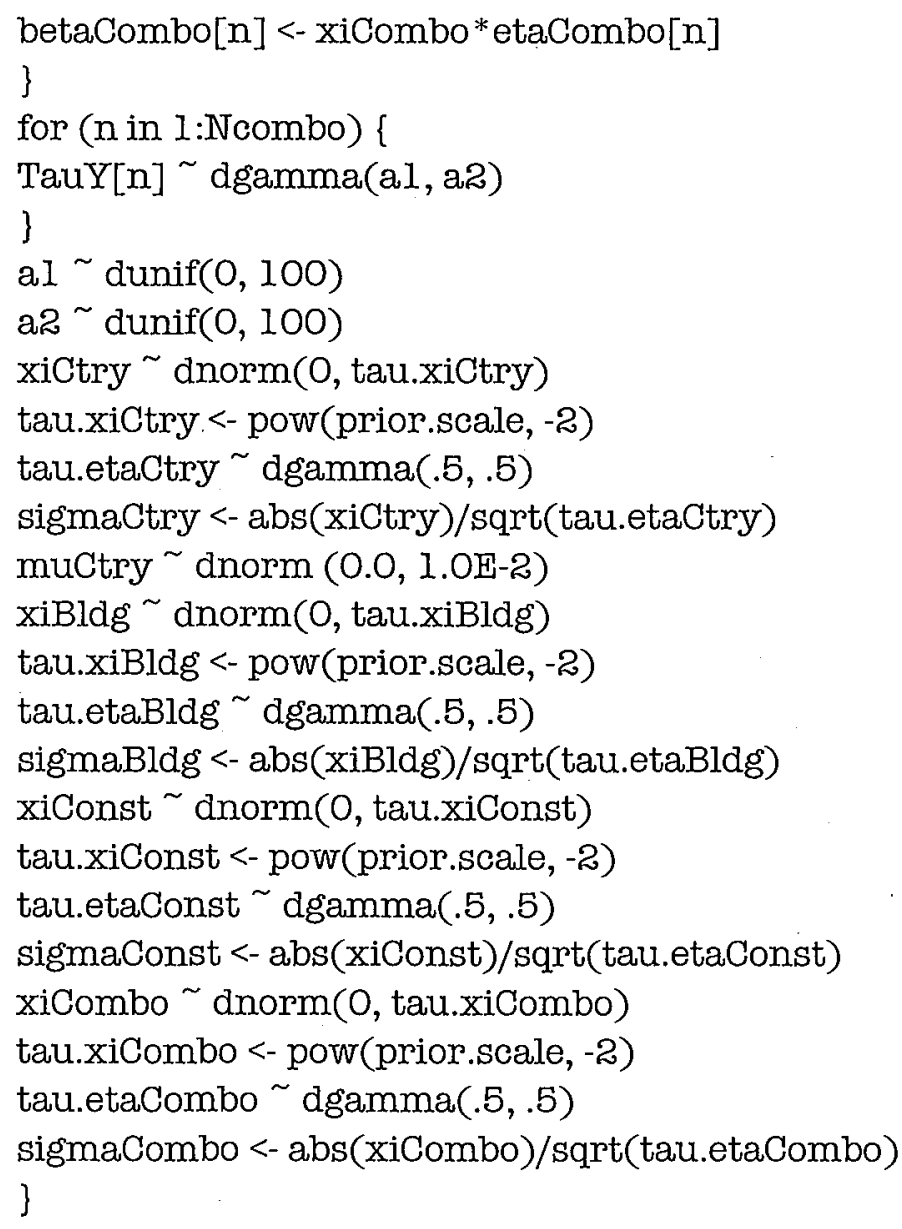

\section{Parameter estimates}

The following table summarizes the parameter estimates and uncertainties for every parameter. Separate coefficient estimates (beta values) are given for each country effect, each building type and activity effect, each "combination" effect (capturing between-building-category variation that is not captured by an additive building type effect plus an additive activity effect) and for footprint and height effects. 


\begin{tabular}{|l|l|c|c|c|c|c|c|c|}
\hline Country & $\begin{array}{l}\text { Coefficient } \\
\text { Name }\end{array}$ & Mean & $\begin{array}{c}\text { Std. } \\
\text { Error }\end{array}$ & $\mathbf{2 . 5 0 \%}$ & $\mathbf{2 5 \%}$ & Median & $\mathbf{7 5 \%}$ & $\mathbf{9 7 . 5 0 \%}$ \\
\hline US & betaCtry[1] & 0.445 & 3.220 & -7.350 & 0.024 & 0.575 & 1.029 & 7.474 \\
\hline Canada & betaCtry[2] & 0.235 & 3.221 & -7.584 & -0.191 & 0.360 & 0.826 & 7.262 \\
\hline Sweden & betaCtry[3] & 0.369 & 3.223 & -7.440 & -0.063 & 0.493 & 0.975 & 7.403 \\
\hline England & betaCtry[4] & 0.609 & 3.221 & -7.183 & 0.184 & 0.735 & 1.209 & 7.635 \\
\hline France & betaCtry[5] & 0.406 & 3.221 & -7.403 & -0.017 & 0.535 & 1.000 & 7.432 \\
\hline
\end{tabular}

\begin{tabular}{|l|l|l|l|l|l|l|l|c|}
\hline BuildingType & $\begin{array}{l}\text { Coefficient } \\
\text { Name }\end{array}$ & Mean & $\begin{array}{c}\text { Std. } \\
\text { Error }\end{array}$ & $\mathbf{2 . 5 0 \%}$ & $\mathbf{2 5 \%}$ & Median & $\mathbf{7 5 \%}$ & $\mathbf{9 7 . 5 0 \%}$ \\
\hline Education & betaBldg[1] & -0.080 & 0.083 & -0.259 & -0.132 & -0.073 & -0.020 & 0.064 \\
\hline Supermarket & betaBldg[2] & 0.058 & 0.112 & -0.151 & -0.012 & 0.047 & 0.126 & 0.303 \\
\hline Mall & betaBldg[3] & 0.093 & 0.147 & -0.152 & -0.003 & 0.069 & 0.174 & 0.437 \\
\hline Office & betaBldg[4] & -0.016 & 0.080 & -0.180 & -0.064 & -0.013 & 0.032 & 0.143 \\
\hline Warehouse & betaBldg[5] & $\mathbf{0 . 1 5 3}$ & 0.110 & -0.027 & 0.070 & 0.147 & 0.226 & 0.384 \\
\hline SmallRetail & betaBldg[6] & -0.004 & 0.090 & -0.190 & -0.057 & -0.002 & 0.052 & 0.176 \\
\hline StripMall & betaBldg[7] & 0.143 & 0.122 & -0.055 & 0.049 & 0.133 & 0.222 & 0.404 \\
\hline HealthCare & betaBldg[8] & 0.008 & 0.094 & -0.183 & -0.048 & 0.006 & 0.064 & 0.197 \\
\hline PublicAssembly & betaBldg[9] & -0.113 & 0.100 & -0.329 & -0.178 & -0.105 & -0.039 & 0.052 \\
\hline Recreational & betaBldg[10] & -0.045 & 0.096 & -0.254 & -0.103 & -0.036 & 0.015 & 0.134 \\
\hline Restaurant & betaBldg[11] & -0.040 & 0.103 & -0.262 & -0.101 & -0.031 & 0.022 & 0.153 \\
\hline Lodging & betaBldg[12] & -0.026 & 0.101 & -0.241 & -0.085 & -0.019 & 0.035 & 0.170 \\
\hline n/a & betaBldg[13] & -0.120 & 0.123 & -0.394 & -0.197 & -0.105 & -0.027 & 0.080 \\
\hline
\end{tabular}

\begin{tabular}{|l|l|c|c|c|c|c|c|c|}
\hline $\begin{array}{l}\text { Between } \\
\text { Building Type } \\
\text { Variability }\end{array}$ & $\begin{array}{l}\text { Variable } \\
\text { Name }\end{array}$ & Mean & $\begin{array}{c}\text { Std. } \\
\text { Error }\end{array}$ & $\mathbf{2 . 5 0} \%$ & $\mathbf{2 5 \%}$ & Median & $\mathbf{7 5 \%}$ & $\mathbf{9 7 . 5 0 \%}$ \\
\cline { 2 - 9 } & sigmaBldg & 0.139 & 0.069 & 0.018 & 0.093 & 0.134 & 0.178 & 0.292 \\
\hline
\end{tabular}

\begin{tabular}{|l|l|r|r|r|r|r|r|r|}
\hline ConstructionType & $\begin{array}{l}\text { Coefficient } \\
\text { Name }\end{array}$ & Mean & $\begin{array}{c}\text { Std. } \\
\text { Error }\end{array}$ & $\mathbf{2 . 5 0 \%}$ & $\mathbf{2 5 \%}$ & Median & \multicolumn{1}{|c|}{$\mathbf{7 5 \%}$} & $\mathbf{9 7 . 5 0 \%}$ \\
\hline Masonry & betaConst[1] & -0.008 & 0.054 & -0.127 & -0.032 & -0.003 & 0.016 & 0.100 \\
\hline FrameMasonry & betaConst[2] & 0.035 & 0.079 & -0.088 & -0.007 & 0.014 & $\mathbf{0 . 0 6 5}$ & 0.239 \\
\hline ConcretePanel & betaConst[3] & -0.038 & 0.073 & -0.223 & -0.069 & -0.018 & 0.004 & 0.074 \\
\hline MetalFrame & betaConst[4] & 0.004 & 0.058 & -0.117 & -0.022 & 0.001 & 0.029 & 0.129 \\
\hline Curtainwall & betaConst[5] & -0.009 & 0.082 & -0.204 & -0.036 & -0.002 & 0.024 & 0.155 \\
\hline Manufactured & betaConst[6] & -0.008 & 0.075 & -0.181 & -0.036 & -0.002 & 0.023 & 0.143 \\
\hline WoodFrame & betaConst[7] & 0.054 & 0.080 & -0.051 & 0.000 & 0.030 & 0.090 & 0.257 \\
\hline n/a & betaConst[8] & -0.027 & 0.065 & -0.186 & -0.056 & -0.013 & 0.007 & 0.083 \\
\hline
\end{tabular}

\begin{tabular}{|l|l|r|r|r|r|r|r|r|}
\hline $\begin{array}{l}\text { Between } \\
\text { Construction } \\
\text { Type Variability }\end{array}$ & $\begin{array}{l}\text { Variable } \\
\text { Name }\end{array}$ & Mean & $\begin{array}{c}\text { Std. } \\
\text { Error }\end{array}$ & $\mathbf{2 . 5 0 \%}$ & $\mathbf{2 5 \%}$ & Median & $\mathbf{7 5 \%}$ & $\mathbf{9 7 . 5 0 \%}$ \\
\cline { 2 - 9 } & sigmaConst & 0.073 & 0.064 & 0.003 & 0.027 & 0.057 & 0.102 & 0.234 \\
\hline
\end{tabular}




\begin{tabular}{|l|l|l|c|c|c|c|c|c|}
\hline Footprint & $\begin{array}{l}\text { Coefficient } \\
\text { Name }\end{array}$ & Mean & $\begin{array}{c}\text { Std. } \\
\text { Error }\end{array}$ & $\mathbf{2 . 5 0 \%}$ & $\mathbf{2 5 \%}$ & Median & $\mathbf{7 5 \%}$ & $\mathbf{9 7 . 5 0 \%}$ \\
\hline$<1000 \mathrm{~m}^{2}$ & betaFP[1] & 0.210 & 3.218 & -6.805 & -0.360 & 0.080 & 0.617 & 8.018 \\
\hline$>1000 \mathrm{~m}^{2}$ & betaFP[2] & 0.046 & 3.218 & -6.982 & -0.527 & -0.076 & 0.450 & 7.863 \\
\hline
\end{tabular}

\begin{tabular}{|c|c|c|c|c|c|c|c|c|}
\hline \multirow{2}{*}{$\begin{array}{l}\text { Between } \\
\text { Footprint } \\
\text { Variability }\end{array}$} & \begin{tabular}{|l} 
Variable \\
Name
\end{tabular} & Mean & $\begin{array}{c}\text { Std. } \\
\text { Error }\end{array}$ & $2.50 \%$ & $25 \%$ & Median & $75 \%$ & $97.50 \%$ \\
\hline & sigmaFP & 4.017 & 7.948 & 0.075 & 0.350 & 1.230 & 4.279 & 24.120 \\
\hline
\end{tabular}

\begin{tabular}{|l|l|l|c|c|c|c|c|c|}
\hline Stories & $\begin{array}{l}\text { Coefficient } \\
\text { Name }\end{array}$ & Mean & $\begin{array}{c}\text { Std. } \\
\text { Error }\end{array}$ & $\mathbf{2 . 5 0 \%}$ & $\mathbf{2 5 \%}$ & Median & $\mathbf{7 5 \%}$ & $\mathbf{9 7 . 5 0 \%}$ \\
\hline 1 & betaFN[1] & 0.019 & 0.090 & -0.093 & -0.006 & 0.008 & 0.040 & $\mathbf{0 . 1 7 2}$ \\
\hline 2to3 & betaFN[2] & 0.001 & 0.089 & -0.125 & -0.020 & 0.000 & 0.020 & $\mathbf{0 . 1 4 0}$ \\
\hline 4to5 & betaFN[3] & -0.018 & 0.094 & -0.186 & -0.039 & -0.006 & 0.010 & $\mathbf{0 . 1 0 6}$ \\
\hline 6orMore & betaFN[4] & -0.002 & 0.092 & -0.146 & -0.024 & 0.000 & 0.020 & $\mathbf{0 . 1 4 1}$ \\
\hline
\end{tabular}

\begin{tabular}{|l|l|c|c|c|c|c|c|c|}
\hline $\begin{array}{l}\text { Between } \\
\text { Story } \\
\text { Variability }\end{array}$ & $\begin{array}{l}\text { Variable } \\
\text { Name }\end{array}$ & Mean & $\begin{array}{c}\text { Std. } \\
\text { Error }\end{array}$ & $\mathbf{2 . 5 0 \%}$ & $\mathbf{2 5 \%}$ & Median & $\mathbf{7 5 \%}$ & $\mathbf{9 7 . 5 0 \%}$ \\
\cline { 2 - 9 } & sigmaFN & 0.078 & 0.158 & 0.002 & 0.019 & 0.044 & 0.088 & 0.349 \\
\hline
\end{tabular}




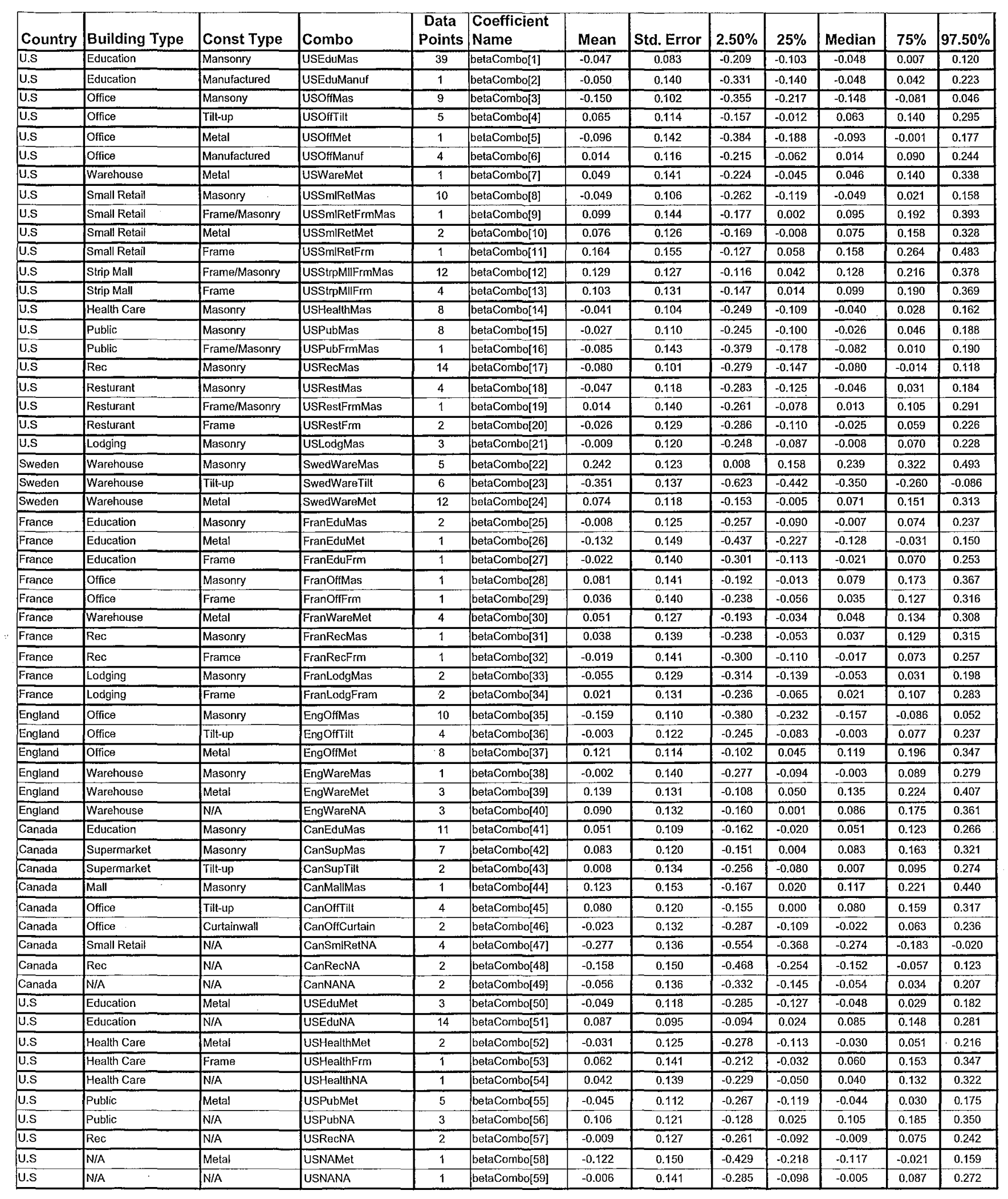

\begin{tabular}{|l|l|r|r|r|r|r|r|r|}
\hline $\begin{array}{l}\text { Between } \\
\begin{array}{l}\text { Combo } \\
\text { Variability }\end{array}\end{array}$ & $\begin{array}{l}\text { Variable } \\
\text { Name }\end{array}$ & Mean & Std. Error & $2.50 \%$ & $25 \%$ & Median & \multicolumn{1}{c|}{$\mathbf{7 5 \%}$} & $\mathbf{9 7 . 5 0 \%}$ \\
\cline { 2 - 9 } & SigmaCombo & 0.165 & 0.034 & 0.100 & 0.142 & 0.163 & 0.186 & 0.236 \\
\hline
\end{tabular}




\section{APPENDIX III: COMMERCIAL BUILDING DATA}

STUDY_ID

SOURCE CY Shaw and $L$ Jones, "Air tightness and air infiltration of school buildings", ASHRAE Transactions, Vol 85, Part I, p.85-95 COUNTRY Canada STUDY_YEAR 1979

DATA_TABLE

$\begin{array}{cr} & \begin{array}{r}\text { FloorArea } \\ \text { [m2] }\end{array} \\ \text { A } & 2694 \\ \text { B } & 1858 \\ \text { C } & 3771 \\ \text { D } & 3493 \\ \text { E } & 3689 \\ \text { F } & 3093 \\ \text { G } & 5388 \\ \text { H } & 5156 \\ \text { I } & 2620 \\ \text { J } & 3003 \\ \text { K } & 3219\end{array}$

Height
[m]
4.3
4
3.4
3.8
3.8
3.7
3.7
4
3.8
4
3.8

STANDARDIZED_TABLE

$\begin{array}{cccc} & \text { EntrylD } & \text { FootprintArea } & \text { FloorArea } \\ \text { A } & 1 & 2694 & 2694 \\ \text { B } & 2 & 1858 & 1858 \\ \text { C } & 3 & 3771 & 3771 \\ \text { D } & 4 & 3493 & 3493 \\ \text { E } & 5 & 3689 & 3689 \\ \text { F } & 6 & 3093 & 3093 \\ \text { G } & 7 & 5388 & 5388 \\ \text { H } & 8 & 5156 & 5156 \\ \text { I } & 9 & 2620 & 2620 \\ \text { J } & 10 & 3003 & 3003 \\ \text { K } & 11 & 3219 & 3219\end{array}$

NOTES

(1) FloorArea $=L^{*} W^{*} n$

(2) EnvelopeArea $=2^{*} H^{*}(L+W$

Assuming all buildings are single-storey i.e. $n=1$ (by inspection of $H$ ) Solve for $W$ using (1) and (2)

$W^{\wedge} 2$ - (EnvelopeArea/2H) ${ }^{*} W+$ FloorArea $=0$

The aspect ratios of $W$ to $L$ look off... it is plausible that the

reported $\mathrm{H}$ is slightly too low for this calculation

$$
\text { If | set: }
$$$$
H=H^{*} \text { factor }
$$

Then I get slightly 'more reasonable' results

ELA50 is normalized by the 'exterior wall area', assumed that this

includes the window area' because this seems to be the intention of the of authors in their Table 1

$\begin{array}{cccccccc}\begin{array}{c}\text { Volume } \\ \text { [m3] }\end{array} & \begin{array}{c}\text { ELA50 } \\ \text { [m3/s/m2] }\end{array} & \text { Year Built } & \text { Year Tested } & \text { Building Type } & \text { Const Type } & \text { Country US State } \\ 11495 & 0.0067 & 1970 & 1976 & \text { Education } & \text { Masonry } & \text { Canada n/a } \\ 7361 & 0.00475 & 1971 & 1976 & \text { Education } & \text { Masonry } & \text { Canada n/a } \\ 12644 & 0.0065 & 1965 & 1976 & \text { Education } & \text { Masonry } & \text { Canada n/a } \\ 13307 & 0.009 & 1973 & 1976 & \text { Education } & \text { Masonry } & \text { Canada n/a } \\ 14054 & 0.0056 & 1957 & 1976 & \text { Education } & \text { Masonry } & \text { Canada n/a } \\ 11314 & 0.00483 & 1952 & 1976 & \text { Education } & \text { Masonry } & \text { Canada n/a } \\ 19706 & 0.00567 & 1968 & 1976 & \text { Education } & \text { Masonry } & \text { Canada n/a } \\ 20427 & 0.00425 & 1965 & 1976 & \text { Education } & \text { Masonry } & \text { Canada n/a } \\ 9980 & 0.0086 & 1968 & 1976 & \text { Education } & \text { Masonry } & \text { Canada n/a } \\ 11900 & 0.0067 & 1972 & 1976 & \text { Education } & \text { Masonry } & \text { Canada n/a } \\ 12263 & 0.00467 & 1968 & 1976 & \text { Education } & \text { Masonry } & \text { Canada n/a }\end{array}$

$\begin{array}{cc}\text { SurfaceArea } & \text { Volume } \\ 3869 & 11495 \\ 2994 & 7361 \\ 5646 & 12644 \\ 5103 & 13307 \\ 5791 & 14054 \\ 4349 & 11314 \\ 7355 & 19706 \\ 6769 & 20427 \\ 3861 & 9980 \\ 4368 & 11900 \\ 5034 & 12263\end{array}$

\section{Nfloors}

Height

2644

13307

314

19706

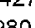

11900
12263

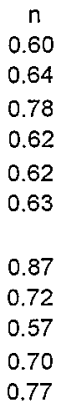

$\begin{array}{cccc}\text { Width } & \text { Length } & \text { DeltaP } & Q \\ 44.3 & 60.8 & 50 & 7.9 \\ 21.1 & 88.2 & 50 & 5.4 \\ 19.6 & 192.5 & 50 & 12.2 \\ 25.4 & 137.6 & 50 & 14.5 \\ 19.0 & 193.7 & 50 & 11.8 \\ 31.1 & 99.5 & 50 & 6.1 \\ 31.1 & 173.4 & 50 & 11.2 \\ 48.3 & 106.8 & 50 & 6.9 \\ 26.4 & 99.2 & 50 & 10.7 \\ 29.5 & 101.7 & 50 & 9.1 \\ 19.6 & 164.1 & 50 & 8.5\end{array}$

$n$
0.60
0.64
0.78
0.62
0.62
0.63
0.87
0.72
0.57
0.70
0.77

Year_Built
1970
1971
1965
1973
1957
1952

1968
1965
1968
1972
1968

Year_Tested Building_TypeConst_Type Country US_State 1976 1976

1976

1976

1976

1976

1976

1976 
STUDY_ID

SOURCE CY Shaw, "Air tightness: supermarkets and shopping malls", ASHRAE Journal, March 1981, p.44-46

COUNTRY Canada

STUDY_YEAR 1981

DATA TABLE

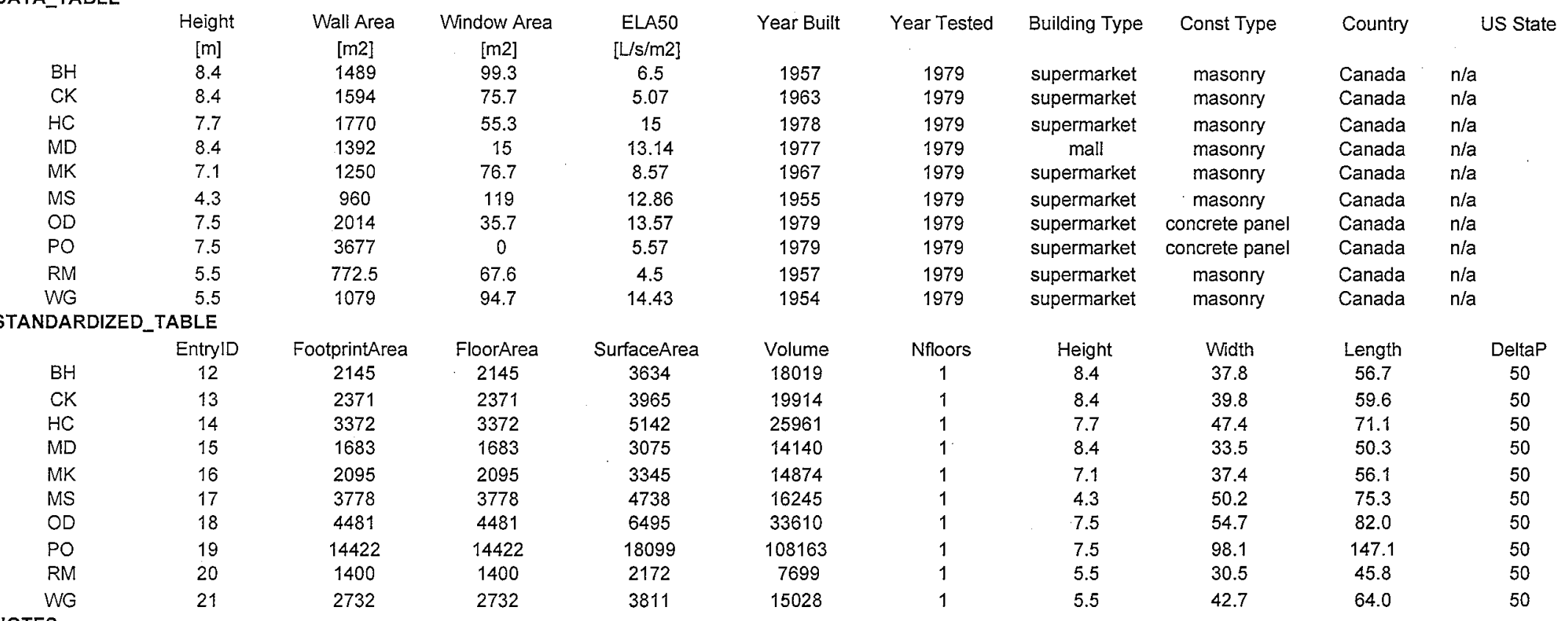

(1) EnvelopeArea $=2^{*} H^{*}(L+W)$

Assuming an aspect ratio of 1.5 , and that Wall area + Window area $=$ Envelope area

$W=($ Wall + Window area $) / 2 / H / 2.5$

Assumed that all buildings are 1-storey (seems reasonable for malls and supermarkets, but some 2-storey or bi-level are certainly plausible)

ELA50 is normalized by the 'exterior wall area', I assumed that this excludes the 'window area' because this seems to be the intention of the of authors in their Table 1

\begin{tabular}{|c|c|c|c|c|c|c|c|c|c|c|}
\hline & & & $Q$ & $\mathrm{n}$ & n_Flag & Year_Built & Year_Tested & Building_Type & Const_Type & Country \\
\hline & Est. Width & Est. Length & 9.7 & 0.57 & $M$ & 1957 & 1979 & 2 & 1 & Canada \\
\hline $\mathrm{BH}$ & 37.8 & 56.7 & 8.1 & 0.62 & $M$ & 1963 & 1979 & 2 & 1 & Canada \\
\hline CK & 39.8 & 59.6 & 26.6 & 0.72 & $\mathrm{M}$ & 1978 & 1979 & 2 & 1 & Canada \\
\hline $\mathrm{HC}$ & 47.4 & 71.1 & 18.3 & 0.56 & $\mathrm{M}$ & 1977 & 1979 & 3 & 1 & Canada \\
\hline MK & 37.4 & 56.1 & 12.3 & 0.67 & $M$ & 1955 & 1979 & 2 & 1 & Canada \\
\hline MS & 50.2 & 75.3 & 27.3 & 0.66 & $M$ & 1979 & 1979 & 2 & 3 & Canada \\
\hline OD & 54.7 & 82.0 & 20.5 & 0.79 & $\mathrm{M}$ & 1979 & 1979 & 2 & 3 & Canada \\
\hline PO & 98.1 & 147.1 & 3.5 & 0.69 & $\mathrm{M}$ & 1957 & 1979 & 2 & 1 & Canada \\
\hline
\end{tabular}


CY Shaw, JT Reardon, "Changes in Airtightness Levels of Six Office Buildings", Airflow Performance of Building Envelopes, Components, and Systems, ASTM STP 1255.

STUDY YEAR 1974

DATA_TABLE

A

$\begin{array}{cr} & \text { Heigh } \\ \text { nfloors } & 0 \\ & {[\mathrm{~m}]} \\ 9 & 4 \\ 17 & 3.4 \\ 20 & 3.2 \\ 21 & 3.2 \\ 16 & 3.2 \\ 25 & 3.2\end{array}$

$\begin{gathered}\text { Height/F] } \\ \text { oor }\end{gathered}$
$[\mathrm{m}]$

Width
[m]
51
27
23
25
25
37

$\begin{array}{cc}\begin{array}{cc}\text { Length } & \text { Wall } \\ \text { Area/Floor }\end{array} \\ {[\mathrm{m}]} & {[\mathrm{m} 2]} \\ 64 & 908 \\ 43 & 466 \\ 28 & 328 \\ 48 & 466 \\ 56 & 525 \\ 44 & 524\end{array}$

Window
$[\%]$
38
33
26
35
52
26

Roof to

ofea
Areall
$[\%]$
31
12
8
11
15
11

ELA50
[L/s/m2]
4.85
2.17
2.54
1.81
1.73
2.49

Year Built
1970
1964
1971
1968
1973
1974

Year
1970
1971
1971
1974
1974
1974

970
971
971
974
974
974

Building

office
office
office
office
office
office

concret panel

curtainwall

curtainwall

$\begin{array}{ll}\text { concret panel } & \text { Canada } \\ \text { concret panel } & \text { Canada }\end{array}$

Country

US Sta:

STANDARDIZED_TABLE

\begin{tabular}{|c|c|c|c|}
\hline Footprint & & SurfaceA & \\
\hline Area & FloorArea & rea & Volume \\
\hline 3264 & 29376 & 10705 & 117504 \\
\hline 1161 & 19737 & 8873 & 67105.8 \\
\hline 644 & 12880 & 7085 & 41216 \\
\hline 1200 & 25200 & 10862 & 80640 \\
\hline 1400 & 22400 & 9660 & 71680 \\
\hline 1628 & 40700 & 14541 & 130240 \\
\hline
\end{tabular}

Nfloors
9
17
20
21
16
25

$\begin{array}{cc}\text { Height } & \text { Width } \\ 36 & 51 \\ 57.8 & 27 \\ 64 & 23 \\ 67.2 & 25 \\ 51.2 & 25 \\ 80 & 37\end{array}$

Assumed that: Height $=$ nfloors ${ }^{*}$ Height/Floor

Assumed that: Volume $=L^{*} W^{*} H$

Assumed that: Footprint Area $=L^{*} W$

Assumed that: FloorArea $=L^{*} W^{*}$ nfloors

Assumed that: SurfaceArea $=$ Wall Area/Floor ${ }^{n} \mathrm{nFloors}+(1+$ Roof to Wall Area Ratio $)$

Assumed that ELA50 is normalized to Wall Area/Floor * nFloor 
STUDY_ID 4

SOURCE RA Grot and AK Persily, "Pressureization testing of federal buildings", Measured Air Leakage of Buildings, ASTM STP 904, p. 151-183.

COUNTRY US

STUDY_YEAR 1986

\section{DATA_TABLE}

$\begin{array}{ccc} & \text { Floor Area } & \text { Volum } \\ & {[\mathrm{m} 2]} & {[\mathrm{m} 3]} \\ \text { Anchorage } & 48470 & 174000 \\ \text { Ann Arbor } & 5270 & 31700 \\ \text { Columbia } & 21600 & 1590 \\ \text { Huron } & 6910 & 27500 \\ \text { Norfolk } & 18570 & 60300 \\ \text { Pittsfield } & 1860 & 852 \\ \text { Springiield } & 14560 & 57700\end{array}$

$\begin{array}{cc}\begin{array}{c}\text { Volume } \\ \text { [m3] }\end{array} & \text { nFloors } \\ 174000 & 4 \\ 31700 & 4 \\ 159000 & 15 \\ 27500 & 4 \\ 60300 & 8 \\ 8520 & 2 \\ 57700 & 5\end{array}$

Q25
[Volume/h]
0.80
0.86
0.67
0.45
1.45
0.95
1.43

$\begin{array}{cc}\text { ELA25 } & \text { SurfaceArea } \\ \text { [m3/h/m2] } & \text { [m2] } \\ 6.7 & 23000 \\ 4.1 & 6630 \\ 6 & 13800 \\ 1.9 & 6620 \\ 7.2 & 12100 \\ 3.5 & 2300 \\ 9.2 & 8940\end{array}$

Year Built
1981
1981
1981
1981
1981
1981
1981

Year Tested
1986
1986
1986
1986
1986
1986
1986

$\begin{array}{ccc}\text { uilding Type } & \text { Const Type } & \text { Country } \\ & & \\ \text { office } & \text { concrete panel } & \text { U.S. } \\ \text { office } & \text { concrete panel } & \text { U.S. } \\ \text { office } & \text { concrete panel } & \text { U.S. } \\ \text { office } & \text { masony } & \text { U.S. } \\ \text { office } & \text { concrete panel } & \text { U.S. } \\ \text { office } & \text { masony } & \text { U.S. } \\ \text { office } & \text { concrete panel } & \text { U.S. }\end{array}$

US State

\section{STANDARDIZED_TABLE}

$\begin{array}{cccccc} & \text { EntrylD } & \text { FootprintArea } & \text { FloorArea } & \text { SurfaceArea } & \text { Volume } \\ \text { Anchorage } & 28 & 11375 & 45500 & 23000 & 174000 \\ \text { Ann Arbor } & 29 & 1225 & 4900 & 6630 & 31700 \\ \text { Columbia } & 30 & 1647 & 24700 & 13800 & 159000 \\ \text { Huron } & 31 & 1605 & 6420 & 6620 & 27500 \\ \text { Norfolk } & 32 & 2162.5 & 17300 & 12100 & 60300 \\ \text { Pittsfield } & 33 & 865 & 1730 & 2300 & 8520 \\ \text { Springfield } & 34 & 2700 & 13500 & 8940 . & 57700\end{array}$

$\begin{array}{cc}\text { Nfloors } & \text { Height } \\ 4 & 15.3 \\ 4 & 25.9 \\ 15 & 96.6 \\ 4 & 17.1 \\ 8 & 27.9 \\ 2 & 9.8 \\ 5 & 21.4 \\ \text { n_Flag } & \text { Year_Built } \\ \text { M } & 1981 \\ \text { M } & 1981 \\ \text { M } & 1981 \\ \text { M } & 1981 \\ \text { M } & 1981 \\ \text { M } & 1981 \\ \text { M } & 1981\end{array}$

Width
81.8
28.6
40.6
40.1
38.0
24.0
47.4
Year_Tested
1986
1986
1986
1986
1986
1986
1986

Length
139.1
42.9
40.6
40.1
57.0
36.0
56.9
Building_Type

DeltaP
25
25
25
25
25
25
25

\section{NOTES}

AF.oors are estimated (at times averaged) according to the building schematic provided Estimated FootprintArea $=$ FloorArea $/ \mathrm{nFloors}$

$$
\text { (1) FloorArea }=L^{*} W^{*} n
$$

Estimated Height $=$ Volume $/$ FloorArea * $n$

Estimate aspect ratio from schematic (many buildings are irregular shaped, but $X$ refers to best approximation of a rectangular building)

Estimated Width $=$ SQRT (Volume $/ H / X)$

Eublication

Estimated Year Built (paper write that all building were built in the last 10 years)

Estimated Construction Type from photographs 
STUDY_ID 5

SOURCE T Brennan, et al. "Fan pressurization of school buildings", ASHRAE

COUNTRY US

STUDY_YEAR 1992

DATA_TABLE

\begin{tabular}{|c|c|c|c|}
\hline & $\begin{array}{l}\text { Surface Area } \\
\text { [m2] }\end{array}$ & $\begin{array}{l}\text { Floor Area } \\
\text { [m2] }\end{array}$ & $\begin{array}{l}\mathrm{C} \\
{\left[\mathrm{m} 3 / h^{\star} \mathrm{Pa} a^{\wedge} n\right]}\end{array}$ \\
\hline Albany & 27872 & 22297 & 15459 \\
\hline Admin & 5853 & 8194 & 2564 \\
\hline Argentine & 794 & 688 & 533 \\
\hline BishopRyan & 6875 & 5574 & 1602 \\
\hline CLC. & 3270 & 4645 & 449 \\
\hline GreenMtn & 2027 & 2369 & 2732 \\
\hline GmMitnGym & 1672 & 929 & 2232 \\
\hline Laurel & 3468 & 1517 & 1828 \\
\hline MiddleSchool & 9142 & 7172 & 9390 \\
\hline Spines & 5704 & 4422 & 860 \\
\hline STamaGym & 1301 & 650 & 1038 \\
\hline Russell & 4181 & 3252 & 907 \\
\hline Velva & 6875 & 5574 & 4372 \\
\hline
\end{tabular}

\section{$\mathrm{ACH} 25 \quad$ Year Built}

$\begin{array}{rr}0.7 & 2 . \\ 0.34 & 0.3 \\ 0.63 & 1.33 \\ 0.82 & 1.3 \\ 0.75 & 0.35 \\ 0.46 & 1 . \\ 0.52 & 2.1 \\ 0.44 & 1.08 \\ 0.61 & 3.03 \\ 0.76 & 0.73 \\ 0.5 & 2 . \\ 0.99 & 2.24 \\ 0.63 & 1.04\end{array}$

\section{STANDARDIZED_TABLE}

$\begin{array}{cccc} & \text { EntrylD } & \text { FootprintArea } & \text { FloorArea } \\ \text { Albany } & 35 & 22297 & 22297 \\ \text { Admin } & 36 & 4097 & 8194 \\ \text { Argentine } & 37 & 344 & 688 \\ \text { BishopRyan } & 38 & 5574 & 5574 \\ \text { CLC } & 39 & 2322.5 & 4645 \\ \text { GreenMtn } & 40 & 1184.5 & 2369 \\ \text { GmMtnGym } & 41 & 464.5 & 929 \\ \text { Laurel } & 42 & 1517 & 1517 \\ \text { MiddleSchool } & 43 & 7172 & 7172 \\ \text { Spines } & 44 & 4422 & 4422 \\ \text { STamaGym } & 45 & 650 & 650 \\ \text { Russell } & 46 & 3252 & 3252 \\ \text { Velva } & 47 & 5574 & 5574\end{array}$

\section{NOTES}

Estimated that $\mathrm{ACH} 25[\mathrm{~h}-1]=\mathrm{C}\left[\mathrm{m} 3 / h^{*} \mathrm{~Pa} a^{\wedge} \mathrm{n}\right]^{*}(25 \mathrm{~Pa})^{\wedge} \mathrm{n} /$ Volume

$$
\text { Therefore, Volume }=\mathrm{ACH} 25 / \mathrm{C}^{*} 25^{\wedge} \mathrm{n}
$$

$$
\text { (1) } V=L^{*} W^{*} H
$$

(2) SurfaceArea $=2^{*} H^{*}(L+W)+L^{*} W$

$$
\text { (3) FloorArea }=L^{*} W^{*} n
$$

Estimate Height/Floors by: Volume / FloorArea

Seems like all school buildings are 1 story $=>H=$ Height/Floors

$2^{*} \mathrm{H}^{*} \mathrm{~W}^{\wedge} 2+(\mathrm{FA} / \mathrm{n}-\mathrm{SA})^{*} \mathrm{~W}+2^{*} \mathrm{H}^{*} \mathrm{FA} / \mathrm{n}=0$

where $F A=$ FloorArea, $S A=$ SurfaceArea, and $n=$ number of floors

BUT... I don't get reasonable aspect ratio this way.

Try another method. Let's just assume that $X=1.5$ and see if $W$ and $L$ fits

Assumed Year Tested in same year and journal publication

SurfaceArea
27872
5853
794
6875
3270
2027
1672
3468
9142
5704
1301
4181
6875
$n$

$\begin{array}{cc}\text { Volume } & \text { Nfloors } \\ 66883 & 1.00 \\ 25533 & 2.00 \\ 3045 & 2.00 \\ 17260 & 1.00 \\ 14343 & 2.00 \\ 8640 & 2.00 \\ 5614 & 2.00 \\ 6977 & 1.00 \\ 22078 & 1.00 \\ 13602 & 1.00 \\ 1966 & 1.00 \\ 9802 & 1.00 \\ 17123 & 1.00 \\ n \text { Flag } & \text { Year_Built } \\ M & n / a \\ M & n / a \\ M & n / a \\ M & n / a \\ M & n / a \\ M & n / a \\ M & n / a \\ M & n / a \\ M & n / a \\ M & n / a \\ M & n / a \\ M & n / a \\ M & n / a\end{array}$

$n / a$
$n / a$
$n / a$
$n / a$
$n / a$
$n / a$
$n / a$
$n / a$
$n / a$
$n / a$
$n / a$
$n / a$

\section{Year Tested}

1992
1992
1992
1992
1992
1992
1992
1992
1992
1992
1992
1992
1992
Educationa
Educational
Educational
Educational
Educational
Educational
Educational
Educational
Educational
Educational
Educational
Educational

Educational

Const Type

Country

masonry

masonry

masonry

masonry

masonry

masonry

masonry

masonry

masonry

masonry

masonry

US State

\begin{tabular}{cc} 
Height & Widt \\
3.0 & 121. \\
6.2 & 52.3 \\
8.9 & 15.1 \\
3.1 & 61.0 \\
6.2 & 39.3 \\
7.3 & 28.1 \\
12.1 & 17. \\
4.6 & 31. \\
3.1 & 69.1 \\
3.1 & 54.3 \\
3.0 & 20.8 \\
3.0 & 46. \\
3.1 & 61.0 \\
\hline
\end{tabular}

$\begin{array}{cr}\text { Width } & \text { Len } \\ 121.9 & 182.9 \\ 52.3 & 78.4 \\ 15.1 & 22.7 \\ 61.0 & 91.4 \\ 39.3 & 59.0 \\ 28.1 & 42.2 \\ 17.6 & 26.4 \\ 31.8 & 47.7 \\ 69.1 & 103.7 \\ 54.3 & 81.4 \\ 20.8 & 31.2 \\ 46.6 & 69.8 \\ 61.0 & 91.4\end{array}$

\begin{tabular}{c} 
Length \\
182.9 \\
78.4 \\
22.7 \\
91.4 \\
59.0 \\
42.2 \\
26.4 \\
47.7 \\
103.7 \\
81.4 \\
31.2 \\
69.8 \\
91.4 \\
\hline
\end{tabular}

$\begin{array}{cc}\text { DeltaP } & \text { Q } \\ 25 & 40.9 \\ 25 & 2.1 \\ 25 & 1.1 \\ 25 & 6.2 \\ 25 & 1.4 \\ 25 & 3.3 \\ 25 & 3.3 \\ 25 & 2.1 \\ 25 & 18.6 \\ 25 & 2.8 \\ 25 & 1.4 \\ 25 & 6.1 \\ 25 & 9.2 \\ \text { Country } & \text { US_State } \\ \text { U.S. } & n / a \\ \text { U.S. } & n / a \\ \text { U.S. } & n / a \\ \text { U.S. } & n / a \\ \text { U.S. } & n / a \\ \text { U.S. } & n / a \\ \text { U.S. } & n / a \\ \text { U.S. } & n / a \\ \text { U.S. } & n / a \\ \text { U.S. } & n / a \\ \text { U.S. } & n / a \\ \text { U.S. } & n / a \\ \text { U.S. } & n / a\end{array}$

Year_Tested

1992

1992

1992
1992

1992

1992

1992

1992

1992

1992

1992
1992

1992

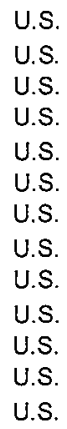

$\mathrm{n} / \mathrm{a}$

n/a

n/a

n/a

n/a

na

$\mathrm{n} / \mathrm{a}$ 
STUDY_ID 6

SOURCE Leif I. Lundin, "Air leakage in industrial bulidings - description of equipment", Measured Air Leakage of Buildings,

COUNTRY Sweden ASTM STP 904, HR Trechsel and PL Lagus, Eds., ASTM, Philadelphia, 1986, p. 101-105

STUDY_YEAR 1986

DATA_TABLE

\begin{tabular}{|c|c|c|c|c|c|c|c|c|c|}
\hline $\begin{array}{c}\text { FloorArea } \\
\text { [m2] }\end{array}$ & $\begin{array}{c}\text { EnvelopeArea } \\
{[\mathrm{m} 2]}\end{array}$ & $\begin{array}{c}\text { Volume } \\
\text { [m3] }\end{array}$ & $\begin{array}{l}\text { Mean ELA } \\
{[\mathrm{m} 3 / \mathrm{h} / \mathrm{m} 2]}\end{array}$ & - Year Built & Year Tested & Building Type & Const Type & Country & US State \\
\hline 4137 & 6796 & 36373 & 7.9 & $\mathrm{n} / \mathrm{a}$ & 1986 & warehouse & concrete panel & Sweden & $\mathrm{n} / \mathrm{a}$ \\
\hline 6524 & 9876 & 61127 & 6 & $n / a$ & 1986 & warehouse & concrete panel & Sweden & $\mathrm{n} / \mathrm{a}$ \\
\hline 4236 & 5809 & 31622 & 3 & $\mathrm{n} / \mathrm{a}$ & 1986 & warehouse & metal panel & Sweden & $n / a$ \\
\hline 1840 & 3150 & & 5.4 & $\mathrm{n} / \mathrm{a}$ & 1986 & warehouse & metal panel & Sweden & $n / a$ \\
\hline 1265 & 2100 & 8535 & 4.3 & $n / a$ & 1986 & warehouse & metal panel & Sweden & $n / a$ \\
\hline 1620 & 2650 & 10050 & 3.1 & $n / a$ & 1986 & warehouse & concrete panel & Sweden & $\mathrm{n} / \mathrm{a}$ \\
\hline 1025 & 1960 & 6275 & 5 & $n / a$ & 1986 & warehouse & concrete panel & Sweden & $\mathrm{n} / \mathrm{a}$ \\
\hline 1846 & 2950 & 12528 & 2.5 & $\mathrm{n} / \mathrm{a}$ & 1986 & warehouse & concrete panel & Sweden & $n / a$ \\
\hline 4140 & 6804 & 29975 & 2.1 & $\mathrm{n} / \mathrm{a}$ & 1986 & warehouse & concrete panel & Sweden & $\mathrm{n} / \mathrm{a}$ \\
\hline
\end{tabular}

\section{STANDARDIZED_TABLE}

$\begin{array}{ccc}\text { EntrylD } & \text { FootprintArea } & \text { FloorArea } \\ 48 & 4609 & 4137 \\ 49 & 6864 & 6524 \\ 50 & 3681 & 4236 \\ 51 & 1840 & 1840 \\ 52 & 996 & 1265 \\ 53 & 1635 & 1620 \\ 54 & 1229 & 1025 \\ 55 & 1715 & 1846 \\ 56 & 5089 & 4140\end{array}$

$\begin{array}{cc}\text { SurfaceArea } & \text { Volume } \\ 6796 & 36373 \\ 9876 & 61127 \\ 5809 & 31622 \\ 3150 & 13764 \\ 2100 & 8535 \\ 2650 & 10050 \\ 1960 & 6275 \\ 2950 & 12528 \\ 6804 & 29975 \\ \mathrm{Q} & \mathrm{n} \\ 14.9 & 0.65 \\ 16.5 & 0.65 \\ 4.8 & 0.65 \\ 4.7 & 0.65 \\ 2.5 & 0.65 \\ 2.3 & 0.65 \\ 2.7 & 0.65 \\ 2.0 & 0.65 \\ 4.0 & 0.65\end{array}$

$\begin{array}{cc}\text { Nfloors } & \text { Height } \\ 0.9 & 7.9 \\ 1.0 & 8.9 \\ 1.2 & 8.6 \\ 1.0 & 7.5 \\ 1.3 & 8.6 \\ 1.0 & 6.1 \\ 0.8 & 5.1 \\ 1.1 & 7.3 \\ 0.8 & 5.9\end{array}$

NOTES

Year Tested assumed ot by date of journal publication

$$
\text { (1) FloorArea }=L^{*} W^{*} n
$$

(3) Volume $=H^{*} L^{*} W$

Assuming an aspect ratio of $x=1.5$, i.e. $L=1.5^{*} \mathrm{~W}$

Solve for W using (2) and (3)

n_Flag - Year_Built

$\begin{array}{ll}A & n / a \\ A & n / a \\ A & n / a \\ A & n / a \\ A & n / a \\ A & n / a \\ A & n / a \\ A & n / a\end{array}$

\begin{tabular}{c} 
Width \\
55.4 \\
67.6 \\
49.5 \\
35.0 \\
25.8 \\
33.0 \\
28.6 \\
33.8 \\
58.2 \\
Year_Tested \\
\hline 1986 \\
1986 \\
1986 \\
1986 \\
1986 \\
1986 \\
1986 \\
1986 \\
1986
\end{tabular}

$\begin{array}{cc}\text { Length } & \text { DeltaP } \\ 83.1 & 50 \\ 101.5 & 50 \\ 74.3 & 50 \\ 52.5 & 50 \\ 38.6 & 50 \\ 49.5 & 50 \\ 42.9 & 50 \\ 50.7 & 50 \\ 87.4 & 50\end{array}$

Use 3Roots. R to solve this cubic equation to get W (1st root used (2nd root is -ve, and 3rd root too small (i.e. H too large: can't be 10 storey?)

Setting $L=1.5^{*} \mathrm{~W}$, find $\mathrm{H}$ by $(3)$

Use (1) to find number of storey $n$ 
STUDY_ID 7

SOURCE IN Potter, TJ Jones, WB Booth, "Air leakage of office buildings", Technical Note TN 8/95, BSRIA.

DATA_TABLE

$\begin{array}{cr} & \text { Envelop } \\ & {[\mathrm{m}]} \\ 1 & 881 \\ 2 & 51 \\ 3 & 891 \\ 4 & 4457 \\ 5 & 4508 \\ 6 & 2689 \\ 7 & 3328 \\ 8 & 4783 \\ 9 & 8810 \\ 10 & 2786 \\ 11 & 5504 \\ 12 & 4724 \\ \end{array}$

$\begin{array}{cc}\begin{array}{c}\text { FloorArea } \\ \text { [m2] }\end{array} & \text { Height } \\ 616 & {[\mathrm{~m}]} \\ 2972 & 6.1 \\ 12474 & 8.5 \\ 2476.5 & 18.9 \\ 6666 & 7 \\ 3093 & 14.5 \\ 4884 & 10.3 \\ 6875 & 20 \\ 6174 & 18.3 \\ 1047 & 11.4 \\ 5727.5 & 10.1 \\ 4632.5 & 13.6 \\ & 10\end{array}$

Volume
$[\mathrm{m} 3]$
1951
14109
39149
14855
16571
10590
15360
21008
44335
10357
20379
17577

$\begin{array}{cc}\text { nFloors } & \begin{array}{c}\text { Q50 } \\ \text { [m3/s] }\end{array} \\ 2 & 2.47 \\ 2 & 16.78 \\ 5.5 & 29.94 \\ 1.5 & 37.38 \\ 6 . & 18.89 \\ 3 & 17.63 \\ 6 & 37.06 \\ 5 & 15.94 \\ 2 & 47.09 \\ & 13.38 \\ 2.5 & 49.89 \\ 2.5 & 48.98\end{array}$

$\begin{array}{cc}n & \text { Year Built } \\ & \\ 0.61 & 1970 \\ 0.59 & 1900 \\ 0.52 & 1991 \\ 0.52 & 1985 \\ 0.6 & 1963 \\ 0.48 & 1991 \\ 0.52 & 1986 \\ 0.53 & 1989 \\ 0.61 & 1991 \\ 0.54 & 1990 \\ 0.67 & 1992 \\ 0.49 & 1992\end{array}$

Year Tested

Building Type

Const Type

Country

US State

STANDARDIZED_TABLE

$\begin{array}{cccccc} & \text { EntrylD } & \text { FootprintArea } & \text { FloorArea } & \text { SurfaceArea } & \text { Volum } \\ 1 & 57 & 308 & 616 & 881.5 & 1951 \\ 2 & 58 & 1486 & 2972 & 5131 & 14109 \\ 3 & 59 & 2268 & 12474 & 8932 & 39149 \\ 4 & 60 & 1651 & 2476.5 & 4457 & 14855 \\ 5 & 61 & 1111 & 6666 & 4508 & 1657 \\ 6 & 62 & 1031 & 3093 & 2689 & 10590 \\ 7 & 63 & 814 & 4884 & 3328 & 15360 \\ 8 & 64 & 1375 & 6875 & 4783 & 21008 \\ 9 & 65 & 3087 & 6174 & 8810 & 44335 \\ 10 & 66 & 349 & 1047 & 2786 & 10357 \\ 11 & 67 & 2291 & 5727.5 & 5504 & 20379 \\ 12 & 68 & 1853 & 4632.5 & 4724 & 17577\end{array}$

NOTES
(1) Envelope Area $=2^{*} H^{*}(L+W)+L^{*} W$
(2) Floor Area $=n^{*} L^{*} W$
(3) Volume $=H^{*} L^{*} W$

It seems like the 'EnvelopeArea' reported include roof. Assuming that $X=1.5$,

"Victorian" construction date assumed to be 1900

"mid-1990s" testing date assumed to be 1995

Building \#10 has no number of storey.

Assumed it is a 3 -storey building (it has height similar to $\# 6, \# 9$, \#12)

Height
6.1
8.5
18.9
7
14.5
10.3
20
18.3
11.4
10.1
13.6
10

Width
14.6
33.3
37.2
37.6
27.6
26.2
22.6
27.7
50.9
26.1
31.6
34.2
ear Built

Year_Built

$$
1970
$$

1900

199

1985
1963

1963

1986
1989

1989

1991
1990
1992

1992

$$
\begin{aligned}
& 1995 \\
& 1995 \\
& 1995 \\
& 1995 \\
& 1995 \\
& 1995 \\
& 1995 \\
& 1995 \\
& 1995 \\
& 1995 \\
& 1995 \\
& 1995
\end{aligned}
$$

office

office

office
office
office

office

office

office

office

office

office

office

concrete panels

masonry

masonry

concrete panels

metal frame

metal frame

metal frame

metal frame

metal frame

England

England $\quad n / a$

England $\quad n / a$

England $\quad n / a$

England $\quad n / a$

England $\quad n / a$

England $\quad n / a$

England $\quad \mathrm{n} / \mathrm{a}$

England $\quad n / a$

England $\quad n / a$

England

n/a

Length DeltaP

21.9

DeltaP
50

49.9

55.7

41.4

39.3

39.3
33.9

41.5

76.4

39.2

47.4
51.3

Year_Tested

1995

1995

1995

1995

1995
1995

1995

1995

1995

1995
1995

1995

$$
\begin{gathered}
Q \\
2.47 \\
16.78 \\
29.94 \\
37.38 \\
18.89 \\
17.63 \\
37.06 \\
15.94 \\
47.09 \\
13.38 \\
49.89 \\
48.98
\end{gathered}
$$

Building_Type

Const_Type

$\begin{array}{cc}n & n \_F l a g \\ 0.61 & M \\ 0.59 & M \\ 0.52 & M \\ 0.52 & M \\ 0.6 & M \\ 0.48 & M \\ 0.52 & M \\ 0.53 & M \\ 0.61 & M \\ 0.54 & \mathrm{M} \\ 0.67 & \mathrm{M} \\ 0.49 & \mathrm{M} \\ \text { Country } & \mathrm{US} \text { State } \\ \text { England } & \mathrm{n} / \mathrm{a} \\ \text { England } & \mathrm{n} / \mathrm{a} \\ \text { England } & \mathrm{n} / \mathrm{a} \\ \text { England } & \mathrm{n} / \mathrm{a} \\ \text { England } & \mathrm{n} / \mathrm{a} \\ \text { England } & \mathrm{n} / \mathrm{a} \\ \text { England } & \mathrm{n} / \mathrm{a} \\ \text { England } & \mathrm{n} / \mathrm{a} \\ \text { England } & \mathrm{n} / \mathrm{a} \\ \text { England } & \mathrm{n} / \mathrm{a} \\ \text { England } & \mathrm{n} / \mathrm{a} \\ \text { England } & \mathrm{n} / \mathrm{a}\end{array}$




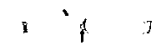

STUDY_ID 8

SOURCE JB Cummings, CR Withers, N Moyer, P Fairey, B McKendry, "Uncontrolled air flow in non-residential buildings", Florida Solar Energy Center

STUDY YEAR 199

DATA_TABLE

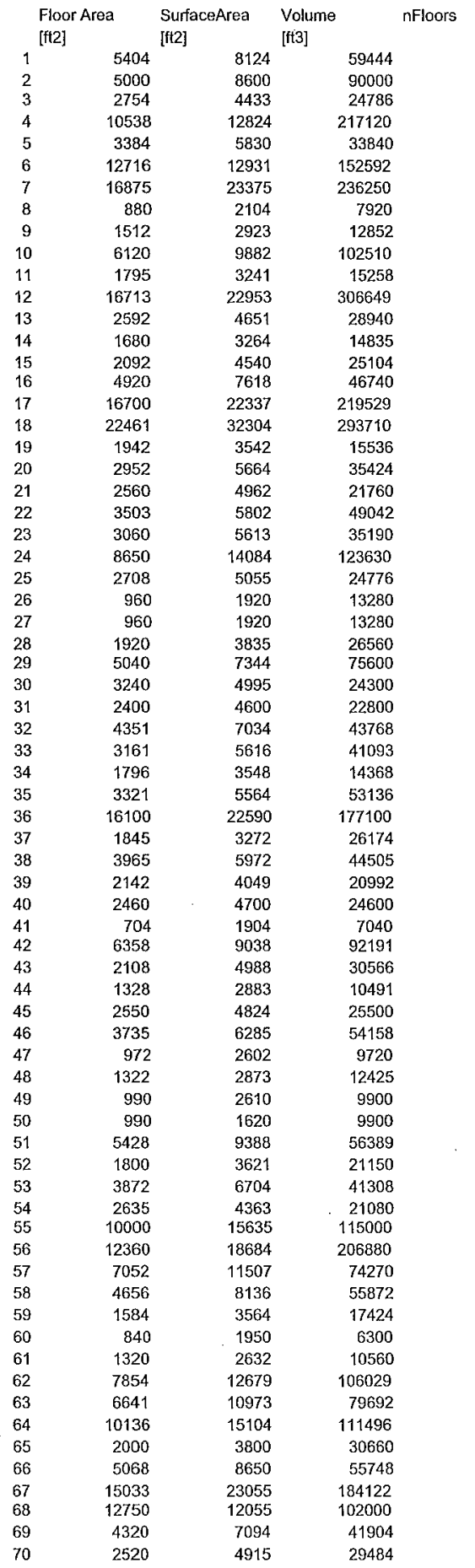

28.31684659

171.0833333
050

1980

88260.5

9618

6193

27583

3926
3265

11195

7472

22383
12161

2051

4371
4898

18607

17521

4137

3296
9005

2164

11845

2565

12987
5714

5667

7848

16727

20385

6651
8426

8426
6995
6145

6145

3689
11993

11993
2241

3056

5879

10646

3394
20201

20201
15625

7560

9133

32886
5012

Year Built Year Tested

$1965 \quad 1996$

$\begin{array}{ll}1965 & 1996 \\ 1992 & 1996 \\ 1970 & 1996\end{array}$

$\begin{array}{ll}1970 & 1996 \\ 1959 & 1996\end{array}$

1961

$1968 \quad 1996$

$\begin{array}{ll}1968 & 1996 \\ 1981 & 1996\end{array}$

$1959 \quad 1996$

$1986 \quad 1996$

$1987 \quad 1996$

$\begin{array}{ll}1987 & 1996 \\ 1970 & 1996\end{array}$

$1990 \quad 1996$

$\begin{array}{ll}1986 & 1996 \\ 1988 & 1996\end{array}$

$1975 \quad 1996$

$1986 \quad 1996$

$1975 \quad 1996$

$\begin{array}{ll}1969 & 1996 \\ 1987 & 1996\end{array}$

$1987 \quad 1996$

$1984 \quad 1996$

$1989 \quad 1996$

$\begin{array}{ll}1987 & 1996 \\ 1994 & 1996\end{array}$

$1994 \quad 1996$

$1994 \quad 1996$

$1983 \quad 1996$

$1941 \quad 1996$

$1986 \quad 1996$

$1994 \quad 1996$

$1931 \quad 1996$

$\begin{array}{ll}1931 & 1996 \\ 1986 & 1996\end{array}$

$1966 \quad 1996$

$1972 \quad 1996$

$1972 \quad 1996$

$\begin{array}{ll}1946 & 1996 \\ 1966 & 1996\end{array}$

$\begin{array}{ll}1966 & 1996 \\ 1966 & 1996\end{array}$

$1966 \quad 1996$

$1966 \quad 1996$

$1966 \quad 1996$

$\begin{array}{ll}1966 & 1996 \\ 1966 & 1996\end{array}$

$\begin{array}{ll}1966 & 1996 \\ 1966 & 1996\end{array}$

$1966 \quad 1996$

$0.57 \quad 1966 \quad 1996$

0.58

0.62

0.62

0.66
0.76
0.6

0.59
0.48

0.48
0.62

0.73

0.61

0.59
0.86

0.46

0.65

0.53

0.45

0.62
0.62

0.65 $\begin{array}{ll}1966 & 1996 \\ 1951 & 1996\end{array}$

$\begin{array}{ll}1951 & 1996 \\ 1964 & 1996\end{array}$

$\begin{array}{ll}1964 & 1996 \\ 1986 & 1996\end{array}$

$\begin{array}{ll}1976 & 1996 \\ 1978 & 1996\end{array}$

$1983 \quad 1996$

$1982 \quad 1996$

$1994 \quad 1996$

$1973 \quad 1996$

$1985 \quad 1996$

$\begin{array}{ll}1983 & 1996 \\ 1963 & 1996\end{array}$

$\begin{array}{ll}1990 & 1996 \\ 1965 & 1996\end{array}$

$1965 \quad 1996$

$1965 \quad 1996$

$1977 \quad 1996$

$\begin{array}{ll}1977 & 1996 \\ 1989 & 1996\end{array}$

$1969 \quad 1996$
Building Type Const Type

office

health masonry

public assembly frame/masonry

office masonry

$\begin{array}{cc}\text { office } & \text { masonry } \\ \text { strip mall } & \text { frame/masonry }\end{array}$

strip mall frame/masonry U.S.

health care masonry U.S.

$\begin{array}{lll}\text { office } & \text { masonry } & \text { U.S. } \\ \text { mall retail } & \text { metal/masonry } & \text { U.S. }\end{array}$

public assembly masonry U.S.

educational masonry US.

educational manufactured

health care masonry

office Manufactured

educational masonry

U.S.

restaurant U.S.

public assembly masonry U.S.

restaurant masonry

warehouse melal

melal U.S.

masonry U.S.

small retail masonry U.S.

strip mall frame U.S.

strip mall frame U.S.

small retail

manufactured

restaurant masonry

restaurant

restaurant

strip mall masonry

restaurant rame/masonry

small retail masony

small retail masonry

small retail

small retail

strip mall

strip mall

strip mall

strip mall frame/masonry

strip mall frame/masonry

strip mall frame/masonry U.S.

strip mall frame/masonry U.S.

strip mall frame/masonry U.S.

strip mall frame/masonry U.S.

office masonry

office

office

small retail

small retail

small retail

recreational

small retail

small retail

office

office

restaurant

public assembly

educational

educational

lodging

lodging

small retail

meta

masonry

metal

metal

masonry

masonry

manufactured frame

masony

masonry

masonry

masonry

masonry

masonry

US State 
STUDY_ID $\quad 2$

SOURCE IN Potter, TJ Jones, "Ventilation heat loss in factories and warehouses", Technical Note TN 7/82, BSRIA

COUNTRY UK

STUDY YEAR 1992

DATA_TABLE

EnvelopeArea FootprintArea Height Volume

$\begin{array}{cc}\text { [m2] } & {[\mathrm{m} 2]} \\ 1262 & 645 \\ 2351 & 1373 \\ 2449 & 1363 \\ 2351 & 1319 \\ 3734 & 1501 \\ 6763 & 4617 \\ 3641 & 2364 \\ 1089 & 447 \\ 1506 & 848 \\ 2685 & 1747 \\ 1771 & 972 \\ 3235 & 2081 \\ 757 & 318 \\ 3471 & 1983\end{array}$

$[\mathrm{m}]$
6.74
6.74
8.75
8.75
16
6.6
6.6
8.5
6.1
6.8
8
8
7
9.75

12.16
12.94

$\begin{array}{ll}19.94 & 0.48 \\ 10.78 & 0.67\end{array}$

$\begin{array}{ll}16.78 & 0.67 \\ 17.02 & 0.57\end{array}$

$17.02 \quad 0.57$

$26.75 \quad 0.61$

$\begin{array}{ll}51.46 & 0.46 \\ 28.6 & 0.52\end{array}$

$13.61 \quad 0.65$

$34.47 \quad 0.46$

$\begin{array}{ll}29.97 & 0.52 \\ 10.73 & 0.58\end{array}$

$\begin{array}{ll}16.73 & 0.58 \\ 29.57 & 0.57\end{array}$

$29.57 \quad 0.57$

2088
17599

$26.64 \quad 0.59$

STANDARDIZED_TABLE

$\begin{array}{ccc}\text { EntrylD } & \text { FootprintArea } & \text { FloorArea } \\ 138 & 645 & 645 \\ 139 & 1373 & 1373 \\ 140 & 1363 & 1363 \\ 141 & 1319 & 1319 \\ 142 & 1501 & 1501 \\ 143 & 4617 & 4617 \\ 144 & 2364 & 2364 \\ 145 & 447 & 447 \\ 146 & 848 & 848 \\ 147 & 1747 & 1747 \\ 148 & 972 & 972 \\ 149 & 2081 & 2081 \\ 150 & 318 & 318 \\ 151 & 1983 & 1983\end{array}$

NOTES

Year Tested assumed ot by date of journal publication

Year Built is not indicated in paper.

Are all these warehouses and factories 1-storey? We'll just assume so.

If we assume that $X=1.5$, we get pretty close to the reported surface area $=)$

$[\mathrm{m} 3]$
3276
7033
10686
10380
19513
30007
15364
3467
4909
10399
6787
14569
2088
17599

Year Built Year Tested Building Type Const Type Country US State

n/a $\quad 1992$

1992 warehouse masonry Sweden n/a

warehouse metalpanels Sweden

warehouse metal panels sweden

warehouse metals

warehouse masonry Sweden n/a

warehouse masonry Sweden n/a

warehouse metal panels Sweden n/a

warehouse metal panels Sweden n/a

warehouse masonry Sweden n/a

warehouse metal panels Sweden n/a

warehouse metal panels Sweden n/a

warehouse metal panels Sweden n/a

warehouse metalpanels Sweden

\begin{tabular}{|c|c|c|c|c|c|c|c|c|}
\hline $\begin{array}{c}\text { SurfaceArea } \\
1262\end{array}$ & $\begin{array}{c}\text { Volume } \\
3276\end{array}$ & Nfloors & $\begin{array}{c}\text { Height } \\
6.74\end{array}$ & $\begin{array}{r}\text { Width } \\
18.0\end{array}$ & $\begin{array}{l}\text { Length } \\
27.0\end{array}$ & $\begin{array}{c}\text { DeltaP } \\
50\end{array}$ & $Q$ & $\begin{array}{c}n \\
0.5\end{array}$ \\
\hline 2351 & 7033 & 1 & 6.74 & 26.4 & 39.6 & 50 & 19.9 & 0.48 \\
\hline 2449 & 10686 & 1 & 8.75 & 28.5 & 42.8 & 50 & 16.8 & 0.67 \\
\hline 2351 & 10380 & 1 & 8.75 & 28.1 & 42.2 & 50 & 17.0 & 0.57 \\
\hline 3734 & 19513 & 1 & 16 & 28.5 & 42.8 & 50 & 26.8 & 0.61 \\
\hline 6763 & 30007 & 1 & 6.6 & 55.1 & 82.6 & 50 & 51.5 & 0.46 \\
\hline 3641 & 15364 & 1 & 6.6 & 39.4 & 59.1 & 50 & 28.6 & 0.52 \\
\hline 1089 & 3467 & 1 & 8.5 & 16.5 & 24.7 & 50 & 13.6 & 0.65 \\
\hline 1506 & 4909 & 1 & 6.1 & 23.2 & 34.7 & 50 & 34.5 & 0.46 \\
\hline 2685 & 10399 & 1 & 6.8 & 31.9 & 47.9 & 50 & 30.0 & 0.52 \\
\hline 1771 & 6787 & 1 & 8 & 23.8 & 35.7 & 50 & 16.7 & 0.58 \\
\hline 3235 & 14569 & 1 & 8 & 34.8 & 52.3 & 50 & 29.6 & 0.57 \\
\hline 757 & 2088 & 1 & 7 & 14.1 & 21.2 & 50 & 9.0 & 0.44 \\
\hline \multirow[t]{6}{*}{3471} & 17599 & 1 & 9.75 & 34.7 & 52.0 & 50 & 26.6 & 0.59 \\
\hline & & n_flag & Year_Built & Year_Tested & Building_Type & Const_Type & Country & US_State \\
\hline & & $M$ & $\bar{n} / a$ & $\overline{1} 992$ & 5 & $\overline{1}$ & Sweden & $\bar{n} / \mathrm{a}$ \\
\hline & & M & $n / a$ & 1992 & 5 & 1 & Sweden & $\mathrm{n} / \mathrm{a}$ \\
\hline & & M & $n / a$ & 1992 & 5 & 4 & Sweden & $\mathrm{n} / \mathrm{a}$ \\
\hline & & M & $n / a$ & 1992 & 5 & 4 & Sweden & $\mathrm{n} / \mathrm{a}$ \\
\hline \multirow[t]{10}{*}{ area $=$ ) } & & M & $n / a$ & 1992 & 5 & 4 & Sweden & $n / a$ \\
\hline & & M & n/a & 1992 & 5 & 1 & Sweden & $n / a$ \\
\hline & & M & n/a & 1992 & 5 & 1 & Sweden & $n / a$ \\
\hline & & M & $n / a$ & 1992 & 5 & 4 & Sweden & $n / a$ \\
\hline & & M & $n / a$ & 1992 & 5 & 4 & Sweden & $\mathrm{n} / \mathrm{a}$ \\
\hline & & M & $n / a$ & 1992 & 5 & 1 & Sweden & $\mathrm{n} / \mathrm{a}$ \\
\hline & & M & $n / a$ & 1992 & 5 & 4 & Sweden & $n / a$ \\
\hline & & M & $n / a$ & 1992 & 5 & 4 & Sweden & $n / a$ \\
\hline & & M & $n / a$ & 1992 & 5 & 4 & Sweden & $n / a$ \\
\hline & & M & $n / a$ & 1992 & 5 & 4 & Sweden & $n / a$ \\
\hline
\end{tabular}


STUDY_ID 10

SOURCE A Litvak, D Boze, M Kilberger, "Airtightness of 12 non residential large buildings results from field measurement studies", 22nd AIVC conference, 11-14 Sept 2001, Bath, UK. COUNTRY France

STUDY_YEAR 2001

\begin{tabular}{|c|c|c|c|c|c|c|c|c|c|c|c|}
\hline ATA_TABLE & $\begin{array}{l}\text { Envelope Area } \\
\text { [m2] }\end{array}$ & $\begin{array}{l}\text { Volume } \\
\text { [m3] }\end{array}$ & & $\begin{array}{l}\text { ELA4 } \\
\text { [m3/h/m2] }\end{array}$ & & Year Built & Year Tested & Building Type & Const Type & Country & US State \\
\hline Foyer CAT & 800 & & 2695 & 7 & 0.53 & 1998 & 2001 & lodging & wood frame & France & $n / a$ \\
\hline Etap Hotel & 520 & & 660 & 2.75 & 0.57 & 1998 & 2001 & lodging & masonry & France & $n / a$ \\
\hline Hotel Parada & 717 & & 2871 & 2.05 & 0.64 & 1998 & 2001 & lodging & masonry & France & $n / a$ \\
\hline Etang du puits & 682 & & 1115 & 1.9 & 0.74 & 1998 & 2001 & lodging & wood frame & France & $\mathrm{n} / \mathrm{a}$ \\
\hline Ecole & 1736 & & 4287 & 1.8 & 0.625 & 1998 & 2001 & educational & wood frame & France & $\mathrm{n} / \mathrm{a}$ \\
\hline College Joilot-Curi & 1602 & & 4862 & 2.05 & 0.69 & 1998 & 2001 & educational & masonry & France & $n / a$ \\
\hline Ecole & 2045 & & 4563 & 1.25 & 0.77 & 1998 & 2001 & educational & masonry & France & $n / a$ \\
\hline Lycee Millitaire & 2473 & & 7426 & 0.8 & 0.58 & 1998 & 2001 & educational & metal frame & France & $n / a$ \\
\hline ONF & 878 & & 1809 & 4.3 & 0.64 & 1998 & 2001 & office & wood frame & France & $\mathrm{n} / \mathrm{a}$ \\
\hline CMR & 685 & & 1688 & 6.15 & 0.55 & 1998 & 2001 & office & masonry & France & $\mathrm{n} / \mathrm{a}$ \\
\hline Salle municipale & 814 & & 1702 & 3.2 & 0.58 & 1998 & 2001 & recreational & wood frame & France & $n / a$ \\
\hline Cosec & 1245 & & 3306 & 4 & 0.6 & 1998 & 2001 & recreational & masonry & France & $n / a$ \\
\hline
\end{tabular}

STANDARDIZED_TABLE

$\begin{array}{cccccc} & \text { EntrylD } & \text { FootprintArea } & \text { FloorArea } & \text { SurfaceArea } & \text { Volume } \\ \text { Foyer CAT } & 152 & 312 & 623 & 800 & 2695 \\ \text { Etap Hotel } & 153 & 382 & 382 & 520 & 660 \\ \text { Hotel Parada } & 154 & 325 & 650 & 717 & 2871 \\ \text { Etang du puits } & 155 & 473 & 473 & 682 & 1115 \\ \text { Ecole } & 156 & 1239 & 1239 & 1736 & 4287 \\ \text { ollege Joilot-Curie } & 157 & 962 & 962 & 1602 & 4862 \\ \text { Ecole } & 158 & 1576 & 1576 & 2045 & 4563 \\ \text { Lycee Millitaire } & 159 & 1748 & 1748 & 2473 & 7426 \\ \text { ONF } & 160 & 568 & 568 & 878 & 1809 \\ \text { CMR } & 161 & 242 & 484 & 685 & 1688 \\ \text { Salle municipale } & 162 & 505 & 505 & 814 & 1702 \\ \text { Cosec } & 163 & 753 & 753 & 1245 & 3306\end{array}$

Niloors
2
1
2
1
1
1
1
1
1
2
1
1

NOTES

Paper states "buildings measured between 11/00 and 06/01." Year Tested assumed to be 2001 Paper states "building $<5$ years old." Year Built assumed to be 1998

(1) Envelope Area $=2^{*} H^{*}(L+W)+L^{*} W$

(2) Volume $=H^{*} L^{*} W$

If we assume that $X=1.5$

(1) and (2) reduce to:

$1.5^{*}\left(W^{*} 3\right)-$ EnvelopeArea* $W+10 / 3^{*}$ Volume $=0$

\begin{tabular}{|c|c|c|c|c|c|c|}
\hline Height & Width & Length & DeltaP & $Q$ & & \\
\hline 8.6 & 14.4 & 21.6 & 4 & 1.56 & & \\
\hline 2.5 & 16.0 & 23.9 & 4 & 0.40 & & \\
\hline 8.8 & 14.7 & 22.1 & 4 & 0.41 & & \\
\hline 2.4 & 17.8 & 26.6 & 4 & 0.36 & & \\
\hline 3.5 & 28.7 & 43.1 & 4 & 0.87 & & \\
\hline 5.1 & 25.3 & 38.0 & 4 & 0.91 & & \\
\hline 2.9 & 32.4 & 48.6 & 4 & 0.71 & & \\
\hline 4.2 & 34.1 & 51.2 & 4 & 0.55 & & \\
\hline 3.2 & 19.5 & 29.2 & 4 & 1.05 & & \\
\hline 7.0 & 12.7 & 19.1 & 4 & 1.17 & & \\
\hline 3.4 & 18.3 & 27.5 & 4 & 0.72 & & \\
\hline 4.4 & 22.4 & 33.6 & 4 & 1.38 & & \\
\hline$n$ & n_Flag & Year_Built & Year_Tested & Building_Type & Const_Type & Country \\
\hline 0.53 & $M$ & 1998 & 2001 & 12 & & 7 France \\
\hline 0.57 & $M$ & 1998 & 2001 & 12 & & 1 France \\
\hline 0.64 & $M$ & 1998 & 2001 & 12 & & 1 France \\
\hline 0.74 & M & 1998 & 2001 & 12 & & 7 France \\
\hline 0.625 & $M$ & 1998 & 2001 & 1 & & 7 France \\
\hline 0.69 & M & 1998 & 2001 & 1 & & 1 France \\
\hline 0.77 & M & 1998 & 2001 & 1 & & 1 France \\
\hline 0.58 & M & 1998 & 2001 & 1 & & 4 France \\
\hline 0.64 & M & 1998 & 2001 & 4 & & 7 France \\
\hline 0.55 & $M$ & 1998 & 2001 & 4 & & 1 France \\
\hline 0.58 & M & 1998 & 2001 & 10 & & 7 France \\
\hline 0.6 & $M$ & 1998 & 2001 & 10 & & 1 France \\
\hline
\end{tabular}


STUDY_ID 11

SOURCE E. Flury et al. "Theoretical and field study of air change in industrial buildings," 19th AlVC Conference, Oslo, Norway, 28-30 September, 1998.

COUNTRY France

STUDY_YEAR 1998

DATA_TABLE

Building

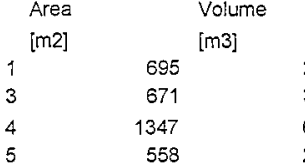

Q50 (inc. P) $\quad Q 50$ (dec. P) $\quad$ Average $Q 50 \quad n$ (inc. P) $\quad n$ (dec. P) $[\mathrm{m} 3 / \mathrm{h}$

32378

$\begin{array}{rr}\text { Q50 } & n \text { (inc. P) } \\ 31302.5 & \\ 27248.5 & 0.55 \\ 23771 & 0.79 \\ 45826.5 & 0.81\end{array}$
$\begin{array}{ll}2967 & 30227 \\ 3086 & 27637\end{array}$

6957

27637
23705
44930

26860

23837

45826.5

0.55
0.68
0.79

0.79
0.81

$\begin{array}{lr}0.65 & 0.6 \\ 0.68 & 0.68\end{array}$

0.68

0.82

0.79
0.815

Year Tested

Building Type

Const Type

Country

US State

STANDARDIZED_TABLE

$\begin{array}{cc} & \text { Entry|D } \\ 1 & 164 \\ 3 & 165 \\ 4 & 166 \\ 5 & 167\end{array}$

$\begin{array}{cc}\text { FootprintArea } & \text { FloorArea } \\ 695 & 695 \\ 671 & 671 \\ 1347 & 1347 \\ 558 & 558\end{array}$

$\begin{array}{cc}\text { SurfaceArea } & \text { Volume } \\ 1154 & 2967 \\ 1157 & 3086 \\ 2121 & 6957 \\ 990 & 2500\end{array}$

Nfloors
1
1
1
1

Height
4.3
4.6
5.2
4.5

Width
21.5
21.2
30.0
19.3

Length
32.3
31.7
44.9
28.9

NOTES

We assumed that by 'Area', the authors mean Floor Area

Height $=$ Volume $/$ FloorAre

Assumed that all buildings are 1 storey

To find $W$ and $L$, we assumed an aspect ratio of 1.5

Assumed that SufaceArea $=27 \mathrm{H}(L+M)+L^{*} W$

Year Tested assumed ot by date of joumal oublication

Paper identifies buildings as "industrial." Building appear to be single story from volume/area ratio. Building Type assumed to be Warehouse.

Paper identifies buildings to have a "metallic structure." Construction Type assumed to be Metal Panel. 
STUDY_ID $\quad 12$

SOURCE MDAES Perera, J Henderson, and BC Webb, "Predicting Envelope Air Leakage in Large Commercial Buildings Before Construction", 18th AIVC Conference, Athens, Greece, 23-26 September, 1997 $\begin{array}{lll}\text { COUNTRY } & \text { UK } \\ \text { STUDY YEAR } & 1997\end{array}$

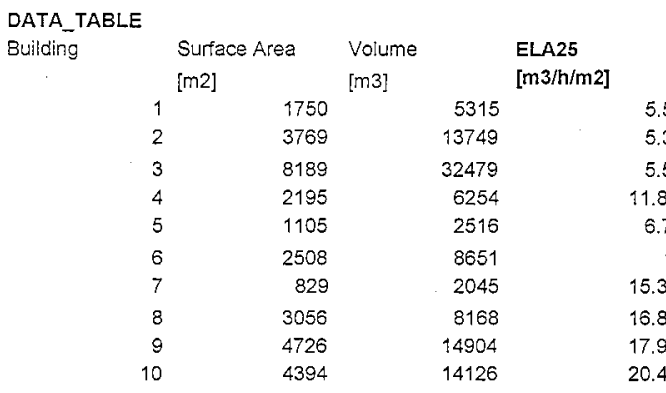

$\begin{array}{rr}\text { Year Built } & \text { Year Te } \\ & \\ 1980 & 1997 \\ 1963 & 1997 \\ 1991 & 1997 \\ 1965 & 1997 \\ 1987 & 1997 \\ 1990 & 1997 \\ 1990 & 1997 \\ 1971 & 1997 \\ 1986 & 1997 \\ 1985 & 1997\end{array}$

Country

US State

STANDARDIZED_TABLE

$\begin{array}{ccccc}\text { EntrylD } & \text { FootprintArea } & \text { FloorArea } & \text { SurfaceArea } & \text { Volum } \\ 168 & \text { \#REF! } & \text { \#REF! } & 1750 & 5315 \\ 169 & 255 & 4583 & 3769 & 13749 \\ 170 & 281 & 10826 & 8189 & 32479 \\ 171 & 782 & 2345 & 2195 & 6254 \\ 172 & 106 & 839 & 1105 & 2516 \\ 173 & 243 & 2884 & 2508 & 8651 \\ 174 & 152 & 682 & 829 & 2045 \\ 175 & 130 & 2723 & 3056 & 8168 \\ 176 & 179 & 4958 & 4726 & 14904 \\ 177 & 188 & 4709 & 4394 & 1412\end{array}$

1997
1997
1997
1997
1997
1997
1997
1997
1997
1997

office
office
office
office
office
office
office
office
office
office

masonry

England $\quad n / a$

Enasonry England n/a

masonry England $n$

masony

mete panel

masonry

$n / a$

$\begin{array}{ll}1 & \text { Entrit } \\ 2 & \\ 3 & \\ 4 & \\ 5 & \\ 6 & \\ 7 & \\ 8 & \\ 9 & \\ 10 & \end{array}$

NOTES

Year Tested assumed ot by date of journal publication

De:ails on Duiliding 1 and 4 are described in: MDAES Perera, RK Stephen, RG Tull, "Airtightness measurements of two UK office buildings",

Air Change Rate and Airtightness in Buildings, ASTM STP 1057, MH Sherman, Ed., ASTM, Philadelphia, 1990, p 211-221.

For those withoul reported Q25, values are Computed by ELA25 "Area

Building 4 has non-regular shape (T-shaped consists of a 2-storey block and a 4-storey block)

Dut we assumed that it is rectangular when estimating $W$ and $L$

For Building 4:

Assumed that $\mathrm{H}=8 \mathrm{~m}$ (b/c 3-storey)

Get $L$ and $W$ to fit both the reported Volume and SurfaceArea

$18^{*} W^{\wedge} 2+(\text { Volume/8 - SuraceArea) })^{*} W+2^{*}$ Volume $=0$

Width
12.0
13.0
13.7
10.2
8.4
12.7
10.1
9.3
10.9
11.2

$\begin{array}{cccccc}\text { Length } & \text { DeltaP } & \text { Q } & n & \text { n_Flag } & \text { Year_Bu } \\ 60.0 & 25 & 3.2 & 0.6 & \text { M } & 1980 \\ 19.6 & 25 & 5.5 & 0.65 & \text { A } & 1963 \\ 20.5 & 25 & 12.5 & 0.65 & \text { A } & 1991 \\ 76.9 & 25 & 7.2 & 0.51 & \text { M } & 1965 \\ 12.6 & 25 & 2.1 & 0.55 & \text { A } & 1987 \\ 19.1 & 25 & 6.3 & 0.65 & \text { A } & 1990 \\ 15.1 & 25 & 3.5 & 0.65 & \text { A } & 1990 \\ 14.0 & 25 & 14.3 & 0.65 & \text { A } & 1971 \\ 16.4 & 25 & 23.5 & 0.65 & \text { A } & 1986 \\ 16.8 & 25 & 24.9 & 0.65 & \text { A } & 1985 \\ \text { Year_Tested } & \text { Building_Type } & \text { Const_Type } & \text { Country } & \text { US_State } & \\ 1997 & 4 & 1 & \text { England } & \text { n/a } & \\ 1997 & 4 & 1 & \text { England } & \text { n/a } & \\ 1997 & 4 & 1 & \text { England } & \text { n/a } & \\ 1997 & 4 & 1 & \text { England } & \text { n/a } & \\ 1997 & 4 & 1 & \text { England } & \text { n/a } & \\ & & & & & \\ 1997 & 4 & 1 & \text { England } & \text { n/a } & \\ 1997 & 4 & 1 & \text { England } & \text { n/a } & \\ 1997 & 4 & 3 & \text { England } & \text { n/a } & \\ 1997 & 4 & 1 & \text { England } & \text { n/a } & \\ 1997 & 4 & 3 & \text { England } & \text { n/a } & \end{array}$


STUDY_ID 13

SOURCE MDAES Perera, RG Tull, "Envelope leakiness of large, naturally ventilated buildings", 10th AIVC Conference, Dipoli, Finland, 25-28 September, 1989.

COUNTRY UK

STUDY_YEAR 1989

DATA_TABLE

$\begin{array}{lccc} & \begin{array}{c}\text { Surface Area } \\ {[\mathrm{m} 2]}\end{array} & \begin{array}{c}\text { Volume } \\ {[\mathrm{m} 3]}\end{array} & \begin{array}{c}\text { Leakage Coeff } \\ {\left[\mathrm{m} 3 / \mathrm{s}^{*} \mathrm{~Pa} a^{\wedge} \mathrm{n}\right]}\end{array} \\ \text { UK\#1 } & 1400 & 4690 & 2.041 \\ \text { UK\#2 } & 3459 & 15000 & 3.08 \\ \text { UK\#3 } & 1100 & 3050 & 2.492 \\ \text { UK\#4 } & 1694 & 4955 & 4.162\end{array}$

STANDARDIZED_TABLE

$\begin{array}{lccc} & \text { EntrylD } & \text { FootprintArea } & \text { FloorArea } \\ \text { UK\#1 } & 178 & 648 & 648 \\ \text { UK\#2 } & 179 & 2133 & 2133 \\ \text { UK\#3 } & 180 & 585 & 585 \\ \text { UK\#4 } & 181 & 1078 & 1078\end{array}$

\section{NOTES}

Year Tested assumed ot by date of journal publication

Data reported in Table 1 of the paper

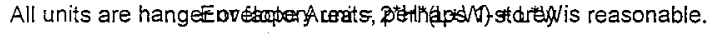
(1) Volume $=H^{*} L^{*} W$ (2)

If we assume that $X=15$

(1) and (2) reduce $105^{*}\left(W^{\wedge} 3\right)$ - EnvelopeArea* $W+10 / 3^{*}$ Volume $=0$

$\begin{array}{lccc} & \text { Est. W } & \text { Est. L } & \text { Est. H } \\ & 20.77852 & 31.16778 & 7.241897312 \\ \text { UK\#1 } & 37.71033 & 56.565495 & 7.032007645 \\ \text { UK\#2 } & 19.75417 & 29.631255 & 5.21063925 \\ \text { UK\#3 } & 26.80603 & 40.209045 & 4.597136521 \\ \text { UK\#4 } & & & \end{array}$

All four buildings are factory/industrial warehouses 


\begin{tabular}{|c|c|c|c|c|c|c|c|c|c|}
\hline $\begin{array}{l}\text { STUDY_ID } \\
\text { SOURCE }\end{array}$ & $\begin{array}{l}14 \\
\text { PJ Jones, G Pov }\end{array}$ & well, "Reducing a & ir infiltration loss & ses in naturally & ntilated industria & al buildings", & & & \\
\hline $\begin{array}{l}\text { COUNTRY } \\
\text { STUDY_YEAR }\end{array}$ & $\begin{array}{l}\text { UK } \\
1994\end{array}$ & The Role of Ven & tilation, 15th AIV & /C Conference, & uxton, Great Brit & tian, 27-30 Septe & ember, 1994. & & \\
\hline \multicolumn{10}{|l|}{ DATA_TABLE } \\
\hline & $\begin{array}{l}\text { Height } \\
{[\mathrm{m}]}\end{array}$ & $\begin{array}{c}\text { Surface Area } \\
\text { [m2] }\end{array}$ & $\begin{array}{c}Q 50 \\
{[\mathrm{~m} 3 / \mathrm{s}]}\end{array}$ & Year Built & Year Tested & Building Type & Const Type & Country & US State \\
\hline Unit 40 & 7 & 840 & 7.72 & 1990 & 1994 & warehouse & metal_panels & England & $\mathrm{n} / \mathrm{a}$ \\
\hline Unit 41 & 7 & 840 & 8.17 & 1990 & 1994 & warehouse & metal_panels & England & $\mathrm{n} / \mathrm{a}$ \\
\hline Unit 42 & 7 & 720 & 6.75 & 1990 & 1994 & warehouse & metal_panels & England & $\mathrm{n} / \mathrm{a}$ \\
\hline \multicolumn{10}{|c|}{ STANDARDIZED_TABLE } \\
\hline & EntrylD & FootprintArea & FloorArea & SurfaceArea & Volume & Nfloors & Height & Width & Length \\
\hline UK \#1 & 182 & 325 & 325 & 840 & 2274.273507 & 1 & 7.0 & 14.7 & 22.1 \\
\hline UK \#2 & 183 & 325 & 325 & 840 & 2274.273507 & 1 & 7.0 & 14.7 & 22.1 \\
\hline UK \#3 & 184 & 260 & 260 & 720 & 1817.044864 & 1 & 7.0 & 13.2 & 19.7 \\
\hline DeltaP & $Q$ & $n$ & n_Flag & Year_Built & Year_Tested & Building_Type & Const_Type & Country & US_State \\
\hline 50 & 7.7 & 0.61 & $M$ & $19 \overline{90}$ & 1994 & 5 & 4 & England & $\mathrm{n} / \mathrm{a}$ \\
\hline 50 & 8.2 & 0.62 & M & 1990 & 1994 & 5 & 4 & England & $\mathrm{n} / \mathrm{a}$ \\
\hline 50 & 6.8 & 0.59 & M & 1990 & 1994 & 5 & 4 & England & $\mathrm{n} / \mathrm{a}$ \\
\hline \multicolumn{10}{|l|}{ NOTES } \\
\hline \multicolumn{10}{|c|}{$\begin{array}{l}\text { Year Tested assumed ot by date of journal publication } \\
\text { Factories decribed as "new." Year Built assumed to be } 1990 . \\
\text { By assuming an aspect ratio of } 1.5 \text {, }\end{array}$} \\
\hline \multicolumn{10}{|c|}{ Surface Area $=2^{*} H^{*}(L+W)+L^{*} W$} \\
\hline & Est. W & Est. L & Est. Volume & Estimate $n:$ & & & & & \\
\hline Unit 40 & 14.71725099 & 22.07587649 & 2274.273507 & & & & & & \\
\hline Unit 41 & 14.71725099 & 22.07587649 & 2274.273507 & & & & & & \\
\hline Unit 42 & 13.15491892 & 19.73237838 & 1817.044864 & & & & & & \\
\hline
\end{tabular}


STUDY_ID 15

SOURCE Dumont, Personal Communication, 2000 (Data reported in G Proskiw, 2001 for CMHC) COUNTRY Canada

STUDY_YEAR 2000

\section{DATA_TABLE}

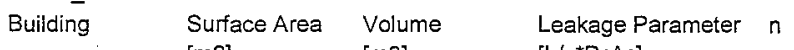

US State

Radio station

Land titles building

buliding

$2228 \quad 622$

$\left[\sqcup \mathrm{s}^{*} \mathrm{~Pa}{ }^{\wedge} \mathrm{n}\right]$

$\begin{array}{rll}423 & 0.56 & 1929 \\ 132 & 0.63 & 1960 \\ 82 & 0.68 & 1950 \\ 106 & 0.73 & 1991 \\ 157 & 0.68 & 1990 \\ 196 & 0.56 & 1975 \\ 263 & 0.51 & 1975 \\ 61 & 0.62 & 1998\end{array}$

1999 public assembly
1999 small retail
1999 small retail
1999 small retail
$1999 \mathrm{small}$ retail
$1999 \mathrm{n} / \mathrm{a}$
$1999 \mathrm{n} / \mathrm{a}$
$1999 \mathrm{public}$ assembly

$\begin{array}{lll}\mathrm{n} / \mathrm{a} & \text { Canada } & \mathrm{n} / \mathrm{a} \\ \mathrm{n} / \mathrm{a} & \text { Canada } & \mathrm{n} / \mathrm{a} \\ \mathrm{n} / \mathrm{a} & \text { Canada } & \mathrm{n} / \mathrm{a} \\ \mathrm{n} / \mathrm{a} & \text { Canada } & \mathrm{n} / \mathrm{a} \\ \mathrm{n} / \mathrm{a} & \text { Canada } & \mathrm{n} / \mathrm{a} \\ \mathrm{n} / \mathrm{a} & \text { Canada } & \mathrm{n} / \mathrm{a} \\ \mathrm{n} / \mathrm{a} & \text { Canada } & \mathrm{n} / \mathrm{a} \\ \mathrm{n} / \mathrm{a} & \text { Canada } & \mathrm{n} / \mathrm{a}\end{array}$

\section{STANDARDIZED_TABLE}

$\begin{array}{lc} & \text { EntrylD } \\ \text { Court house } & 185 \\ \text { Radio station } & 186 \\ \text { Land titles building } & 187 \\ \text { Youth camp buliding } & 188 \\ \text { Fire control office } & 189 \\ \text { WB building } & 190 \\ \text { POB } & 191\end{array}$

FootprintArea

1591
762
1556
584
573
701
1306
3297

FloorArea
1591
762
1556
584
573
701
1306
3297
$Q$
3.8
1.6
1.2
1.8
2.2
1.8
1.9
0.7

SurfaceArea
2228
1888
1951
1473
1879
1136
1675
3982
$n$
0.56
0.63
0.68
0.73
0.68
0.56
0.51
0.62

Volume
6226
2287
3818
1753
1718
2819
3265
9630
nFlag
$M$
$M$
$M$
$M$
$M$
$M$
$M$
$M$

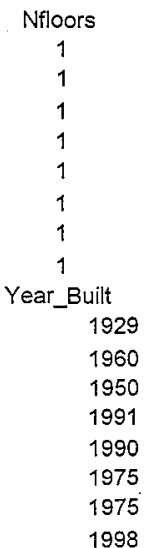

Height
3.9
3.0
2.5
3.0
3.0
4.0
2.5
2.9
Year_Tested Buildin
1999
1999
1999
1999
1999
$1999 \mathrm{n} / \mathrm{a}$
$1999 \mathrm{n} / \mathrm{a}$
1999

\begin{tabular}{|c|c|c|c|}
\hline th & Length & DeltaP & \\
\hline 2.6 & 48.8 & 50.0 & \\
\hline .5 & 33.8 & 50.0 & \\
\hline 2.2 & 48.3 & 50.0 & \\
\hline 9.7 & 29.6 & 50.0 & \\
\hline 9.5 & 29.3 & 50.0 & \\
\hline 1.6 & 32.4 & 50.0 & \\
\hline 29.5 & 44.3 & 50.0 & \\
\hline 6.9 & 70.3 & 50.0 & \\
\hline _Type & Const_Type & Country & US_St \\
\hline & $9 \mathrm{n} / \mathrm{a}$ & Canada & \\
\hline & $6 \mathrm{n} / \mathrm{a}$ & Canada & $\mathrm{n} / \mathrm{a}$ \\
\hline & $6 \mathrm{n} / \mathrm{a}$ & Canada & $n / a$ \\
\hline & $5 \mathrm{n} / \mathrm{a}$ & Canada & n/a \\
\hline & n/a & Canada & $\mathrm{n} / \mathrm{a}$ \\
\hline & $n / a$ & Canada & n/a \\
\hline & $n / a$ & Canada & n/a \\
\hline & & Canada & 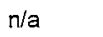 \\
\hline
\end{tabular}

(1) Envelope Area $=2^{*} H^{*}(L+W)+L^{*} W$

(2) Volume $=H^{*} L^{\star} W$

(1) and (2) reduce to:

\begin{tabular}{|c|c|c|c|c|}
\hline Est & & Est. L & Est. $H$ & \\
\hline Court house & 32.56489 & 48.847335 & 3.913980217 & \\
\hline Radio station & 33.25413 & 49.881195 & 1.378744284 & (Too Low!) \\
\hline Land titles building & 32.20595 & 48.308925 & 2.453988009 & \\
\hline Youth camp buliding & 29.12465 & 43.686975 & 1.377746216 & (Too Low!) \\
\hline Fire control office & 33.75756 & 50.63634 & 1.005054943 & (Too Low!) \\
\hline WB building & 21.62525 & 32.437875 & 4.018662582 & \\
\hline$P O B$ & 29.50919 & 44.263785 & 2.499639329 & \\
\hline Library & 46.88533 & 70.327995 & 2.920525979 & \\
\hline
\end{tabular}

Looks like all are 1-storey

Set $H=3 \mathrm{~m}$, re-estimate $W$ by sqrt(Volume/3m/1.5)

Est. W Est. L

$\begin{array}{ll}22.5437846 & 33.81567684 \\ & \\ 19.7371618 & 29.60574269 \\ 19.5391345 & 29.30870178\end{array}$

70.327995

2.920525979 


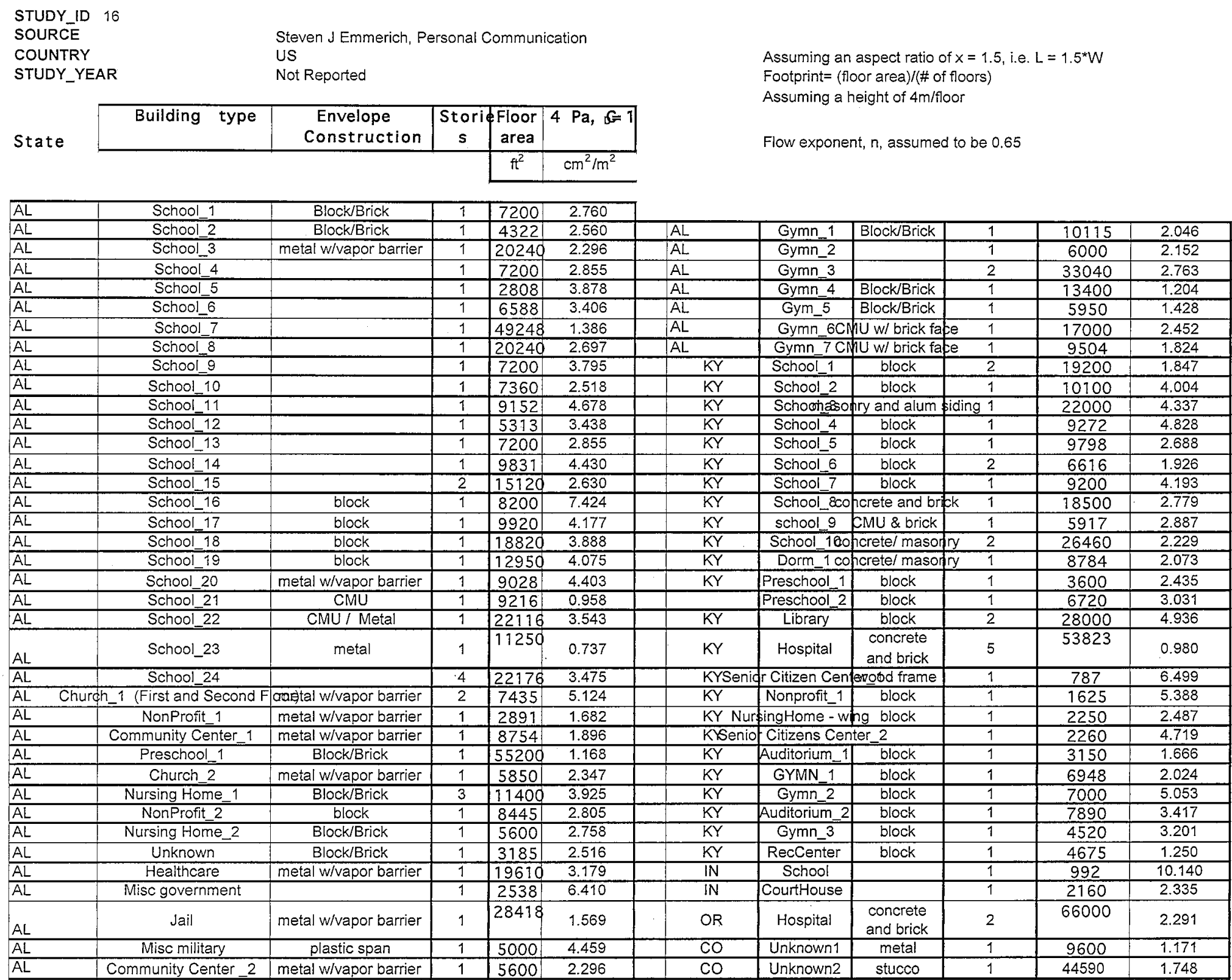




\section{APPENDIX IV: APARTMENT BUILDING DATA}

Title Suite Ventilation Characteristics of Current Canadian Mid- and High- Rise Residential Buildings Author C.P. Wray

Reference ASHRAE Transactions, Vol. 106, Part 2, 2000

\begin{tabular}{|c|c|c|c|c|c|c|c|c|c|c|}
\hline Study & DataEntry & CityState & Country & Year & $\begin{array}{l}\text { Norm } \\
\text { Flow }\end{array}$ & IgNormFlow & ConstN & Const & $\mathrm{BN}$ & Building \\
\hline 1 & 1 & Vancouver & Canada & 1992.5 & 0.57 & -0.25 & $\mathrm{n} / \mathrm{a}$ & $\mathrm{n} / \mathrm{a}$ & 1 & \\
\hline 1 & 2 & Vancouver & Canada & 1992.5 & 0.50 & -0.31 & $\mathrm{n} / \mathrm{a}$ & $\mathrm{n} / \mathrm{a}$ & 2 & \\
\hline 1 & 3 & Vancouver & Canada & 1992.5 & 0.23 & -0.65 & $\mathrm{n} / \mathrm{a}$ & $n / a$ & 3 & \\
\hline 1 & 4 & Vancouver & Canada & 1992.5 & 0.24 & -0.62 & $\mathrm{n} / \mathrm{a}$ & $\mathrm{n} / \mathrm{a}$ & 4 & \\
\hline 1 & 5 & Toronto & Canada & 1992.5 & 0.68 & -0.17 & $n / a$ & $\mathrm{n} / \mathrm{a}$ & 5 & \\
\hline 1 & 6 & Toronto & Canada & 1992.5 & 0.42 & -0.38 & $\mathrm{n} / \mathrm{a}$ & $\mathrm{n} / \mathrm{a}$ & 6 & \\
\hline 1 & 7 & Winnipeg & Canada & 1992.5 & 0.26 & -0.58 & $\mathrm{n} / \mathrm{a}$ & $\mathrm{n} / \mathrm{a}$ & 7 & \\
\hline 1 & 8 & Winnipeg & Canada & 1992.5 & 0.47 & -0.33 & $\mathrm{n} / \mathrm{a}$ & $n / a$ & 8 & \\
\hline 1 & 9 & Winnipeg & Canada & 1992.5 & 1.18 & 0.07 & $\mathrm{n} / \mathrm{a}$ & $\mathrm{n} / \mathrm{a}$ & 9 & \\
\hline 1 & 10 & Winnipeg & Canada & 1992.5 & 0.30 & -0.53 & $\mathrm{n} / \mathrm{a}$ & $\mathrm{n} / \mathrm{a}$ & 10 & , \\
\hline $\begin{array}{l}\text { Leakage } \\
\text { leasurement }\end{array}$ & Units & Season & InOut & Delta T & Wind & Temp & Location & Method & Facility Discription & Site \\
\hline 1.63 & $\mathrm{ACH}$ & $\mathrm{n} / \mathrm{a}$ & 1 & 21 & 0.56 & 4 & Vancouver, Canada & tracer gas decay & 10 buildings & building \\
\hline 1.55 & $\mathrm{ACH}$ & $\mathrm{n} / \mathrm{a}$ & 1 & 20 & 0.83 & 5 & Vancouver, Canada & tracer gas decay & 10 buildings & \\
\hline 0.73 & $\mathrm{ACH}$ & $\mathrm{n} / \mathrm{a}$ & 1 & 20 & 0.56 & 5 & Vancouver, Canada & tracer gas decay & 10 buildings & \\
\hline 0.63 & $\mathrm{ACH}$ & $\mathrm{n} / \mathrm{a}$ & 1 & 19 & 0.83 & 6 & Vancouver, Canada & tracer gas decay & 10 buildings & \\
\hline 1.83 & $\mathrm{ACH}$ & $n / a$ & 1 & 16 & 4.44 & 9 & Toronto, Canada & tracer gas decay & 10 buildings & \\
\hline 0.95 & $\mathrm{ACH}$ & $\mathrm{n} / \mathrm{a}$ & 1 & 14 & 4.17 & 11 & Toronto, Canada & tracer gas decay & 10 buildings & \\
\hline 0.6 & $\mathrm{ACH}$ & $\mathrm{n} / \mathrm{a}$ & 1 & 24 & 3.33 & 1 & Winnipeg, Canada & tracer gas decay & 10 buildings & \\
\hline 1.23 & $\mathrm{ACH}$ & $n / a$ & 1 & 23 & 6.94 & 2 & Winnipeg, Canada & tracer gas decay & 10 buildings & \\
\hline 2.73 & $\mathrm{ACH}$ & $\mathrm{n} / \mathrm{a}$ & 1 & 18 & 4.44 & 7 & Winnipeg, Canada & tracer gas decay & 10 buildings & \\
\hline 0.88 & $\mathrm{ACH}$ & $\mathrm{n} / \mathrm{a}$ & 1 & 18 & 2.5 & 7 & Winnipeg, Canada & tracer gas decay & 10 buildings & \\
\hline
\end{tabular}


Title Measured Airflows in a Multifamily Building

Author Lary Palmiter, Jonathan Heller, Max Sherman

Reference American Society for Testing and Materials, Philidelphia, 1995, pp. 7-22

\begin{tabular}{|c|c|c|c|c|c|c|c|}
\hline \multirow[b]{2}{*}{ Study } & \multirow[b]{2}{*}{ DataEntry } & \multicolumn{6}{|c|}{ Norm } \\
\hline & & CityState & Country & Year & Flow & IgNormFlow & ConstN \\
\hline 2 & 11 & Portland & US & 1992 & 0.07 & -1.19 & \\
\hline 2 & 12 & Portland & US & 1992 & 0.08 & -1.07 & \\
\hline 2 & 13 & Portland & US & 1992 & 0.06 & -1.23 & \\
\hline 2 & 14 & Portland & US & 1992 & 0.05 & -1.28 & \\
\hline 2 & 15 & Portland & US & 1992 & 0.07 & -1.19 & \\
\hline 2 & 16 & Portland & US & 1992 & 0.10 & -1.00 & \\
\hline ment & Units & Season & InOut & Delta T & Wind & Temp & Location \\
\hline 0.2 & $\mathrm{ACH}$ & $\mathrm{n} / \mathrm{a}$ & 1 & 15.2 & 0.9 & 15.2 & \\
\hline 0.26 & $\mathrm{ACH}$ & $\mathrm{n} / \mathrm{a}$ & 1 & 15.2 & 0.9 & 15.2 & Portland, Oregon, \\
\hline 0.18 & $\mathrm{ACH}$ & $\mathrm{n} / \mathrm{a}$ & 1 & 15.2 & 0.9 & 15.2 & U.S. \\
\hline 0.16 & $\mathrm{ACH}$ & $\mathrm{n} / \mathrm{a}$ & 1 & 15.2 & 0.9 & 15.2 & \\
\hline 0.2 & $\mathrm{ACH}$ & $\mathrm{n} / \mathrm{a}$ & 1 & 15.2 & 0.9 & 15.2 & \\
\hline 0.31 & $\mathrm{ACH}$ & $n / a$ & 1 & 15.2 & 0.9 & 15.2 & \\
\hline
\end{tabular}

Title Multizone Infiltration Measurements in Homes and Buildings Using a Passive Perfourocarbon Tracer Method Author R.N. Dietz, T.W. D'Ottavio, RW. Goodrich

Reference

\begin{tabular}{|c|c|c|c|c|c|c|c|c|c|}
\hline Study & DataEntry & CityState & Country & Year & $\begin{array}{l}\text { Norm } \\
\text { Flow }\end{array}$ & IgNormFlow & ConstN & Const & BN \\
\hline 3 & 17 & Longlsland & US & $\mathrm{n} / \mathrm{a}$ & 0.12 & -0.92 & $\mathrm{n} / \mathrm{a}$ & $n / a$ & \\
\hline 3 & 18 & Longlsland & US & $\mathrm{n} / \mathrm{a}$ & 0.32 & -0.50 & $\mathrm{n} / \mathrm{a}$ & $\mathrm{n} / \mathrm{a}$ & \\
\hline 3 & 19 & Longlsland & US & $n / a$ & 0.26 & -0.58 & $\mathrm{n} / \mathrm{a}$ & $n / a$ & \\
\hline 3 & 20 & Longisland & US & $n / a$ & 0.26 & -0.59 & $\mathrm{n} / \mathrm{a}$ & $\mathrm{n} / \mathrm{a}$ & \\
\hline Leakage & & & & & & & & & \\
\hline Measurement & Units & Season & InOut & Delta T & Wind & Temp & Location & Method & Facility Discription \\
\hline 0.32 & $\mathrm{ACH}$ & $\mathrm{n} / \mathrm{a}$ & 1 & & & & Arizona, U.S. & tracer tests & \\
\hline 0.85 & $\mathrm{ACH}$ & $\mathrm{n} / \mathrm{a}$ & 1 & & & & Arizona, U.S. & tracer tests & 4 apartments in 4- \\
\hline 0.72 & $\mathrm{ACH}$ & $\mathrm{n} / \mathrm{a}$ & 1 & & & & Arizona, U.S. & tracer tests & unit building \\
\hline 0.71 & $\mathrm{ACH}$ & $\mathrm{n} / \mathrm{a}$ & 1 & & & & Arizona, U.S. & tracer tests & \\
\hline
\end{tabular}


Title Air Leakage and Fan Pressurization Measurements in Selected Naval Housing

Author Peter L. Lagus, John C. King Reference

\begin{tabular}{|c|c|c|c|c|c|c|}
\hline Study & DataEntry & CityState & Country & Year & $\begin{array}{c}\text { Norm } \\
\text { Flow }\end{array}$ & IgNormFlow \\
\hline 4 & 31 & Norfolk & US & $n / a$ & 0.25 & -0.61 \\
\hline 4 & 32 & Norfolk & US & $\mathrm{n} / \mathrm{a}$ & 0.25 & -0.59 \\
\hline 4 & 33 & Norfolk & US & $\mathrm{n} / \mathrm{a}$ & 0.26 & -0.59 \\
\hline 4 & 34 & Norfolk & US & $n / a$ & 0.45 & -0.35 \\
\hline 4 & 35 & Norfolk & US & $n / a$ & 0.66 & -0.18 \\
\hline 4 & 36 & Norfolk & US & $\mathrm{n} / \mathrm{a}$ & 0.34 & -0.47 \\
\hline 4 & 37 & Norfolk & US & $n / a$ & 0.17 & -0.77 \\
\hline 4 & 38 & Norfolk & US & $\mathrm{n} / \mathrm{a}$ & 0.23 & -0.64 \\
\hline 4 & 39 & Norfolk & US & $\mathrm{n} / \mathrm{a}$ & 0.36 & -0.44 \\
\hline 4 & 40 & Norfolk & US & $n / a$ & 0.16 & -0.80 \\
\hline 4 & 41 & Norfolk & US & $\mathrm{n} / \mathrm{a}$ & 0.19 & -0.73 \\
\hline 4 & 42 & Norfolk & US & $n / a$ & 0.15 & -0.83 \\
\hline 4 & 43 & Norfolk & US & $\mathrm{n} / \mathrm{a}$ & 0.31 & -0.51 \\
\hline 4 & 44 & Norfolk & US & $\mathrm{n} / \mathrm{a}$ & 0.27 & -0.58 \\
\hline 4 & 45 & Norfolk & US & $\mathrm{n} / \mathrm{a}$ & 0.38 & -0.42 \\
\hline 4 & 46 & Norfolk & US & $n / a$ & 0.41 & -0.39 \\
\hline 4 & 47 & Norfolk & US & $\mathrm{n} / \mathrm{a}$ & 0.69 & -0.16 \\
\hline 4 & 48 & Norfolk & US & $\mathrm{n} / \mathrm{a}$ & 0.29 & -0.54 \\
\hline 4 & 49 & Norfolk & US & $n / a$ & 0.18 & -0.74 \\
\hline 4 & 50 & Norfolk & US & $\mathrm{n} / \mathrm{a}$ & 0.32 & -0.49 \\
\hline 4 & 51 & Norfolk & US & $\mathrm{n} / \mathrm{a}$ & 0.32 & -0.49 \\
\hline 4 & 52 & Norfolk & US & $\mathrm{n} / \mathrm{a}$ & 0.25 & -0.61 \\
\hline 4 & 53 & Norfolk & US & $\mathrm{n} / \mathrm{a}$ & 0.17 & -0.77 \\
\hline 4 & 54 & Norfolk & US & $\mathrm{n} / \mathrm{a}$ & 0.16 & -0.80 \\
\hline 4 & 55 & Norfolk & US & $\mathrm{n} / \mathrm{a}$ & 0.24 & -0.62 \\
\hline 4 & 56 & Norfolk & US & $\mathrm{n} / \mathrm{a}$ & 0.62 & -0.21 \\
\hline 4 & 57 & Norfolk & US & $n / a$ & 0.46 & -0.34 \\
\hline 4 & 58 & Norfolk & US & $\mathrm{n} / \mathrm{a}$ & 0.22 & -0.66 \\
\hline 4 & 59 & Norfolk & US & $\mathrm{n} / \mathrm{a}$ & 0.26 & -0.58 \\
\hline 4 & 60 & Norfolk & US & $\mathrm{n} / \mathrm{a}$ & 0.21 & -0.68 \\
\hline 4 & 61 & Norfolk & US & $n / a$ & 0.15 & -0.83 \\
\hline
\end{tabular}

ConstN

Const

Meta!

Metal

Metal

Metal

Metal

Metal

Metal

Metal

Metal

Metal

Metal

Metal

Metal

Metal

Metal

Metal

Meta!

Metal

Metal

Metal

Metal

Metal

Metal

Metal

Metal

Metal

Metal

Metal

Metal

Metal

Metal
BN

Building

D1 
Title Air Leakage and Fan Pressurization Measurements in Selected Naval Housing

Author Peter L. Lagus, John C. King

Reference

\begin{tabular}{|c|c|c|c|c|c|c|c|c|c|c|}
\hline Study & DataEntry & CityState & Country & Year & $\begin{array}{l}\text { Norm } \\
\text { Flow }\end{array}$ & IgNormFlow & ConstN & & Const & BN \\
\hline 4 & 62 & Norfolk & us & $\mathrm{n} / \mathrm{a}$ & 0.17 & -0.76 & & 4 & Metal & . \\
\hline 4 & 63 & Norfolk & US & $\mathrm{n} / \mathrm{a}$ & 0.27 & -0.57 & & 4 & Metal & \\
\hline 4 & 64 & Norfolk & US & $n / a$ & 0.28 & -0.56 & & 4 & Metal & \\
\hline 4 & 65 & Norfolk & US & $\mathrm{n} / \mathrm{a}$ & 0.22 & -0.67 & & 4 & Metal & \\
\hline 4 & 66 & Norfolk & US & $n / a$ & 0.14 & -0.84 & & 4 & Metal & \\
\hline 4 & 67 & Norfolk & US & $n / a$ & 0.34 & -0.47 & & 4 & Metal & \\
\hline 4 & 68 & Norfolk & us & $\mathrm{n} / \mathrm{a}$ & 0.68 & -0.16 & & 4 & Metal & \\
\hline 4 & 69 & Norfolk & US & $n / a$ & 0.75 & -0.12 & & 4 & Metal & \\
\hline 4 & 70 & Norfolk & US & $n / a$ & 0.24 & -0.62 & & 4 & Metal & \\
\hline 4 & 71 & Norfolk & US & $n / a$ & 0.25 & -0.61 & & 4 & Metal & \\
\hline 4 & 72 & Norfolk & US & $n / a$ & 0.27 & -0.57 & & 4 & Metal & \\
\hline 4 & 73 & Norfolk & US & $n / a$ & 0.14 & -0.85 & & 4 & Metal & \\
\hline 4 & 74 & Norfolk & US & $n / a$ & 0.15 & -0.81 & & 4 & Metal & \\
\hline 4 & 75 & Norfolk & US & $\mathrm{n} / \mathrm{a}$ & 0.28 & -0.55 & & 4 & Metal & \\
\hline 4 & 76 & Norfolk & US & $n / a$ & 0.27 & -0.56 & & 4 & Metal & \\
\hline 4 & 77 & Norfolk & us & $n / a$ & 0.18 & -0.74 & & 4 & Metal & \\
\hline 4 & 78 & Norfolk & US & $\mathrm{n} / \mathrm{a}$ & 0.11 & -0.95 & & 4 & Metal & \\
\hline $\begin{array}{l}\text { Leakage } \\
\text { leasurement }\end{array}$ & Units & Season & InOut & Delta T & Wind & Temp & Location & & Method & Facility Discription \\
\hline 0.94 & $\mathrm{ACH}$ & 1 & 1 & 2 & 2.3 & 23 & Norfolk, Virginia and & & & 24 units in 4 \\
\hline 0.97 & $\mathrm{ACH}$ & 1 & 1 & 1 & 2.3 & 24 & Pensacola, Florida, & & pressurization, & sixplexes and 2 \\
\hline 0.99 & $\mathrm{ACH}$ & 1 & 1 & 1 & 4.5 & 26 & U.S. & & then converted & units in 1 duplex \\
\hline 1.7 & $\mathrm{ACH}$ & 1 & 1 & 8 & 8.9 & 17 & & & & \\
\hline 2.5 & $\mathrm{ACH}$ & 1 & 1 & 15 & 10.5 & 10 & & & & \\
\hline 1.3 & $\mathrm{ACH}$ & 1 & 1 & 18 & 5.4 & 7 & & & & \\
\hline 0.64 & $\mathrm{ACH}$ & 2 & 1 & 20 & 2 & 5 & & & & \\
\hline 0.87 & $\mathrm{ACH}$ & 2 & 1 & 23 & 2,8 & 2 & & & & \\
\hline 1.39 & $\mathrm{ACH}$ & 2 & 1 & 24 & 3.6 & 1 & & & & \\
\hline 0.6 & $\mathrm{ACH}$ & 2 & 1 & 24 & 2.4 & 1 & & & & \\
\hline 0.71 & $\mathrm{ACH}$ & 2 & 1 & 21 & 2.4 & 4 & & & & \\
\hline 0.56 & $\mathrm{ACH}$ & 2 & 1 & 17 & 1.8 & 8 & & & & \\
\hline 1.17 & $\mathrm{ACH}$ & 1 & 1 & 2 & 2.3 & 23 & & & & \\
\hline 1.01 & $\mathrm{ACH}$ & 1 & 1 & 4 & 2.3 & 21 & & & & \\
\hline 1.45 & $\mathrm{ACH}$ & 1 & 1 & 0 & 4.5 & 25 & & & & \\
\hline
\end{tabular}

building 108, unit 8118

building 108 , unit $812 i$

building 108, unit 8122

building 108 , unit 8123

building 108 , unit 8118

building 108 , unit 8119

building 108 , unit 8120

building 108 , unit 8121

building 108 , unit 8122

building 108 , unit 8123

building 114 , unit 8160

building 114 , unit 8161

building 114 , unit 8162 
Title Air Leakage and Fan Pressurization Measurements in Selected Naval Housing

Author Peter L. Lagus, John C. King

\section{Reference}

\section{Leakage}

Measurement

$\begin{array}{rr}1.57 & \mathrm{ACH} \\ 2.63 & \mathrm{ACH} \\ 1.09 & \mathrm{ACH} \\ 0.7 & \mathrm{ACH} \\ 0.73 & \mathrm{ACH} \\ 1.23 & \mathrm{ACH} \\ 0.94 & \mathrm{ACH} \\ 0.64 & \mathrm{ACH} \\ 0.6 & \mathrm{ACH} \\ 0.92 & \mathrm{ACH} \\ 2.35 & \mathrm{ACH} \\ 1.75 & \mathrm{ACH} \\ 0.84 & \mathrm{ACH} \\ 1 & \mathrm{ACH} \\ 0.79 & \mathrm{ACH} \\ 0.57 & \mathrm{ACH} \\ 0.66 & \mathrm{ACH} \\ 1.02 & \mathrm{ACH} \\ 1.05 & \mathrm{ACH} \\ 0.82 & \mathrm{ACH} \\ 0.55 & \mathrm{ACH} \\ 1.28 & \mathrm{ACH} \\ 2.61 & \mathrm{ACH} \\ 2.87 & \mathrm{ACH} \\ 0.91 & \mathrm{ACH} \\ 0.94 & \mathrm{ACH} \\ 1.02 & \mathrm{ACH} \\ 0.54 & \mathrm{ACH} \\ 0.59 & \mathrm{ACH} \\ 1.07 & \mathrm{ACH} \\ 1.04 & \mathrm{ACH} \\ 0.69 & \mathrm{ACH} \\ 0.43 & \mathrm{ACH}\end{array}$

Season

$\begin{array}{rr}\text { Delta T } & \text { Wind } \\ 5 & 8.9 \\ 9 & 10.5 \\ 19 & 5.6 \\ 16 & 2 \\ 18 & 2.8 \\ 23 & 3.6 \\ 23 & 2.4 \\ 22 & 2.4 \\ 18 & 1.8 \\ 18 & 5.6 \\ 10 & 10.5 \\ 4 & 8.9 \\ 0 & 4.5 \\ 1 & 2.3 \\ 1 & 2.3 \\ 19 & 1.8 \\ 22 & 2.4 \\ 24 & 3.6 \\ 24 & 3.6 \\ 18 & 2.8 \\ 21 & 2 \\ 17 & 5.6 \\ 10 & 10.5 \\ 6 & 8.9 \\ 2 & 4.5 \\ 2 & 2.3 \\ 3 & 2.4 \\ 17 & 1.8 \\ 23 & 2.4 \\ 20 & 3.6 \\ 24 & 3.6 \\ 19 & 3.1 \\ 16 & 2 \\ & \\ 10 & \end{array}$

Temp

\section{0 \\ Norfolk, Virginia and}

U.S

$$
\text { .S. }
$$

\section{Method}

pressurization

then converted
Facility Discription

building 114, unit 8163 building 114, unit 8164 building 114, unit 8165 building 114, unit 8160 building 114 , unit 8161 building 114, unit 8162 building 114, unit 8163 building 114 , unit 8164 building 114, unit 8165 building 110, unit 8130 building 110 , unit 8131 building 110, unit 8132 building 110 , unit 8133 building 110, unit 8134 building 110 , unit 8135 building 110, unit 8130 building 110 , unit 8131 building 110, unit 8132 building 110 , unit 8133 building 110 , unit 8134 building 110 , unit 8135 building 112 , unit 8148 building 112, unit 8149 building 112, unit 8150 building 112, unit 8151 building 112, unit 8152 building 112, unit 8153 building 112, unit 8148 building 112, unit 8149 building 112 , unit 8150 building 112, unit 8151 building 112, unit 8152 building 112, unit 8153 
Airtightness Survey of Row Houses in Calgary, Alberta

James A. Love

American Society for Testing and Materials, Philidelphia, 1990, pp. 194-210

\begin{tabular}{|c|c|c|c|c|c|c|c|c|c|c|}
\hline \multicolumn{11}{|c|}{$\left.\mathrm{L} / \mathrm{s}^{\times} \mathrm{m} 2\right)$ at $50 \mathrm{~Pa}$} \\
\hline Study & DataEntry & CityState & Country & Year & NormFlow & IgNormFlow & ConstN & Const & $\mathrm{BN}$ & Building \\
\hline 5 & 1 & Calgary & Canada & 1967.5 & 2.13 & 0.33 & 1 & Wood & 17 & 1 \\
\hline 5 & 2 & Calgary & Canada & 1967.5 & 2.13 & 0.33 & 1 & Wood & 17 & । \\
\hline 5 & 3 & Calgary & Canada & 1967.5 & 2.07 & 0.32 & 1 & Wood & 17 & I \\
\hline 5 & 4 & Calgary & Canada & 1967.5 & 1.67 & 0.22 & 1 & Wood & 18 & । \\
\hline 5 & 5 & Calgary & Canada & 1967.5 & 1.50 & 0.17 & 1 & Wood & 19 & । \\
\hline 5 & 6 & Calgary & Canada & 1967.5 & 2.24 & 0.35 & 1 & Wood & 19 & । \\
\hline 5 & 7 & Caigary & Canada & 1973.5 & 0.92 & -0.04 & 1 & Wood & 20 & I \\
\hline 5 & 8 & Calgary & Canada & 1973.5 & 0.97 & -0.01 & 1 & Wood & 21 & । \\
\hline 5 & 9 & Calgary & Canada & 1973.5 & 1.04 & 0.02 & 1 & Wood & 22 & । \\
\hline 5 & 10 & Calgary & Canada & 1973.5 & 2.59 & 0.41 & 1 & Wood & 21 & 1 \\
\hline 5 & 11 & Calgary & Canada & 1973.5 & 2.34 & 0.37 & 1 & Wood & 22 & 1 \\
\hline 5 & 12 & Calgary & Canada & 1982 & 2.26 & 0.35 & 1 & Wood & 22 & 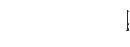 \\
\hline 5 & 13 & Calgary & Canada & 1982 & 2.79 & 0.45 & 1 & Wood & 23 & 1 \\
\hline 5 & 14 & Calgary & Canada & 1982 & 1.92 & 0.28 & 1 & Wood & 24 & 1 \\
\hline 5 & 15 & Calgary & Canada & 1982 & 2.07 & 0.32 & 1 & Wood & 25 & 1 \\
\hline 5 & 16 & Calgary & Canada & 1982 & 1.28 & 0.11 & 1 & Wood & 26 & । \\
\hline 5 & 17 & Calgary & Canada & 1982 & 2.21 & 0.34 & 1 & Wood & 27 & : \\
\hline 5 & 18 & Calgary & Canada & 1982 & 2.55 & 0.41 & 1 & Wood & 28 & 1 \\
\hline 5 & 19 & Calgary & Canada & 1982 & 1.34 & 0.13 & 1 & Wood & 29 & , \\
\hline 5 & 20 & Calgary & Canada & 1982 & 2.67 & 0.43 & 1 & Wood & 23 & 1 \\
\hline 5 & 21 & Calgary & Canada & 1982 & 3.74 & 0.57 & 1 & Wood & 24 & 1 \\
\hline 5 & 22 & Calgary & Canada & 1982 & 3.74 & 0.57 & 1 & Wood & 25 & 1 \\
\hline 5 & 23 & Calgary & Canada & 1982 & 3.16 & 0.50 & 1 & Wood & 26 & 1 \\
\hline 5 & 24 & Calgary & Canada & 1982 & 3.83 & 0.58 & 1 & Wood & 27 & 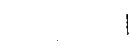 \\
\hline
\end{tabular}


Airtightness Survey of Row Houses in Calgary, Alberta

James A. Love

American Society for Testing and Materials, Philidelphia, 1990, pp. 194-210

\begin{tabular}{|c|c|c|c|c|c|c|}
\hline Method & Site & $\begin{array}{c}\text { Leakage } \\
\text { Measurement }\end{array}$ & Units & Flow & Volume & Facility Discription \\
\hline fan depressurization & building 1 , unit $1 \mathrm{E}(1-1 \mathrm{E})$ & 3.4 & $\mathrm{ACH}$ at $50 \mathrm{~Pa}$ & 1278.4 & 376 & 42 row houses from 9 complexes \\
\hline fan depressurization & $1-4 \mathrm{E}$ & 3.4 & $\mathrm{ACH}$ at $50 \mathrm{~Pa}$ & 1278.40 & 376 & 42 row houses from 9 complexes \\
\hline fan depressurization & $1-5$ & 2.4 & $\mathrm{ACH}$ at $50 \mathrm{~Pa}$ & 902.40 & 376 & 42 row houses from 9 complexes \\
\hline fan depressurization & $2-1 E$ & 2.8 & $\mathrm{ACH}$ at $50 \mathrm{~Pa}$ & 904.40 & 323 & 42 row houses from 9 complexes \\
\hline fan depressurization & $2-2 E$ & 2.5 & $\mathrm{ACH}$ at $50 \mathrm{~Pa}$ & 807.50 & 323 & 42 row houses from 9 complexes \\
\hline fan depressurization & $3-1 E$ & 4.6 & $\mathrm{ACH}$ at $50 \mathrm{~Pa}$ & 910.80 & 198 & 42 row houses from 9 complexes \\
\hline fan depressurization & $5-1$ & 5.4 & $\mathrm{ACH}$ at $50 \mathrm{~Pa}$ & 518.40 & 96 & 42 row houses from 9 complexes \\
\hline fan depressurization & $5-2$ & 5.7 & $\mathrm{ACH}$ at $50 \mathrm{~Pa}$ & 547.20 & 96 & 42 row houses from 9 complexes \\
\hline fan depressurization & $5-3$ & 6.1 & $\mathrm{ACH}$ at $50 \mathrm{~Pa}$ & 585.60 & 96 & 42 row houses from 9 complexes \\
\hline fan depressurization & $6-2$ & 3.2 & $\mathrm{ACH}$ at $50 \mathrm{~Pa}$ & 1136.00 & 355 & 42 row houses from 9 complexes \\
\hline fan depressurization & $6-3$ & 2.9 & $\mathrm{ACH}$ at $50 \mathrm{~Pa}$ & 1029.50 & 355 & 42 row houses from 9 complexes \\
\hline fan depressurization & $7-2$ & 3.9 & $\mathrm{ACH}$ at $50 \mathrm{~Pa}$ & 1450.80 & 372 & 42 row houses from 9 complexes \\
\hline fan depressurization & $7-3$ & 4.8 & $\mathrm{ACH}$ at $50 \mathrm{~Pa}$ & 1785.60 & 372 & 42 row houses from 9 complexes \\
\hline fan depressurization & $7-4 E$ & 3.8 & $\mathrm{ACH}$ at $50 \mathrm{~Pa}$ & 1413.60 & 372 & 42 row houses from 9 complexes \\
\hline fan depressurization & $7-5 E$ & 4.1 & $\mathrm{ACH}$ at $50 \mathrm{~Pa}$ & 1525.20 & 372 & 42 row houses from 9 complexes \\
\hline fan depressurization & $7-6$ & 2.2 & $\mathrm{ACH}$ at $50 \mathrm{~Pa}$ & 818.40 & 372 & 42 row houses from 9 complexes \\
\hline fan depressurization & $7-7$ & 3.8 & $\mathrm{ACH}$ at $50 \mathrm{~Pa}$ & 1413.60 & 372 & 42 row houses from 9 complexes \\
\hline fan depressurization & $7-8$ & 4.4 & $\mathrm{ACH}$ at $50 \mathrm{~Pa}$ & 1636.80 & 372 & 42 row houses from 9 complexes \\
\hline fan depressurization & $7-9$ & 2.3 & $\mathrm{ACH}$ at $50 \mathrm{~Pa}$ & 855.60 & 372 & 42 row houses from 9 complexes \\
\hline fan depressurization & $9-1 E$ & 3.8 & $\mathrm{ACH}$ at $50 \mathrm{~Pa}$ & 1257.80 & 331 & 42 row houses from 9 complexes \\
\hline fan depressurization & $9-2$ & 3.9 & $\mathrm{ACH}$ at $50 \mathrm{~Pa}$ & 1290.90 & 331 & 42 row houses from 9 complexes \\
\hline fan depressurization & $9-3$ & 3.9 & $\mathrm{ACH}$ at $50 \mathrm{~Pa}$ & 1290.90 & 331 & 42 row houses from 9 complexes \\
\hline fan depressurization & $9-4$ & 3.3 & $\mathrm{ACH}$ at $50 \mathrm{~Pa}$ & 1092.30 & 331 & 42 row houses from 9 complexes \\
\hline fan depressurization & $9-5$ & 4 & $\mathrm{ACH}$ at $50 \mathrm{~Pa}$ & 1324.00 & 331 & 42 row houses from 9 complexes \\
\hline
\end{tabular}


Valuing Air Bariers

Duncan Hill

Home Energy, Sept/Oct. 2001, pp. 29-32

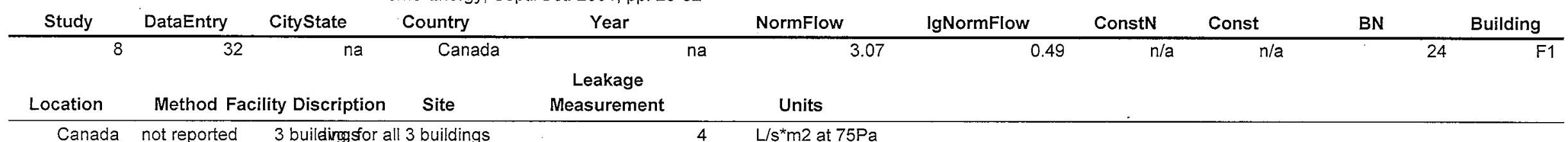

Field Investigation Survey of Airtightness, Air Movement, and Indoor Air Quality in High Rise Apartment Buildings

B.W. Gulay, C.D. Stewart, G.J. Foley

Summary Report for Canada Mortgage and Housing Corporation

\begin{tabular}{|c|c|c|c|c|c|c|c|c|c|c|}
\hline Study & DataEntry & CityState & Country & Year & NormFlow & IgNormFlow & ConstN & Const & BN & Building \\
\hline 9 & 33 & Atlantic & Canada & 1982 & 6.30 & 0.80 & $n / a$ & $n / a$ & 25 & $\mathrm{G1}$ \\
\hline 9 & 34 & Atlantic & Canada & 1982 & 7.80 & 0.89 & $\mathrm{n} / \mathrm{a}$ & $\mathrm{n} / \mathrm{a}$ & 25 & G1 \\
\hline 9 & 35 & Atlantic & Canada & 1982 & 7.80 & 0.89 & $\mathrm{n} / \mathrm{a}$ & $\mathrm{n} / \mathrm{a}$ & 25 & G1 \\
\hline 9 & 36 & Atlantic & Canada & 1982 & 7.40 & 0.87 & $\mathrm{n} / \mathrm{a}$ & $\mathrm{n} / \mathrm{a}$ & 25 & G1 \\
\hline 9 & 37 & Quebec & Canada & 1991 & 2.20 & 0.34 & 2 & Brick & 26 & G2 \\
\hline 9 & 38 & Quebec & Canada & 1960 & 4.58 & 0.66 & 2 & Brick & 27 & G3 \\
\hline 9 & 39 & Praries & Canada & 1973 & 2.50 & 0.40 & 2 & Brick & 28 & $\mathrm{G} 4$ \\
\hline 9 & 40 & Praries & Canada & 1973 & 7.03 & 0.85 & 2 & Brick & 28 & G4 \\
\hline 9 & 41 & Praries & Canada & 1973 & 8.33 & 0.92 & 2 & Brick & 28 & G4 \\
\hline 9 & 42 & Praries & Canada & 1970 & 3.15 & 0.50 & 2 & Brick & 29 & G5 \\
\hline 9 & 43 & Praries & Canada & 1970 & 3.11 & 0.49 & 2 & Brick & 29 & G5 \\
\hline 9 & 44 & Praries & Canada & 1970 & 2.10 & 0.32 & 2 & Brick & 29 & G5 \\
\hline
\end{tabular}

Leakage

Facility Discription

Measurement

Units

Method

Site

10 buildings

10 buildings

10 buildings

10 buildings

/ $\mathrm{s}^{*} \mathrm{~m} 2$ at $50 \mathrm{~Pa}$ fan depressurization

$\mathrm{L} / \mathrm{s}^{*} \mathrm{~m} 2$ at $50 \mathrm{~Pa}$ fan depressurization

$\mathrm{L} / \mathrm{s}^{*} \mathrm{~m} 2$ at $50 \mathrm{~Pa}$ fan depressurization

10 buildings

$\mathrm{L} / \mathrm{s}^{\star} \mathrm{m} 2$ at $50 \mathrm{~Pa}$ fan depressurization

10 buildings

$\mathrm{L} / \mathrm{s}^{*} \mathrm{~m} 2$ at $50 \mathrm{~Pa}$ fan depressurization

10 buildings

$\mathrm{L} / \mathrm{s}^{*} \mathrm{~m} 2$ at $50 \mathrm{~Pa}$ fan depressurization

$\mathrm{L} / \mathrm{s}^{*} \mathrm{~m} 2$ at $50 \mathrm{~Pa}$ fan depressurization

10 buildings

$\mathrm{L} / \mathrm{s}^{*} \mathrm{~m} 2$ at $50 \mathrm{~Pa}$ fan depressurization

10 buildings

$\mathrm{L} / \mathrm{s}^{*} \mathrm{~m} 2$ at $50 \mathrm{~Pa}$ fan depressurization

10 buildings

$\mathrm{L} / \mathrm{s}^{*} \mathrm{~m} 2$ at $50 \mathrm{~Pa}$ fan depressurization

10 buildings

$\mathrm{L} / \mathrm{s}^{\star} \mathrm{m} 2$ at $50 \mathrm{~Pa}$ fan depressurization

10 buildings

$\mathrm{L} / \mathrm{s}^{*} \mathrm{~m} 2$ at $50 \mathrm{~Pa}$ fan depressurization

Atlantic, building 1 , unit \#501

Atlantic, building 1, unit \#503

Atlantic, building 1, unit \#505

Atlantic, building 1 , unit \#507

Quebec, Building 1, single unit

Quebec, Building 2, single unit Praries, Building A, unit 405

Praries, Building A, unit 409

Praries, Building A, unit 909

Praries, Building B, unit 509

Praries, Building $B$, unit 609

Praries, Building B, unit 1009 
Airtightness Testing and Air Flow Modeling of a Three-Unit Multifamily Building

Sebastiano DePani, Paul Fazio

The Canadian Conference on Building Energy Simulation, Proceedings, June 13-14, 2001

\begin{tabular}{|c|c|c|c|c|c|c|c|c|c|c|}
\hline Study & DataEntry & CityState & Country & Year & NormFlow & IgNormFlow & ConstN & Const & BN & Building \\
\hline 10 & 45 & Montreal & Canada & 1969 & 6.97 & 0.84 & $\mathrm{n} / \mathrm{a}$ & $n / a$ & 30 & $\mathrm{H} 1$ \\
\hline 10 & 46 & Montreal & Canada & 1969 & 7.79 & 0.89 & $\mathrm{n} / \mathrm{a}$ & $\mathrm{n} / \mathrm{a}$ & 30 & $\mathrm{H} 1$ \\
\hline 10 & 47 & Montreal & Canada & \#REF! & 5.83 & 0.77 & $n / a$ & $\mathrm{n} / \mathrm{a}$ & 30 & $H 1$ \\
\hline 10 & 48 & Montreal & Canada & 1969 & 11.11 & 1.05 & $\mathrm{n} / \mathrm{a}$ & $\mathrm{n} / \mathrm{a}$ & 30 & $\mathrm{H} 1$ \\
\hline
\end{tabular}

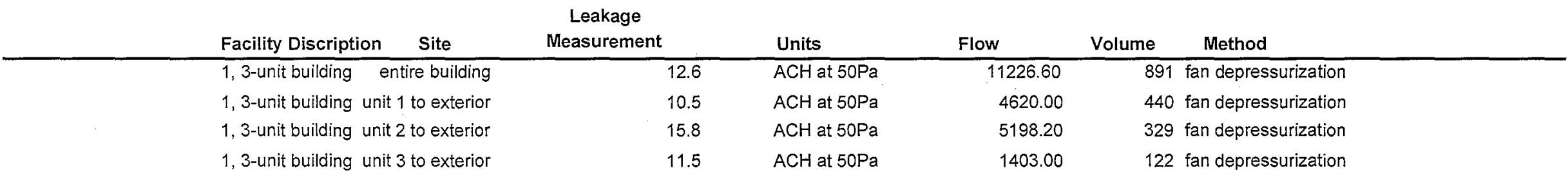

Methods for Measuring Air Leakage in High-Rise Apartments

Chia-yu Shaw, Simona Gasparetto, James T. Reardon

American Society for Testing and Materials, Philadelphia, 1986, pp. 5-16

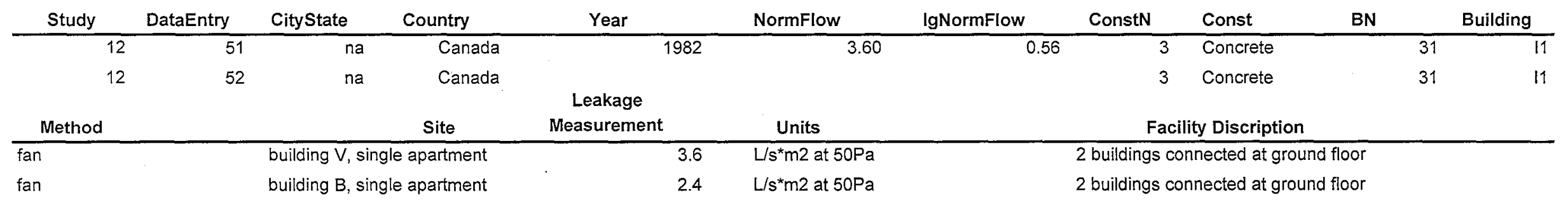


Balanced Fan Depressurization Method for Measuring Component and Overall Air Leakage in Single and Multifamily Dwellings

J.T. Reardon, A.K. Kim, C.Y. Shaw

American Society for Testing and Materials, Philadelphia, 1990, pp. 220-230

\begin{tabular}{|c|c|c|c|c|c|c|c|c|c|c|}
\hline Study & DataEntry & CityState & Country & Year & NormFIow & IgNormFlow & ConstN & Const & BN & Building \\
\hline 13 & 53 & na & Canada & na & 4.50 & 0.65 & 2 & Brick & 32 & \\
\hline 13 & 54 & na & Canada & na & 3.10 & 0.49 & 1 & Wood & 33 & \\
\hline 13 & 55 & na & Canada & na & 2.29 & 0.36 & 1 & Wood & 34 & \\
\hline \multirow[t]{2}{*}{13} & 56 & na & Canada & na & 3.43 & 0.54 & 2 & Brick & 35 & \\
\hline & \multicolumn{3}{|c|}{ Facility Discription } & $\begin{array}{c}\text { Leakage } \\
\text { Measurement }\end{array}$ & Units & Flow & Volume & Method & & Site \\
\hline \multicolumn{4}{|c|}{2 row houses, 2 \& 4 stories, 3 units each 2 stories } & 3.5 & $\mathrm{ACH}$ at $50 \mathrm{~Pa}$ & 728.00 & 208 & fan depressurization & & unit $F$ \\
\hline \multicolumn{4}{|c|}{2 row houses, $2 \& 4$ stories, 3 units each 2 stories } & 5 & $\mathrm{ACH}$ at $50 \mathrm{~Pa}$ & 1370.00 & 274 & fan depressurization & & unit $F$ \\
\hline \multicolumn{4}{|c|}{2 row houses, $2 \& 4$ stories, 3 units each 2 stories } & 7.5 & $\mathrm{ACH}$ at $50 \mathrm{~Pa}$ & 3900.00 & 520 & fan depressurization & & unit $/$ \\
\hline
\end{tabular}

Case Study of Ventilation Improvements in a Multifamily Building

Proceedings 1992 ACEEE Summer Study, vol. 2

Mark Kelly, John McQuail, Robert O'Brien

\begin{tabular}{|c|c|c|c|c|c|c|c|c|c|c|}
\hline Study & DataEntry & CityState & Country & Year & NormFlow & lgNormFlow & ConstN & Const & BN & Building \\
\hline 6 & 25 & $\mathrm{n} / \mathrm{a}$ & US & $\mathrm{n} / \mathrm{a}$ & 1.6 & 0.20 & $\mathrm{n} / \mathrm{a}$ & $n / a$ & 36 & I \\
\hline 6 & 26 & $n / a$ & US & $\mathrm{n} / \mathrm{a}$ & 3.6 & 0.56 & $\mathrm{n} / \mathrm{a}$ & $\mathrm{n} / \mathrm{a}$ & 37 & । \\
\hline 6 & 27 & $\mathrm{n} / \mathrm{a}$ & US & $\mathrm{n} / \mathrm{a}$ & 2.2 & 0.34 & $\mathrm{n} / \mathrm{a}$ & $\mathrm{n} / \mathrm{a}$ & 38 & 1 \\
\hline Location & $\mathrm{Fac}$ & ility Discription & Site & & Method & & & & & \\
\hline US & & tory building & building $A$ & & depressurization & & & & & \\
\hline US & 17 & tory building & building $V$ & & depressurization & & & & & \\
\hline US & 14 & tory building & building $\mathrm{D}$ & & depressurization & & & & & \\
\hline
\end{tabular}


Diagnostics and Measurements of Infiltration and Ventilation Systems in High-Rise Apartment Buildings

Helmut E. Feustel, Richard C. Diamond

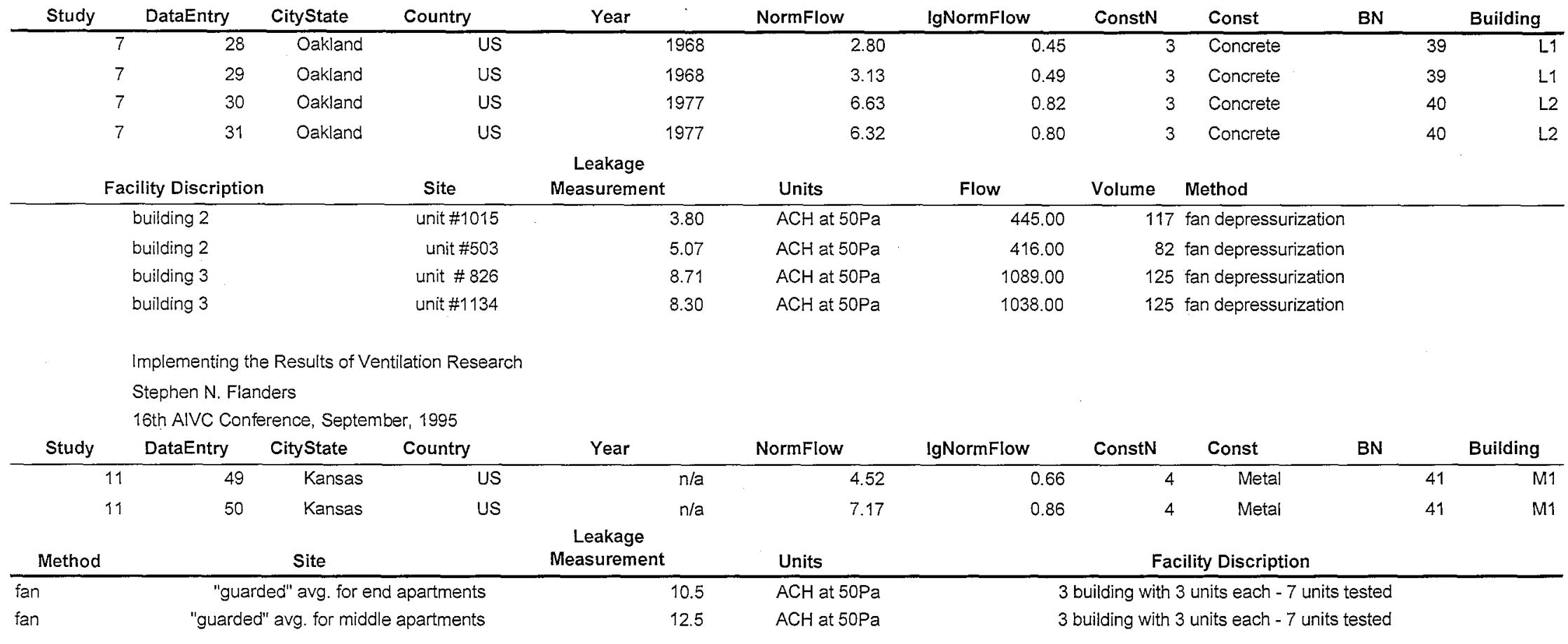


